Aus der Klinik für Kinder- und Jugendmedizin (Prof. Dr. med. Gärtner)

der Medizinischen Fakultät der Universität Göttingen

\title{
Phänotyp-Analyse und Genotyp-Phänotyp-Assoziationen bei 83 Patienten mit FOXG1-Syndrom
}

\author{
INAUGURAL-DISSERTATION \\ zur Erlangung des Doktorgrades \\ der Medizinischen Fakultät der \\ Georg-August-Universität zu Göttingen
}

vorgelegt von

Kim Sarah Plümacher

aus

Haan

Göttingen 2018 
Dekan:

Referent

Ko-Referent:

Drittreferentin:
Prof. Dr. rer. nat. H.K. Kroemer

Prof. Dr. med. Knut Brockmann

Prof. Dr. med. Peter Burfeind

Prof. Dr. med. Margarete Schön

Datum der mündlichen Prüfung: 22. Mai 2019 
Hiermit erkläre ich, die Dissertation mit dem Titel „PhänotypAnalyse und Genotyp-Phänotyp-Assoziationen bei 83 Patienten mit FOXG1-Syndrom" eigenständig angefertigt und keine anderen als die von mir angegebenen Quellen und Hilfsmittel verwendet zu haben.

Göttingen, den 


\section{Inhaltsverzeichnis}

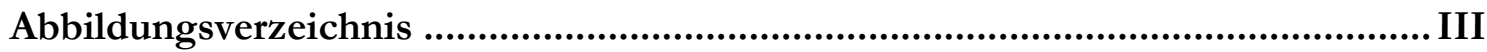

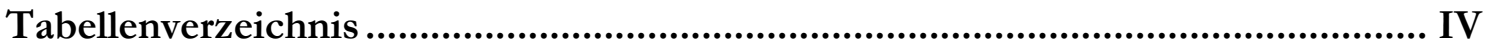

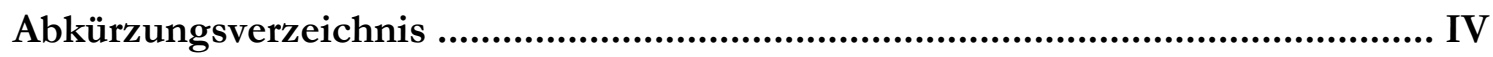

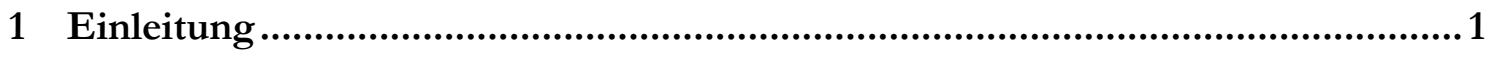

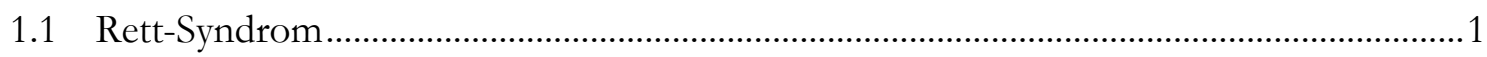

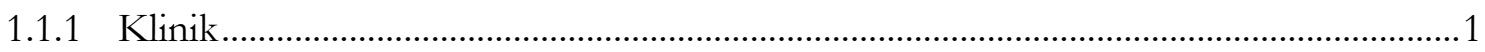

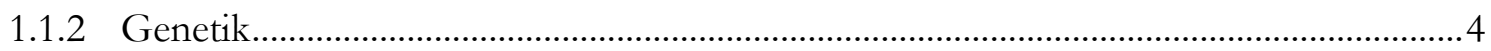

1.1.3 Atypische Varianten des Rett-Syndroms ...................................................................

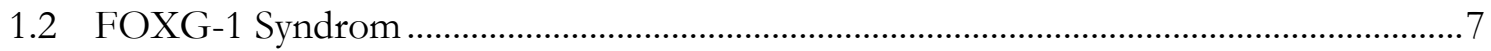

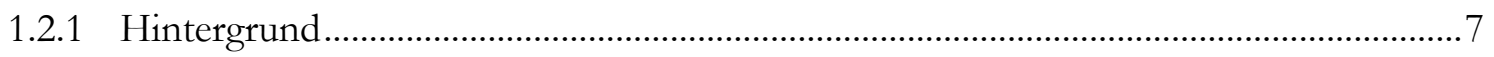

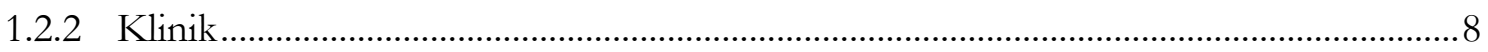

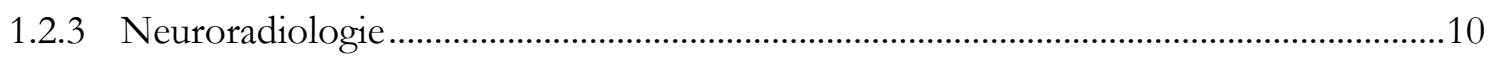

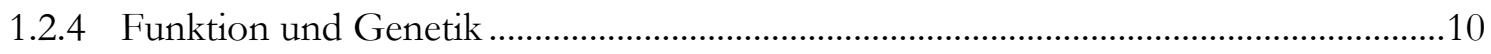

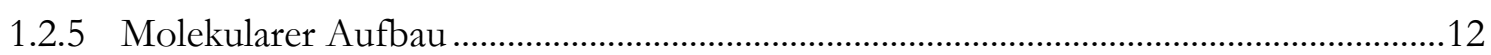

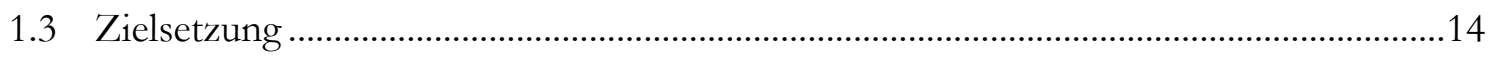

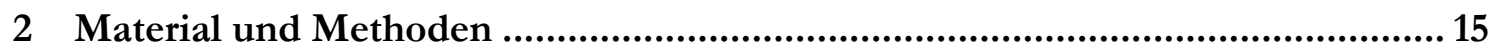

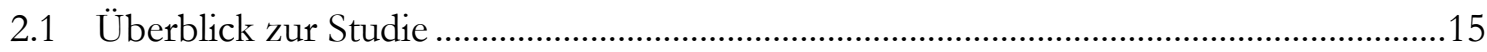

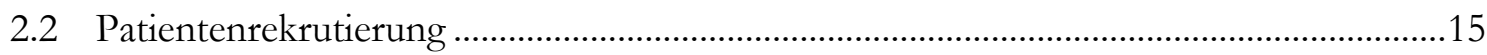

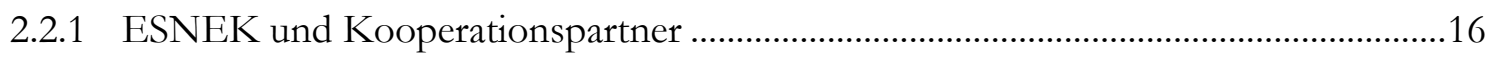

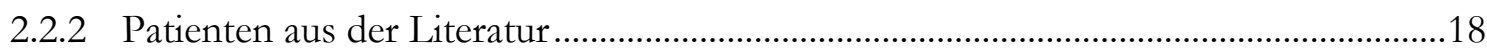

2.3 Erhebung der klinischen, neurologischen und genetischen Patientendaten..................18

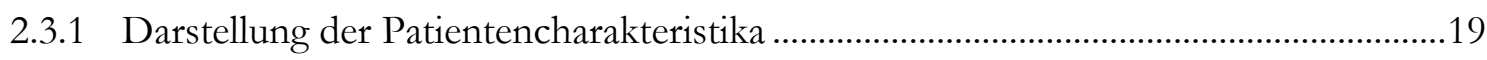

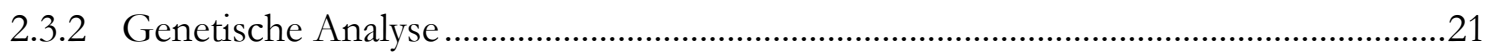

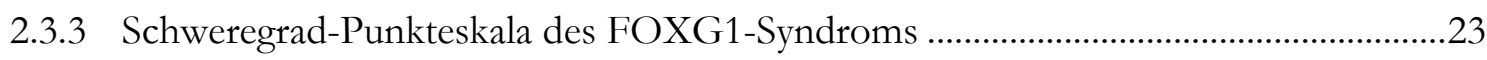

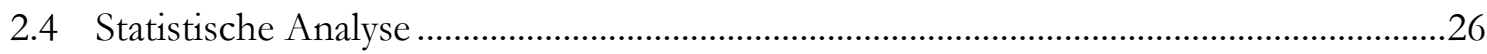

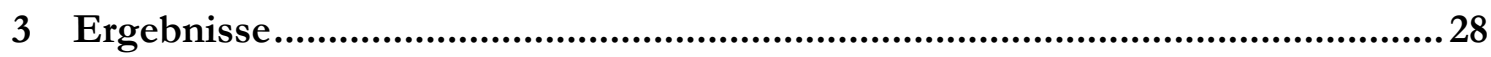

3.1 Analyse des klinischen und neuroradiologischen Phänotyps ........................................28

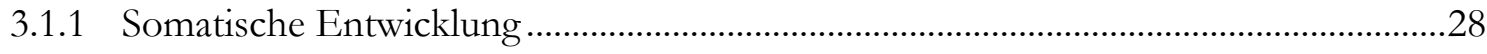

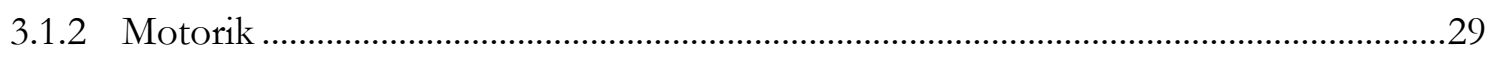

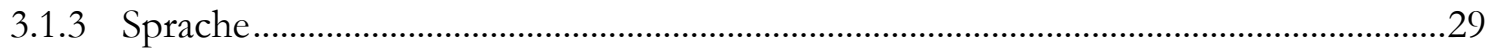

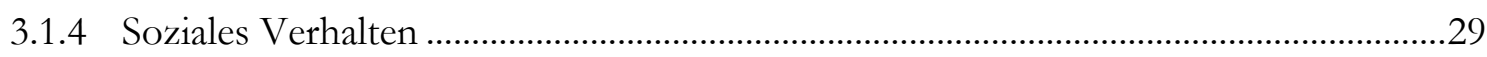

3.1.5 Gastrointestinale und sonstige Symptome …….............................................................29

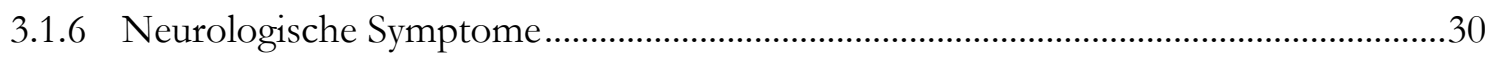

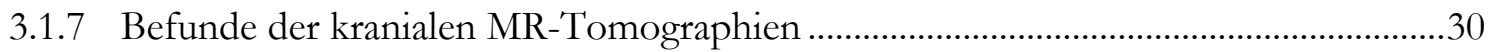




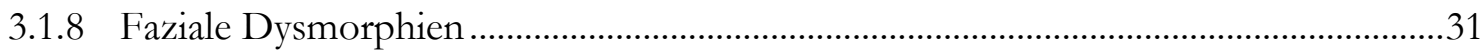

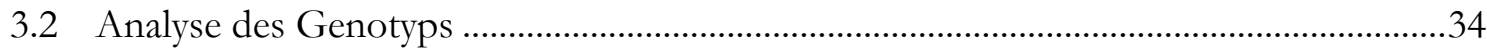

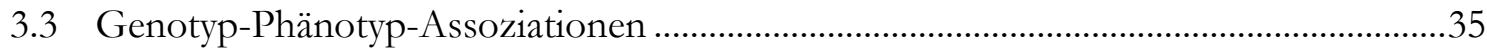

3.4 Schweregradeinteilung mit dem „FOXG1 clinical severity score“ ..................................41

3.4.1 Vergleich der Schweregradeinteilung zwischen den Gruppen der neu rekrutierten und bereits publizierten Patienten.................................................................... 41

3.4.2 Vergleich des Schweregrades zwischen den genetischen Gruppen................................42

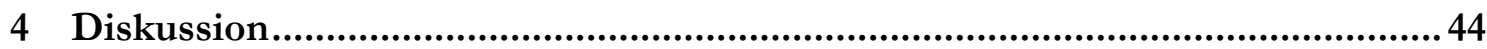

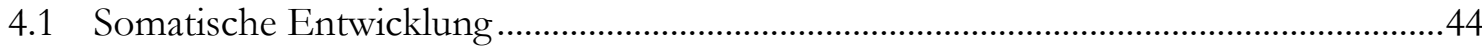

4.2 Motorische und sprachliche Entwicklung.........................................................................4

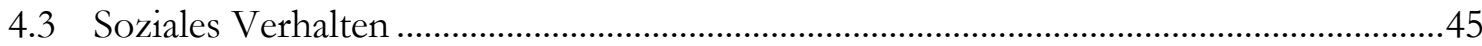

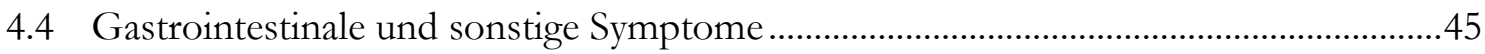

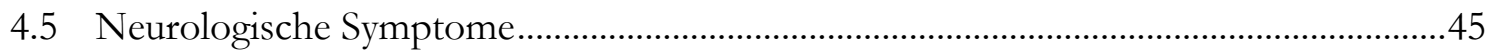

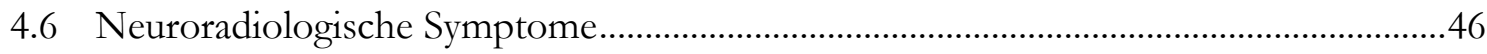

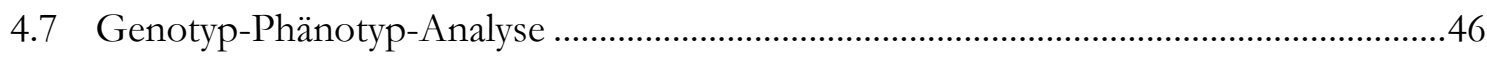

4.8 Unterschiede zwischen neu rekrutierten und bereits publizierten Patienten..................47

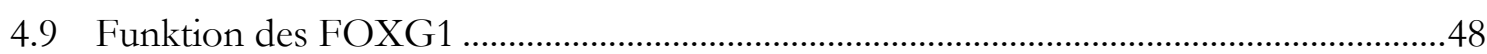

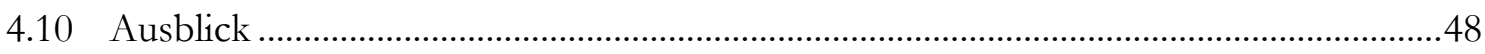

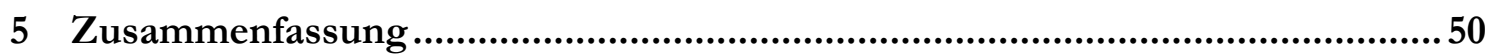

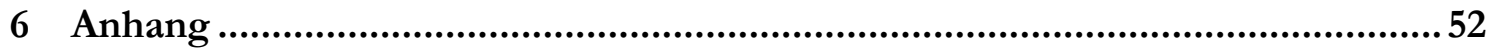

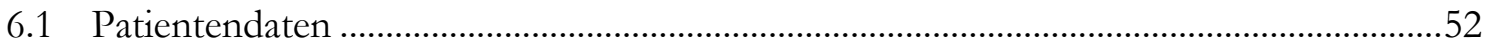

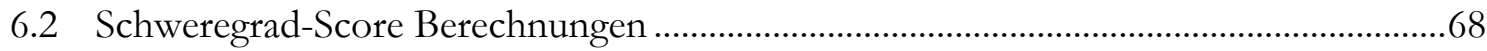

6.3 Informationsschrift und Einverständnis zur Studienteilnahme .......................................69

6.4 Einverständniserklärung zur Veröffentlichung von Photographien.................................72

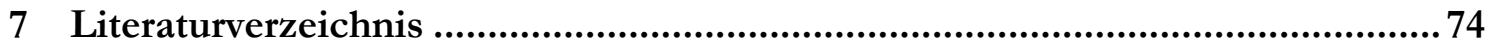




\section{Abbildungsverzeichnis}

Abbildung 1: Schematische Darstellung FOXG1 (Flindt 2011)

Abbildung 2: Schema des methodischen Vorgehens der „Erhebung Seltener Neurologischer Erkrankungen im Kindesalter (ESNEK)“" (modifiziert nach Schröder und Brockmann 2015)

Abbildung 3: Gesichtszüge von Patienten mit FOXG1-Varianten ohne sichere konsistente Dysmorphien 31

Abbildung 4: Lokalisation der Genveränderungen im FOXG1-Gen (Mitter et al. 2017) ......35

Abbildung 5: Genotyp-Phänotyp-Analyse: signifikante Unterschiede zwischen den

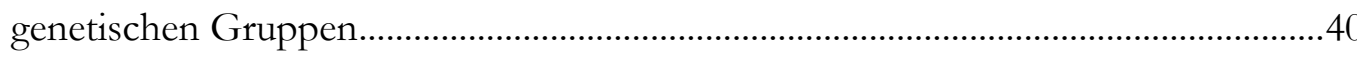

Abbildung 6: Genotyp-Phänotyp-Analyse: grenzwertige Signifikanzen ....................................41

Abbildung 7: Ergebnisse Schweregradanalyse 


\section{Tabellenverzeichnis}

Tabelle 1: Diagnosekriterien Rett-Syndrom (nach Nuel et al. 2010) ...........................................

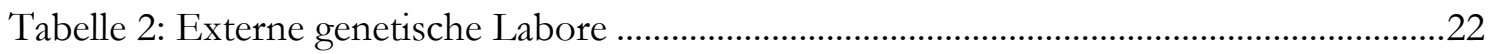

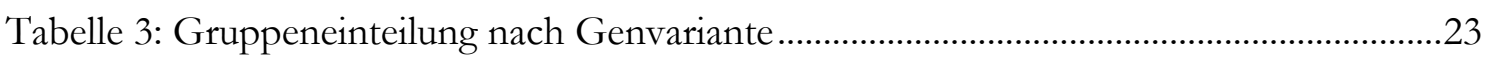

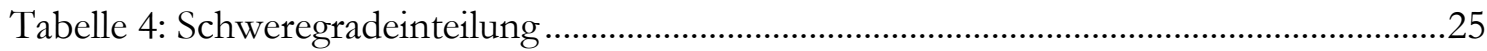

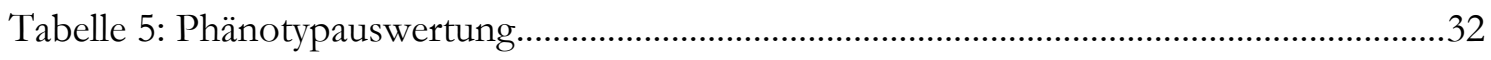

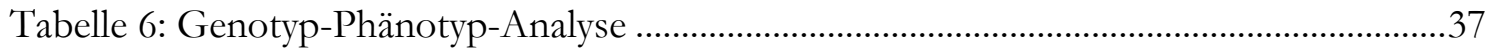

Tabelle 7: Schweregrad-Score: Vergleich neu rekrutierte vs. publizierte Patienten ................42

Tabelle 8: Patientendaten (Allgemeine Daten, FOXG1-Varianten) ……………........................52

Tabelle 9: Patientendaten (somatische Entwicklung) ……………………................................... 55

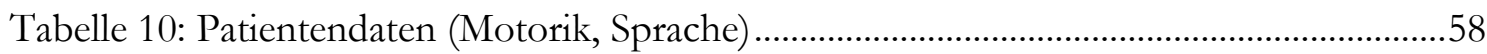

Tabelle 11: Patientendaten (soziales Verhalten, gastrointestinale und skelettale

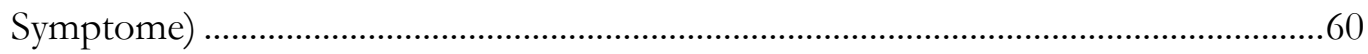

Tabelle 12: Patientendaten (neurologische Symptome) .............................................................63

Tabelle 13: Patientendaten (neurologische Symptome, cMRT Veränderungen) ......................66

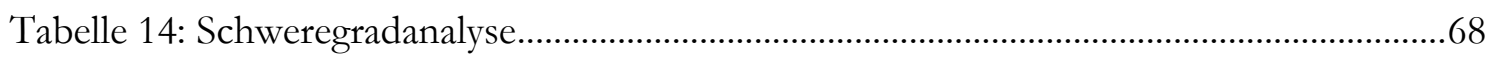




\title{
Abkürzungsverzeichnis
}

\author{
BF-1 brain factor 1 \\ BMI body mass index \\ cMRT kranielle Magnetresonanztomographie \\ ESNEK Erhebung seltener neurologischer Erkrankungen im Kindesalter \\ FHD Forkhead-Domäne \\ FOX Forkhead Box \\ GBD Groucho-Bindungsdomäne \\ h Stunde \\ IQ Interquartilsabstand \\ JBD JARID1 Bindungsdomäne \\ n.a. nicht verfügbar (not available) \\ NGS Next Generation Sequencing \\ SDS Standard Deviation Score \\ SPZ Sozialpädiatrisches Zentrum \\ ZNS zentrales Nervensystem \\ z.T. $\quad$ zum Teil
}




\section{$1 \quad$ Einleitung}

\subsection{Rett-Syndrom}

\subsubsection{Klinik}

Das Rett-Syndrom wurde erstmals 1966 von Professor Andreas Rett in Wien beschrieben und ist eine progressiv verlaufende neuronale Entwicklungsstörung (Rett 1966; Hagberg et al. 1983). Charakteristisch für die Erkrankung ist der Entwicklungsknick, welcher zwischen dem sechsten und 18. Lebensmonat eintritt und mit Verlusten von bereits erworbenen sprachlichen und motorischen Fähigkeiten einhergeht. In ihrer typischen Ausprägung leiden die betroffenen Mädchen unter kognitiven Beeinträchtigungen und sind wachstumsretardiert. Typisch für diese Erkrankung sind außerdem das Auftreten einer Epilepsie, die Entwicklung einer postnatalen Mikrozephalie sowie stereotype Bewegungsmuster der Hände (Deidrick et al. 2004).

Die Prävalenz des Rett-Syndroms beträgt zwischen 1:10.000 bis 1:15.000, die Erkrankung betrifft nahezu ausschließlich das weibliche Geschlecht (Deidrick et al. 2004; Segawa und Nomura 2005). Das Rett-Syndrom ist nach dem Down-Syndrom mit circa $10 \%$ die zweithäufigste Ursache für eine mentale Retardierung bei Mädchen (Hagberg et al. 1983). Die Diagnose wird anhand von klinischen Diagnosekriterien gestellt (Tabelle 1).

Tabelle 1: Diagnosekriterien Rett-Syndrom (nach Neul et al. 2010)

\section{Diagnosekriterien Rett-Syndrom}

\begin{tabular}{|llll}
\hline Obligate Kriterien für die & 1. & Vorliegen einer Regressionsphase mit anschließender Stabilisierung oder Verbesserung \\
klassische Form des Rett- & 2. & Alle Hauptkriterien und alle Ausschlusskriterien \\
Syndroms & 3. & Nebenkriterien sind nicht entscheidend \\
\hline Obligate Kriterien für & 1. & Vorliegen einer Regressionsphase mit anschließender Stabilisierung oder Verbesserung \\
atypische Formen des Rett- & 2. & $2 / 4$ Hauptkriterien \\
Syndroms & 3. & $5 / 11$ Nebenkriterien \\
\hline Hauptkriterien & 1. & Verminderung oder Verlust von zielgerichtetem Gebrauch der Hände \\
& 2. & Verminderung oder Verlust von erworbenen Sprachfähigkeiten \\
& 3. & Gangstörung: Dyspraxien oder Gehunfähigkeit \\
4. & Handstereotypien
\end{tabular}


Fortsetzung Tabelle 1: Diagnosekriterien Rett-Syndrom (nach Neul et al. 2010)

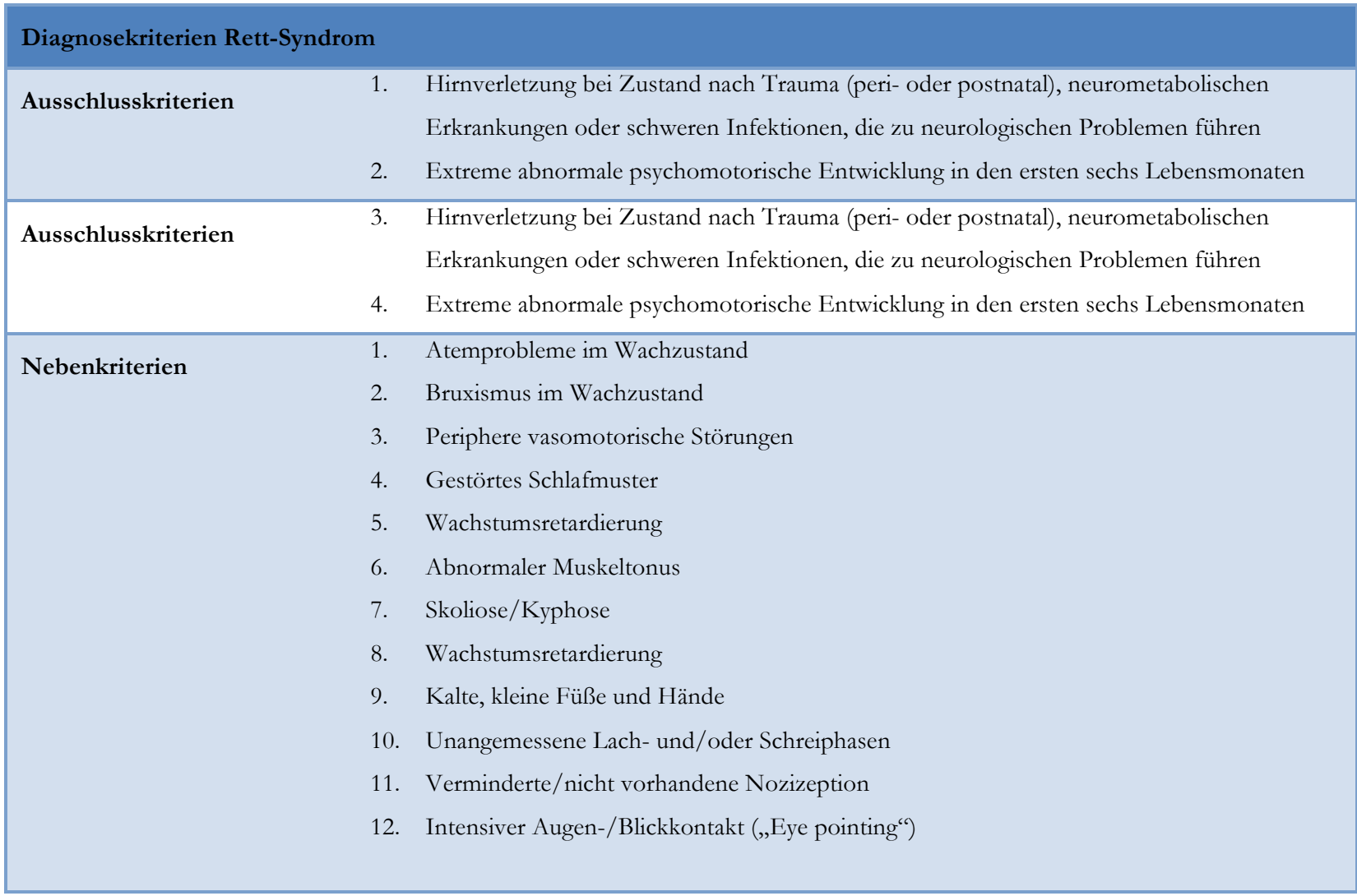

Für den typischen Krankheitsverlauf wurde von Hagberg und Witt-Engerström eine mittlerweile weltweit anerkannte Stadieneinteilung entworfen (Hagberg 2002).

Schwangerschaft und Geburt der Kinder verlaufen in der Regel normal, und oft treten in den ersten sechs bis 18 Lebensmonaten keinerlei Anzeichen für eine Erkrankung auf (Hagberg et al. 1983). Typische Merkmale dieses Lebensalters wie beispielsweise Krabbeln, soziales Lächeln und Sitzen entwickeln sich ohne pathologische Auffälligkeiten.

In der ersten Phase des Rett-Syndroms, dem Stadium der Stagnation, verlangsamt sich die psychomotorische Entwicklung und kommt unter Umständen sogar zum völligen Stillstand. Typischerweise zeigen die Kinder Desinteresse an ihrer Umgebung, vermindern ihre körperliche Aktivität und vermeiden Blickkontakt zu Mitmenschen. Markant ist im Stagnationsstadium ein verzögertes Schädelwachstum bis zur Entstehung einer Mikrozephalie (Hagberg 2002).

Anschließend folgt das Regressions-Stadium, welches zwischen dem ersten und dritten Lebensjahr eintreten kann. Diese Phase wird geprägt durch den Verlust von bereits erlernten motorischen und sprachlichen Fähigkeiten, und die Kinder gelten als schwer mental retardiert. Kennzeichnend für dieses Stadium ist die Entwicklung von 
Handstereotypien. Die Handbewegungen der Kinder sind nicht mehr zweckgebunden und präsentieren sich in waschenden und knetenden Mustern. Oft ziehen sich die Kinder sozial zurück und fallen in ein typisches autistisches Verhaltensmuster, weshalb das Rett-Syndrom als wichtige Differentialdiagnose zum Autismus gilt. Zusätzlich werden Gangbild und andere zielgerichtete Handlungsbewegungen unsicherer, was sich im Verlauf als Ataxie, Apraxie und Tremor manifestiert. Außerdem entwickeln einige Kinder autoaggressive Handlungsmuster, welche sich beispielsweise im Beißen der eigenen Finger oder dem Schlagen in ihr Gesicht zeigen. Häufig neigen sie zu massiven Schlafproblemen. Etwa 6080\% der Patienten leiden unter Epilepsien mit fokalen oder generalisierten Anfällen (Johnston et al. 2014). Die Schwere der Epilepsien umfasst ein weites Spektrum, das bis zum Status epilepticus mit tödlichen Folgen reichen kann. Oft gestaltet sich eine Kontrolle der Anfälle durch Antiepileptika schwierig (Segawa und Nomura 2005).

An das Regressionsstadium schließt sich vom zweiten bis zum zehnten Lebensjahr die sogenannte pseudostationäre Phase an. Einige motorische Symptome wie Handstereotypien oder Ataxien verschlechtern sich weiterhin. Oft werden die Muskeleigenreflexe gesteigert, und der Muskeltonus wird zunehmend höher. Im Gegensatz zu den motorischen Fähigkeiten verbessert sich das Sozialverhalten der Kinder deutlich. Durch die Rückbildung der autismusnahen Verhaltensbesonderheiten verringert sich die zuvor stark ausgeprägte Isolation. Außerdem sind die Kinder nicht mehr so schnell reizbar, wodurch Stresssituationen besser ertragen und bewältigt werden können. Oft treten in diesem Stadium auch Episoden von Hyper- und Hypoventilation auf, und nicht selten entsteht eine Aerophagie.

$\mathrm{Ab}$ dem zehnten Lebensjahr befinden sich die Patienten in einem späten motorischen Verschlechterungsstadium. Fertigkeiten der Grobmotorik nehmen stark ab, was neben massiven Dyskinesien auch eine Zunahme der Spastizität zur Folge haben kann. Zusätzlich atrophieren vor allem die Muskeln der unteren Extremitäten, und die Rigidität schreitet progressiv voran, weshalb die Patienten in den meisten Fällen auf einen Rollstuhl angewiesen sind. Typischerweise entsteht in dieser Phase auch eine Kyphose und/oder Skoliose. Die Patienten magern trotz adäquater Nahrungszufuhr rapide ab, und nicht selten treten Schwächeanfälle auf. Als Resultat vasomotorischer Störungen entwickeln sich rotblaue, livide Verfärbungen der zu kleinen Füße. Üblicherweise bleibt der in der Pubertät typische Wachstumsschub aus, und die Patienten sind im Erwachsenenalter oft durch einen Kleinwuchs zu erkennen.

Die Überlebensrate von Rett-Patienten ist deutlich geringer. Bis zum zehnten Lebensjahr 
unterscheidet sie sich nicht von der für gesunde Kinder. Vermindert ist sie allerdings vom zehnten bis zum 35. Lebensjahr. In diesem Altersbereich überleben lediglich $70 \%$ der erkrankten Kinder, wohingegen 98\% der Normalbevölkerung dieses Alter erreichen (Deidrick et al. 2004). Auffällig ist, dass die Patienten das Erwachsenenalter zwar oft erreichen, aber signifikant häufiger (22\%) an einem plötzlichen Herztod versterben (Clarke 1996). Daher ist die Hypothese entstanden, dass eine Instabilität der kardialen Erregungsweiterleitung vorliegt, die eine Folge von Dysfunktionen des autonomen Nervensystems sein könnte.

Es gibt keine kausale Therapie für das Rett-Syndrom, und der Krankheitsverlauf kann kaum beeinflusst werden (Hagberg 2002; Segawa und Nomura 2005). Die symptomatische Therapie umfasst Physio-, Ergo- und Logotherapie sowie heilpädagogische Förderung. Zusätzlich können mit Hydro-, Musik- und Hippotherapie Erfolge erzielt werden. Darüber hinaus wird symptomorientiert medikamentös behandelt, indem zum Beispiel Antikonvulsiva bei Epilepsien verabreicht werden (Guerrini und Parrini 2012).

\subsubsection{Genetik}

Beim klassischen Rett-Syndrom sind in 90-95\% der Fälle Mutationen des MECP2-Gens nachweisbar (Pini et al. 2016). Die Erkrankung folgt einem X-chromosomal dominanten Erbgang, die Genveränderungen entstehen de novo in den Spermien des Vaters. Dementsprechend sind die Eltern betroffener Kinder in der Regel gesund (Trappe et al. 2001). Die überwiegend paternale Vererbung über das X-Chromosom erklärt, warum zum größten Teil Mädchen betroffen sind. Männliche Patienten versterben in der Regel schon vor Erreichen des zweiten Lebensjahres an den Folgen einer neonatalen Enzephalopathie. Sehr selten leben männliche Patienten mit Mutation des MECP2-Gens länger. Voraussetzung dafür ist, dass eine Mutation mit besonders milden funktionellen Konsequenzen vorliegt. Dieselbe Mutation würde bei Mädchen nur eine sehr schwache klinische Symptomatik verursachen, dagegen zeigen Jungen mit einer solchen Mutation eine schwere mentale Retardierung und deutliche neuronale Entwicklungsstörungen. Ein klassisches Rett-Syndrom mit dem üblichen Phänotyp liegt bei Jungen nur vor, wenn gleichzeitig ein Klinefelter-Syndrom mit einem XXY-Karyotyp oder ein Keimzellmosaik vorliegt (Young et al. 2005).

Das MECP2-Gen befindet sich auf dem langen Arm des X-Chromosoms (Xq28) und umfasst 4 Exons und 3 Introns (D’Esposito et al. 1996; Amir et al. 1999). Etwa 80\% der Mutationen, die ein Rett-Syndrom verursachen, befinden sich innerhalb der Exons drei 
oder vier (Mnatzakanian et al. 2004). Das Gen kodiert für das Methyl Cytosin Phosphatidyl binding protein 2 (MECP2), welches zur Familie der DNA-bindenden Proteine gehört. Es kommt in allen somatischen Geweben vor und hat seine höchsten Expressionsrate im Gehirn (Matijevic et al. 2009). Aufgrund seiner Funktion befindet sich das Protein überwiegend im Nukleus, und seine Aktivitätssteuerung erfolgt über Phosphorylierung.

MECP2 fungiert sowohl als Transkriptionsinhibitor als auch als Transkriptionsaktivator (Li und Pozzo-Miller 2014). Insbesondere während der postnatalen neuronalen Entwicklung und dem anschließenden Funktionserhalt der Neurone ist diese Funktion entscheidend. Pränatal nimmt das Protein für die Entwicklung des Gehirns eine eher untergeordnete Rolle ein (Kishi und Macklis 2005).

Neben den Prozessen der Maturation ist MECP2 auch an der dendritischen Verzweigung und axonalen Projektion der Neurone sowie der Formierung von Synapsen beteiligt (Kishi und Macklis 2005; Li und Pozzo-Miller 2014). Ein Funktionsausfall des Proteins kann durch eine postnatale Wachstumsverzögerung des Gehirns eine Mikrozephalie hervorrufen (Matijevic et al. 2009).

Neben dem Rett-Syndrom kann eine Mutation im MECP2-Gen auch zu anderen Erkrankungen führen. Dazu gehören der Autismus, Angelman-ähnliche Syndrome oder unspezifische intellektuelle Entwicklungsdefizite. Diese Patienten haben zwar teilweise ähnliche klinische Eigenschaften, allerdings fehlt die typische Phase der Regression, weshalb die Diagnose „Rett-Syndrom“ nicht gestellt werden kann. Des Weiteren können andere Gene Ursache eines Rett-Syndroms sein (1.1.3). MECP2--Mutationen sind somit weder notwendig noch beweisend für ein Rett-Syndrom. Dies ist der Grund, warum die klinischen Kriterien entscheidend für die Diagnosefindung sind (Tabelle 1, Neul et al. 2010).

\subsubsection{Atypische Varianten des Rett-Syndroms}

Von der klassischen Form des Rett-Syndroms werden mittlerweile die Preserved-Speechund die Early-Onset-Seizure-Variante sowie das FOXG1-Syndrom als atypische Formen unterschieden (Tabelle 1, Neul et al. 2010). Das in dieser Studie thematisierte FOXG1Syndrom wurde ursprünglich als kongenitale Variante des Rett-Syndroms beschrieben.

\subsubsection{Preserved-Speech-Variante}

Bei der Preserved-Speech- oder Zapella-Variante liegt eine relativ milde Krankheitsausprägung vor. Die Regressionsphase tritt erst zwischen dem ersten und dritten 
Lebensjahr ein und die Kinder behalten ihre Sprachfähigkeit in der Regel oder erlangen sie im Verlauf zurück (Zappella et al. 1998). Stereotypische Bewegungen werden oft kaum bemerkt und auch Körper- und Kopfwachstum sind nahezu normal (De Bona et al. 2000). Auch intellektuell sind die Kinder nicht so stark beeinträchtigt wie bei der klassischen RettVariante und sowohl Epilepsien als auch autonome Dysfunktionen liegen deutlich seltener vor. Die genetische Ursache ist meist eine Mutation des MECP2-Gens (1.1.2).

\subsubsection{Early-Onset-Seizure-Variante}

Hanefeld beschrieb 1985 erstmals die atypische Early-Onset-Seizure-Variante des RettSyndroms (Hanefeld 1985). Grundlage für diese Entdeckung war die klinische Analyse eines Mädchens, welches unter infantilen Spasmen litt und Hypsarrhythmie im EEG zeigte.

Ursache dieser Form des Rett-Syndroms sind Varianten innerhalb des cyclin-dependend-kinase 5 (CDKL5)-Gens, welches X-chromosomal lokalisiert ist. Solche Genveränderungen wurden bereits bei Patienten mit West-Syndrom beschrieben (Kalscheuer et al. 2003; Tao et al. 2004).

Die von der Early-Onset-Seizure-Variante betroffenen Kinder leiden unter einem Symptomkomplex, der sich aus Merkmalen der klassischen Form des Rett-Syndroms und solchen des West-Syndroms zusammensetzt. Das klinische Bild umfasst früh eintretende Epilepsie und psychomotorische Entwicklungsstörung (Fuchs et al. 2014). Nach einer unauffälligen prä- und perinatalen Periode tritt innerhalb der ersten fünf Lebensmonate, noch vor Eintreten der Regressionsphase, eine Epilepsie auf. Diese folgt typischerweise einem drei-phasigen Entwicklungsmuster (Bahi-Buisson et al. 2010a; Fehr et al. 2013).

Die psychomotorische Entwicklung der betroffenen Kinder ist schwer verzögert. Lediglich ein Drittel der Patienten ist in der Lage zu laufen. Zielgerichtete Handbewegungen sind größtenteils nicht möglich, und zusätzlich entwickeln die Patienten Rett-typische Handstereotypien. Augenkontakt kann in den meisten Fällen nicht aufgebaut werden. Des Weiteren ist die Sprachentwicklung deutlich eingeschränkt, und das expressive Sprechen wird meistens nicht erlernt. Neurovegetative Symptome wie Abnormitäten der Atmung, kalte Extremitäten und gastrointestinale Probleme liegen im Vergleich zur klassischen RettVariante eher selten vor. Bei 85\% der Kinder, die von der Early-Onset-Seizure-Variante betroffen sind, ist keine absolute Mikrozephalie nachweisbar, wodurch sie sich deutlich von allen anderen Formen des Rett-Syndroms unterscheiden (Mari 2005).

Die Regressionsphase fehlt oft bei Kindern mit Genveränderungen innerhalb des CDKL5Gens (Bahi-Buisson und Bienvenu 2011). In solchen Fällen kann die Diagnose Early- 
Onset-Seizure-Variante des Rett-Syndroms nicht gestellt werden, da die Regressionsphase als obligates Diagnosekriterium für alle Rett-Varianten gilt (Tabelle 1). Veränderungen des CDKL5-Gens können demnach auch andere Erkrankungen hervorrufen. Dazu gehören unter anderem das oben genannte West-Syndrom und Autistische Erkrankungen.

Die Diagnosestellung erfolgt aufgrund des Nachweises der Genveränderung und bei Zutreffen der Diagnosekriterien für atypische Formen des Rett-Syndroms (Tabelle 1).

\subsection{FOXG1-Syndrom}

\subsubsection{Hintergrund}

Das FOXG1-Syndrom wurde aufgrund der klinischen Ähnlichkeit mit dem Rett-Syndrom ursprünglich als dessen kongenitale Variante bezeichnet (Ariani et al. 2008).

Eine italienische Arbeitsgruppe hatte bei einem Mädchen mit primärer globaler Entwicklungsstörung und Rett-ähnlichen Symptomen mittels vergleichender genomischer Hybridisierung (Array CGH) eine Mikrodeletion im Chromosom 14q12 nachgewiesen (Papa et al. 2008). Diese Deletion umfasste insgesamt fünf Gene, darunter das forkhead box G1 (FOXG1)-Gen. Dieses kodiert für einen hirnspezifischen Transkriptionsrepressor und spielt somit eine wichtige Rolle für die Entwicklung und Funktion des menschlichen Gehirns. Daher erschien es plausibel, dass die Entwicklungsstörung dieser Patientin, die an eine kongenitale Variante des Rett-Syndroms denken ließ, durch einen Funktionsausfall dieses Gens hervorgerufen wurde.

Daraufhin suchte man bei Patienten mit Rett-ähnlicher Symptomatik, bei denen weder Mutationen des MECP2-Gens (1.1.2) noch des CDKL5-Gens (1.1.3.2) nachgewiesen werden konnten, nach Veränderungen im FOXG1-Gen. In einer Kohorte von 53 Patienten wurden somit zwei weitere Patientinnen mit de novo Mutationen im FOXG1-Gen entdeckt (Ariani et al. 2008). Diese beiden nicht miteinander verwandten Mädchen entwickelten nach unauffälliger Schwangerschaft und Geburt jeweils eine schwere globale Retardierung, eine sekundäre Mikrozephalie, Handstereotypien und Atempathologien. Außerdem zeigten sie Defizite in der Kontaktaufnahme, Sprachfertigkeiten erlernten sie nicht.

In weiteren Publikationen konnte gezeigt werden, dass Mutationen des FOXG1-Gens die Ursache für die Entwicklungsstörungen der betroffenen Patientinnen sind (Ariani et al. 2008; Mencarelli et al. 2010; Philippe et al. 2010; Brunetti-Pierri et al. 2011; Kortüm et al. 2011). Kortüm und Koautoren wiesen darauf hin, dass die betroffenen Patientinnen in ihrer klinischen Symptomatik, abgesehen vom Beginn der Entwicklungsstörung in den 
ersten Lebensmonaten, einige erhebliche Unterschiede zum Rett-Syndrom aufwiesen, sodass die Bezeichnung „kongenitale Variante des Rett-Syndroms“ nicht adäquat erschien (Kortüm et al. 2011). Kortüm et al. schlugen stattdessen die Bezeichnung „FOXG1Syndrom"vor, die sich seither vermehrt durchgesetzt hat.

\subsubsection{Klinik}

Nach den vorliegenden wissenschaftlichen Publikationen lassen sich die bisher bekannten Daten zum klinischen Phänotyp des FOXG1-Syndroms wie folgt skizzieren:

Sowohl Schwangerschaft als auch Geburt verlaufen regelhaft und zum Zeitpunkt der Geburt erscheinen die meisten Neugeborenen im Wesentlichen unauffällig. Im Säuglingsalter fallen dann eine rumpfbetonte Muskelhypotonie, eine verminderte Reaktionsbereitschaft und erhöhte Reizbarkeit auf (Mencarelli et al. 2010). Bereits in den ersten Lebensmonaten wird oft ein zu kleiner Kopfumfang festgestellt, im Verlauf entwickelt sich dann eine deutliche Mikrozephalie. Die Wachstumsverzögerung des Kopfes tritt offensichtlich früher auf und ist stärker ausgeprägt als bei Patientinnen mit klassischem Rett-Syndrom (Mencarelli et al. 2010). Auch Körperwachstum und Körpergewicht sind üblicherweise reduziert (Kortüm et al. 2011).

Die Patienten präsentieren bereits sehr früh ausgeprägte psychomotorische Entwicklungsstörungen. Nur ausnahmsweise wird das Laufen erlernt. Zusätzlich wird die Motorik durch Apraxie, Dyskinesien und Spastik beeinträchtigt.

Charakteristisch ist auch eine hyperkinetisch-dyskinetische Bewegungsstörung, die sich meist innerhalb des ersten Lebensjahres manifestiert und insbesondere die obere Extremität betrifft (Mencarelli et al. 2010; Kortüm et al. 2011; Cellini et al. 2016). Das Ausprägungsmaximum wird bereits wenige Monate nach Erstmanifestation erreicht, das entstandene Bewegungsmuster verändert sich anschließend kaum (Cellini et al. 2016).

Rett-typische Handstereotypien und ausladende Bewegungen der Zunge finden sich auch bei Patienten mit FOXG1-Varianten. Als Folge dieser Stereotypien sowie der oben beschriebenen Apraxien sind zielgerichtete Handbewegungen kaum möglich.

In den meisten Fällen sind die Kinder nicht in der Lage zu sprechen. Selten werden einige einzelne Worte erlernt, oft stagniert die Sprachentwicklung im Stadium des Lautierens. Besonders drastisch reduziert sind die Fertigkeiten bei Patienten mit Duplikationen des FOXG1-Gens (Brunetti-Pierri et al. 2011). 
Viele Patienten entwickeln Epilepsien. Diese treten erstmals zwischen dem vierten und 14. Lebensjahr auf und äußern sich in generalisierten tonischen, tonisch-klonischen, myoklonischen und partiell-komplexen zerebralen Anfällen, welche mit unspezifischen fokalen oder multifokalen EEG-Veränderungen einhergehen (Kortüm et al. 2011; Terrone et al. 2014). Oftmals sprechen die Kinder gut auf eine antikonvulsive Therapie an (BahiBuisson et al. 2010b). Auffällig ist, dass bei Patienten mit Duplikationen innerhalb des FOXG1-Gens häufiger infantile Spasmen auftreten. Auf diesen frühen Beginn des Epilepsiegeschehens folgt oft ein schwerwiegender Verlauf. Im Vergleich dazu sind Patienten mit Deletionen oder Genvarianten im Säuglingsalter in der Regel anfallsfrei und zeigen einen deutlich milderen Epilepsieverlauf (Seltzer et al. 2014; Terrone et al. 2014).

Neurovegetativ zeigen die Kinder ein breites Symptomspektrum. Bei einem Großteil der Patienten ist eine adäquate Nahrungszufuhr kaum möglich, da sie unter vielfältigen gastrointestinalen Problemen leiden. Dazu gehören Aspirationen, Aerophagien, Bruxismus, Sialorrhö und ein gastro-ösophagealer Reflux. Des Weiteren führen Obstipationen oft zu starken abdominalen Beschwerden, die eine medikamentöse Behandlung erfordern (Kortüm et al. 2011). Viele Kinder können aufgrund dieser Symptome nur breiige Kost zu sich nehmen, zum Teil müssen sie sogar über eine Magensonde ernährt werden. Da viele Kinder ohnehin ein zu niedriges Körpergewicht aufweisen, ist es in der Therapie von großer Bedeutung, eine konstante und angepasste Nahrungsaufnahme zu gewährleisten.

Bezüglich des sozialen Verhaltens präsentieren die Patienten autismusnahe Verhaltensbesonderheiten. Ihre Kontaktaufnahme und die soziale Interaktion zu anderen Menschen ist gestört (Kortüm et al. 2011).

Das Schlafmuster von FOXG1-Patienten ist durch häufige und kurze Schlafphasen gekennzeichnet. Viele Patienten schlafen nachts nicht durch und verfallen tagsüber öfter in kurze Schlafphasen. In der Regel bessert sich diese Problematik nach einigen Jahren (Kortüm et al. 2011).

Ebenfalls auffallend sind die überwiegend im Säuglingsalter auftretenden Schreiepisoden. $\mathrm{Zu}$ Schreiattacken kommt es oft in der Nacht, wodurch der ohnehin schon pathologische Schlafrhythmus der Kinder gestört wird.

Bei vielen Patienten ist die augenärztliche Behandlung eines Strabismus erforderlich.

Zwar haben einzelne Autoren über faziale Besonderheiten bei Patienten mit FOXG1assoziierten Entwicklungsstörungen berichtet, jedoch weisen diese Patienten überwiegend chromosomale Mikroaberrationen auf, die noch weitere Gene neben dem FOXG1-Gen 
umfassen, sodass eine Assoziation der fazialen Dysmorphien mit dem FOXG1-Gen nicht sicher ist (De Filippis et al. 2012; Cellini et al. 2016). Die meisten Publikationen beschreiben keine spezifischen fazialen Dysmorphien beim FOXG1-Syndrom, auch die Datenbank „Online Mendelian Inheritance in Man (OMIM)“ (http://omim.org/) führt in ihrer klinischen Synopsis keine derartigen Dysmorphien auf.

\subsubsection{Neuroradiologie}

In der Bildgebung des Gehirns zeigt sich charakteristisch eine Hypoplasie des Corpus callosum. Kennzeichnend ist ein dysmorphes oder fehlendes Rostrum (vorderer Balkenbereich) und ein zu schmales oder nicht vorhandenes Splenium (hinterer Teil des Balkens, Kortüm et al. 2011). Als Maximalvariante kann eine komplette Agenesie des Corpus callosum vorliegen. Diese Ausprägungsform wird vergleichsweise häufig bei Patienten mit großen Deletionen des FOXG1-Gens nachgewiesen (Kortüm et al. 2011). Das Volumen der weißen Substanz ist vor allem in den beiden frontalen Hirnlappen und etwas seltener in den parietalen Arealen vermindert, woraus eine Atrophie der betroffenen Bereiche resultiert. Die Myelinisierung verläuft verzögert (Bahi-Buisson et al. 2010b). In vielen Fällen liegt eine Pachygyrie und/oder ein vereinfachtes Muster der Gyrierung vor (Mencarelli et al. 2010; Kortüm et al. 2011). Einige Patienten zeigen infolge der Hirnsubstanzminderung eine Erweiterung der inneren Liquorräume.

\subsubsection{Funktion und Genetik}

Das FOXG1-Gen kodiert für einen winged-helix Transkriptionsfaktor, der zur Gruppe der Forkhead-Box-Proteine (FOX) gehört (Ariani et al. 2008). Forkhead-Box-Proteine kennzeichnen sich durch ihr entwicklungsabhängiges Expressionsmuster aus und sind als Transkriptionsmodulatoren an Entwicklungs- und Differenzierungsprozessen von eukaryotischen Zellen beteiligt. FOXG1, auch als brain factor 1 (BF1) bezeichnet, kommt in Zellen des Gehirns sowie des Hodens vor und nimmt bezüglich der Transkriptionsregulation eine Repressorfunktion ein (Li und Vogt 1993).

Während der Gehirnentwicklung wird FOXG1 bereits in proliferierenden Zellen des Neuroepithels nachgewiesen. Diese frühe Expression erklärt die Entstehung der frühen neuronalen Defizite bei Patienten, deren Gen verändert ist (Ariani et al. 2008). Im weiteren Verlauf der Ontogenese des Zentralnervensystems (ZNS) befindet sich das Protein im Telenzephalon, der nasalen Hälfte der Retina und im Sehstrang (Dou et al. 2000). Die Expression steigt mit den Entwicklungsstadien stetig an. Im adulten Organismus ist FOXG1 sowohl in sich differenzierenden als auch reifen neuronalen Zellen nachweisbar. 
Intrazellulär befindet sich das Protein im Zellkern und weist hier viele Kolokalisationen mit MECP2 auf (1.1.2). MECP2-Genmutationen stellen, wie oben ausgeführt, die weitaus häufigste Ursache für die klassische Form des Rett-Syndroms dar (1.1.2). Analogien im räumlichen sowie im zeitlichen Expressionsprofil von FOXG1 und MECP2 erklären mitunter Übereinstimmungen des klinischen Bildes dieser Patienten (Ariani et al. 2008; Jacob et al. 2009).

In der telenzephalen Entwicklung nimmt FOXG1 zahlreiche Funktionen bezüglich der Strukturierung, Proliferation, Differenzierung und der hier ablaufenden Neurogenese ein (Philippe et al. 2010). Während der Embryonalentwicklung findet eine erste Strukturierung des Telenzephalons mit Ausbildung der verschiedenen Kompartimente statt. Die jeweiligen Zellpopulationen werden dementsprechend zugeordnet, was durch eine Vielzahl von Signalwegen koordiniert wird. FOXG1 beeinflusst diese Regulationsmechanismen, indem es die beteiligten Faktoren hemmt oder weitere Repressoren aktiviert. Ein Fehlen, eine Reduktion oder ein Funktionsverlust von FOXG1 führt zu falschen Zuordnungen der Zellen innerhalb des Gehirns. Dadurch entstehen Strukturanomalien, welche wiederum zu Funktionsdefiziten des ZNS führen (Danesin und Houart 2012).

Nach dieser Spezifizierung erfolgt eine Wachstumsexpansion des Telenzephalons. FOXG1 fördert diese Größenzunahme, indem es Zellzyklusinhibitoren hemmt, weshalb höhere Zellteilungsraten entstehen (Kortüm et al. 2011). Außerdem hemmt FOXG1 ein vorzeitiges Austreten von Progenitorzellen aus dem Zellzyklus, weshalb sie sich weiter teilen und keine vorzeitige Differenzierung stattfindet (Tian et al. 2012). Ein vollständiger Funktionsverlust von FOXG1 ist wegen einer drastischen Größenreduktion vor allem der ventralen Anteile der Großhirnhemisphären nicht mit dem Leben vereinbar (Dou et al. 2000).

In fortgeschrittenen Stadien der Gehirnentwicklung unterbindet FOXG1 eine Reifung von Progenitorzellen zu Cajal-Retzius-Zellen (Ariani et al. 2008; Bahi-Buisson et al. 2010b). Cajal-Retzius-Zellen sind die ersten Neurone, die sich aus kortikalen Progenitorzellen entwickeln. Sie organisieren die Schichtung des Kortex und sind somit für dessen funktionellen Aufbau essentiell. Die physiologische FOXG1-abhängige Inhibition der weiteren Bildung von Cajal-Retzius-Zellen dient der vermehrten Entwicklung von Progenitorzellen zu reifen Neuronen. Bei Funktionsstörungen oder Funktionsverlusten des FOXG1-Proteins entwickeln sich Progenitorzellen weiterhin kontinuierlich zu CajalRetzius-Zellen. Es kommt zu einer Expansion unreifer Neuronenpopulationen, reife Neurone entwickeln sich dagegen kaum. Resultat einer solchen Pathologie sind 
Malformationen in nahezu allen telenzephalen Strukturen. Dazu gehören unter anderem der Kortex, die Basalganglien, subventrikuläre Regionen und der Hippocampus (Dou et al. 2000; Hanashima et al. 2004; Hanashima et al. 2007; Brunetti-Pierri et al. 2011; Dastidar et al. 2011; Tian et al. 2012).

Postnatal sichert FOXG1 das Fortbestehen der Neurone. Eine erhöhte intrazelluläre Konzentration des Proteins verhindert den Zelluntergang. Dementsprechend liegt in Zellen, die sich in apoptotischen Stadien befinden, eine reduzierte Expression von FOXG1 vor. Folglich führt ein Expressionsabfall oder die Suppression von FOXG1 zur Induktion von Apoptosevorgänge (Dastidar et al. 2011).

Tierexperimentell konnte gezeigt werden, dass FOXG1 zudem für die Entwicklung des optischen und olfaktorischen Systems sowie für die korrekte Zellorganisation des Innenohres mitverantwortlich ist (Dastidar et al. 2011). Im Mausmodell hatten Gendefekte im FOXG1-Gen multiple Anomalien der Augenstrukturen und der Sehnerven zur Folge (Huh et al. 1999). Außerdem beeinflussen solche Veränderungen Proliferations- und Differenzierungsprozesse von olfaktorischen Progenitorzellen, was zur fehlerhaften Anordnung des Geruchsepithels führt (Duggan et al. 2008).

Des Weiteren konnte festgestellt werden, dass FOXG1 durch Interaktion mit AndrogenRezeptorproteinen Einfluss auf die Signalwege von Sexualhormonen nimmt (Philippe et al. 2010).

\subsubsection{Molekularer Aufbau}

Das Protein beinhaltet drei wichtige Funktionsdomänen. Die Forkhead-Domäne (FHD) mit der typischen winged-helix-Struktur bindet DNA. C-terminal von dieser liegen zwei Protein-Protein-Interaktionsdomänen, die Groucho-Bindungsdomäne (GBD) sowie die JARID1B-Bindungsdomäne (JBD). Beide Interaktionsdomänen sind entscheidend für die Funktion des FOXG1 als Transkriptionsrepressor (Guen et al. 2011). 


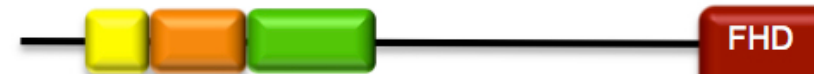

Abbildung 1: Schematische Darstellung FOXG1 (modifiziert nach Flindt 2011)

C-terminal: GBD: Groucho-Bindungsdomäne (blau), JBD: JARID1B-Bindungsdomäne (lila)

FHD: Forkhead-Domäne (rot)

$\mathrm{N}$-terminal: histidin- (gelb), prolin- (orange), glycinreiche- (grün) Region

Die GBD bindet Proteine der Grouchofamilie, welche Korepressoren der Transkription darstellen. Sie binden DNA nicht direkt, sondern fungieren als Adapter zwischen Transkriptionsfaktoren und DNA-bindenden Proteinen (Chen und Courey 2000). Bei Interaktion mit der Groucho-Bindungsdomäne von FOXG1 binden sie den Transkriptionsrepressor Hes1. Hes1 bindet direkt an die DNA und ist während der Embryonalentwicklung an der Regulation von Zellproliferation und Zelldifferenzierung beteiligt (Yao et al. 2001).

Des Weiteren tritt FOXG1 genau wie MECP2 mit Histondeacetylase1-Proteinen in Interaktion. Dies erfolgt nicht direkt, sondern vermutlich ebenso über Groucho-Proteine. Durch die Bindung der Histondeacetylase1-Proteine wird eine Deacethylierung von Histonen induziert. Dadurch wird den Transkriptionsfaktoren ihre Bindung an die DNA erschwert, woraus eine Unterdrückung der Transkription resultiert (Yao et al. 2001).

Die JBD bindet die Demethylase JARID1B. Durch die Bindung/Aktivierung von JARID1B werden Histone demytheliert. Dies hat eine Konfigurationsänderung des Chromatins zur Folge. Das entstehende Chromatinmuster nimmt eine Form an, welche die Transkriptionsvorgänge erschwert.

Über diese Funktionsdomänen tritt FOXG1 in Interkation mit zahlreichen Zielgenen und kann deren Expression regulieren. Wichtige Zielgene sind unter anderem der FibroblastenWachstumsfaktor und der transformierende Wachstumsfaktor $\beta$ (Dou et al. 2000; BahiBuisson et al. 2010a). Diese zahlreichen Beziehungen erklären die komplexen Folgen von Funktionsveränderungen oder -ausfällen des Proteins FOXG1. 
Bei Phänotyp-Genotyp-Analysen kristallisierte sich heraus, dass es entscheidend für die klinische Symptomausprägung der Patienten ist, inwieweit die Funktionsdomänen von den Veränderungen betroffen sind. Schwerwiegende Folgen haben Mutationen (Deletionen oder früh trunkierende Varianten), die einen Funktionsausfall aller Domänen bewirken. Im Vergleich dazu entsteht ein relatives mildes klinisches Bild, falls noch Restaktivitäten der Funktionsdomänen erhalten sind oder wenn diese von der Genveränderung nicht betroffen sind (Philippe et al. 2010).

\subsection{Zielsetzung}

Ziele dieser Studie waren,

1. in einer möglichst großen Kohorte von bereits publizierten und neu rekrutierten Patienten mit pathogenen oder wahrscheinlich pathogenen Varianten im FOXG1-Gen die klinischen, neuroradiologischen und molekulargenetischen Merkmale standardisiert zu erfassen,

2. somit den klinischen Phänotyp des FOXG1-Syndroms differenzierter zu beschreiben als dies bisher möglich war und

3. nach Genotyp-Phänotyp-Assoziationen zu suchen.

Ein Wissenszuwachs hinsichtlich phänotypischer Merkmale soll zukünftig eine bessere klinische Abgrenzung des FOXG1-Syndroms zu ähnlichen Krankheitsbildern wie beispielsweise dem Rett-Syndrom ermöglichen. Die Etablierung von differenzierten Genotyp-Phänotyp-Assoziationen soll die fundierte Beratung von Familien, deren Kind eine FOXG1-Variante aufweist, erleichtern. 


\section{$2 \quad$ Material und Methoden}

\section{1 Überblick zur Studie}

Die vorliegende Studie war Teil einer wissenschaftlichen Kooperation zwischen klinischen Institutionen in Göttingen, Leipzig und Vogtareuth. Die Untersuchung wurde im Rahmen des „Zentrums für Seltene Neurologische Erkrankungen im Kindes- und Jugendalter (GoRare)“ in der Klinik für Kinder und Jugendmedizin (Direktorin Prof. Dr. Jutta Gärtner) mit Sozialpädiatrischem Zentrum (Leiter Prof. Dr. Knut Brockmann) der Universitätsmedizin Göttingen und in enger Kooperation mit Frau Prof. Dr. Dr. Birgit Zirn, ehemalig SPZ Göttingen, jetzt Genetikum Stuttgart sowie mit Frau Dr. Diana Mitter, Oberärztin des Institutes für Humangenetik, Universitätsklinikum Leipzig, durchgeführt.

Das Projekt wurde von der Ethikkommission der Universitätsmedizin Göttingen genehmigt (Antragsnummer 16/12/14).

Die Doktorandin sammelte alle Daten, führte Elterngespräche und teilte die klinischen Merkmale nach einem selbstständig entworfenen Schema ein. Sie entwickelte eine Schweregradeinteilung und berechnete den Schweregrad für alle Patienten. Gemeinsam mit der Arbeitsgruppe wurde die Phänotyp-Genotyp-Analyse durchgeführt. Eine regelmäßige Absprache über alle Arbeitsschritte fand mit dem Betreuer dieser Dissertation statt.

\subsection{Patientenrekrutierung}

Das FOXG1-Syndrom stellt eine sehr seltene neurologische Erkrankung dar, im SPZ Göttingen ist derzeit nur eine einzige Patientin mit dieser Diagnose in regelmäßiger Betreuung. Um zu den oben formulierten Fragestellungen valide Aussagen treffen zu können, war es erforderlich, eine möglichst große Kohorte von Patienten mit FOXG1Syndrom zusammenzutragen.

Dazu wurden zunächst neue, bisher nicht publizierte Patienten mit im Rahmen der Krankenversorgung bereits molekulargenetisch nachgewiesenen heterozygoten pathogenen oder wahrscheinlich pathogenen FOXG1-Varianten rekrutiert. Dies erfolgte einerseits durch das Abfragesystem ESNEK („Erhebung Seltener Neurologischer Erkrankungen im Kindesalter") und andererseits über bestehende nationale und internationale Kooperationen mit anderen Abteilungen für Kinderneurologie oder Humangenetik (2.2.1). 


\subsubsection{ESNEK und Kooperationspartner}

ESNEK ist ein E-Mail-basiertes Abfragesystem zur Rekrutierung ausreichend großer Patientenkohorten für klinisch-wissenschaftliche Projekte auf dem Gebiet seltener neurologischer Erkrankungen des Kindes- und Jugendalters (https://gorare.med.unigoettingen.de/das-esnek-konzept.html). ESNEK wurde in der Klinik für Kinder- und Jugendmedizin der Universitätsmedizin Göttingen, im Rahmen der Gründung des „Zentrums für Seltene Neurologische Erkrankungen im Kindes- und Jugendalter (GoRare)“, etabliert. Das Abfragesystem umfasst derzeit ca. 1000 Kontaktadressen zu Neuropädiatern bzw. schwerpunktmäßig neurologisch tätigen Kinderärzten in Kliniken, Sozialpädiatrischen Zentren und Praxen in ganz Deutschland, z. T auch in der Schweiz und Österreich.

Ziel dieses Abfragesystems ist es, einen unkomplizierten Weg der Kommunikation zwischen Ärzten zu schaffen und dadurch möglichst große Patientenkohorten für wissenschaftliche Studien zu rekrutieren.

ESNEK orientiert sich an den Prinzipien von ESPED („Erhebungseinheit für seltene pädiatrische Erkrankungen in Deutschland“), welches 1992 in der Universitätsklinik Düsseldorf gegründet wurde (www.esped.uniduesseldorf.de).

Während ESPED über ein Jahr im Monatstakt nach einer gegebenen seltenen Erkrankung fragt und so auch die Inzidenz dieser Erkrankung ermittelt, fragt ESNEK nur einmal (mit einer Erinnerungs-Email 4 Wochen später) nach einer gegebenen seltenen neurologischen Erkrankung, kann also aus epidemiologischer Sicht nur Prävalenzen erfassen.

Grundsätzlich hat jeder klinisch-wissenschaftlich arbeitende Neuropädiater des deutschsprachigen Raumes die Möglichkeit, ESNEK für sein Forschungsprojekt zu nutzen. Voraussetzung ist, dass sich das Projekt mit einer seltenen neurologischen Kinder- oder Jugendkrankheit befasst, die sich vor dem 17. Lebensjahr manifestiert.

Nachdem die Durchführung einer Studie von der zuständigen Ethikkommission genehmigt wurde, wird von der Studienleitung ein Exposé verfasst. Dieses beinhaltet eine kurze Beschreibung der Studienziele, der Vorgehensweise und Informationen zu der Erkrankung, welche im Mittelpunkt des Projekts steht. Das Schreiben wird über den ESNEKEmailverteiler an alle registrierten Neuropädiater in Deutschland, Österreich und der Schweiz verschickt. Aus Datenschutzgründen ist eine direkte Übermittlung der Kontaktdaten der Patienten von den betreuenden Ärzten an die Studienleitung nicht möglich. Deshalb übermitteln die Ärzte zunächst eine Fallzahl, sodass ESNEK gemeldet 
wird, wie viele Patienten mit dieser speziellen neurologischen Erkrankung sich in Betreuung des jeweiligen Neuropädiaters befinden. Daraufhin versendet ESNEK per Post ein Schreiben an den meldenden Neuropädiater mit der Bitte, das beigefügte Anschreiben an die Eltern des betroffenen Kindes weiterzuleiten, möglichst im Rahmen einer persönlichen, telefonischen Erläuterung. In diesem Anschreiben erhalten die Familien ein erste kurze Darstellung des Forschungsprojektes mit der Einladung, sich für weitere Informationen mit ESNEK in Verbindung zu setzen und sich an der Studie zu beteiligen (6.3). Somit können die Eltern frei entscheiden, ob sie an der Studie teilnehmen möchten. Falls dies der Fall ist, nehmen die Familien Kontakt zu ESNEK auf. Mit Vorliegen der Einwilligungserklärung besteht nun die Möglichkeit, direkt mit der Familie Kontakt aufzunehmen.

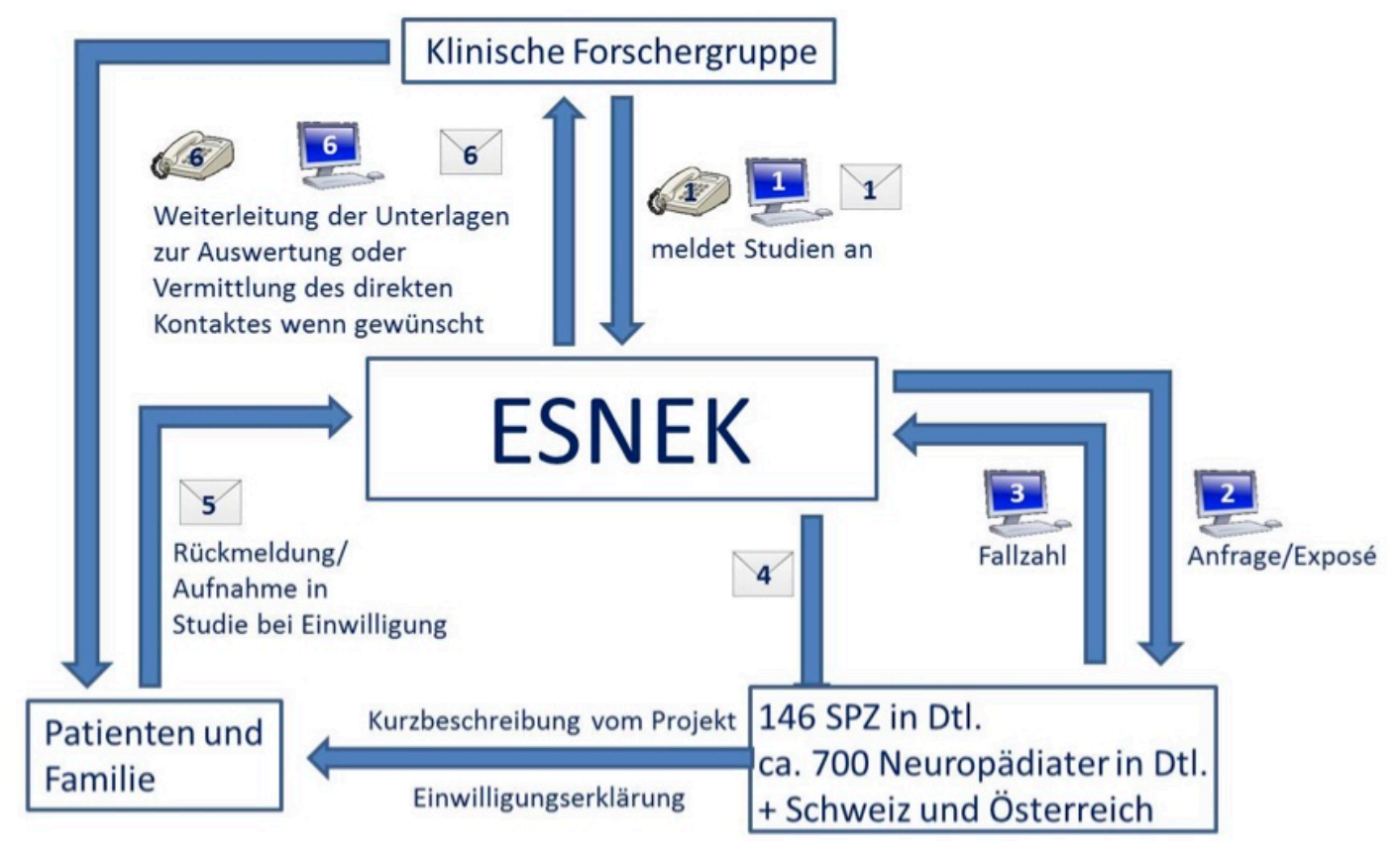

Abbildung 2: Schema des methodischen Vorgehens der „Erhebung Seltener Neurologischer Erkrankungen im Kindesalter (ESNEK)“ (modifiziert nach Schröder et al. 2015)

Bezüglich der vorliegenden Studie zum FOXG1-Syndrom wurde eine Email-Abfrage über den ESNEK-Verteiler am 16.02.2015 versandt. Wir erhielten von den angeschriebenen Neuropädiatern insgesamt 26 Fallmeldungen. Bei 7 dieser Meldungen waren entweder die Eltern nicht an einer Teilnahme interessiert, oder es lag eine chromosomale Mikroaberration vor, die über das FOXG1-Gen hinausgeht. Es verblieben also 19 Patienten mit FOXG1-Varianten, die über ESNEK für diese Studie rekrutiert werden konnten. Die Patientenunterlagen, die wir auf diesem Weg erhielten, sind im SPZ, Klinik 
für Kinder- und Jugendmedizin der Universitätsmedizin Göttingen an einem verschlossenen Ort aufbewahrt und werden nach Abschluss der Studie vernichtet.

Durch Kooperation mit dem Institut für Humangenetik des Universitätsklinikums Leipzig konnten weitere 11 Patienten mit Varianten des FOXG1-Gens ausfindig gemacht werden. $\mathrm{Zu}$ diesen Patienten liegen uns keine Kontaktdaten oder Krankenakten vor, die erforderlichen Daten wurden uns lediglich anonymisiert übermittelt.

So konnten insgesamt 30 bisher nicht publizierte Patienten mit pathogenen FOXG1Varianten rekrutiert werden.

\subsubsection{Patienten aus der Literatur}

Zudem wurden im Rahmen einer Pubmed-Recherche alle bisherigen (bis Dezember 2015) englischsprachigen wissenschaftlichen Publikationen zu Patienten mit pathogenen oder wahrscheinlich pathogenen FOXG1-Varianten ermittelt. So waren klinische, neuroradiologische und molekulargenetische Daten zu 53 bereits publizierten Patienten erhebbar (2.3.1).

Damit konnte für diese Untersuchung eine Kohorte von insgesamt 83 Patienten mit heterozygoten FOXG1-Varianten rekrutiert werden.

\subsection{Erhebung der klinischen, neurologischen und genetischen Patientendaten}

Auf der Grundlage eines ausführlichen Studiums der klinisch-wissenschaftlichen Publikationen zum FOXG1-Syndrom wurde zunächst ein Tabelle mit denjenigen klinischen, neuroradiologischen und molekulargenetischen Merkmalen als Excel-Datei konstruiert, die sich als wesentlich für die Charakterisierung von Patienten mit pathogenen oder wahrscheinlich pathogenen FOXG1-Varianten darstellten. Anhand dieser Tabelle (6.1) wurden nun die Daten aller 53 bereits publizierten und aller 30 neuen Patienten mit FOXG1-Varianten standardisiert und systematisch zusammengetragen.

Die Daten zu den 53 in der wissenschaftlichen Literatur beschriebenen Patienten wurden aus den jeweiligen Publikationen extrahiert, soweit sie dort angeführt wurden.

Die Daten der 19 über ESNEK rekrutierten Patienten wurden im schriftlichen Einverständnis mit den Eltern aus den uns zur Verfügung gestellten Arztbriefen und Befundberichten extrahiert sowie ergänzend von den Eltern direkt in Form eines standardisierten Telefoninterviews erhoben. 
Die Daten der 11 Patienten, die von Frau Dr. Mitter, Humangenetik Leipzig, über nationale und internationale Kooperationen mit Instituten für Humangenetik rekrutiert worden waren, wurden uns anonymisiert zur Verfügung gestellt, indem wir dem jeweils betreuenden Arzt die leere Excel-Tabelle zusandten, mit der Bitte, zu allen aufgelisteten Merkmalen einen Eintrag vorzunehmen.

Zahlreiche Eltern stellten uns zudem Photographien ihres betroffenen Kindes zur Verfügung.

\subsubsection{Darstellung der Patientencharakteristika}

Jeder Patient wird pseudonymisiert aufgelistet, sodass eine Identifikation durch Dritte nicht möglich ist.

Neben den allgemeinen Patienteninformationen wurden alle erhältlichen Daten zum somatischen Wachstum seit der Geburt, zur motorischen, sprachlichen und sozialen Entwicklung sowie gastrointestinalen und neurologischen Symptomen erhoben (6.1).

Fehlende Informationen zu einem Patienten werden mit dem Kürzel „n.a.“ (not available) angeben.

\subsubsection{Allgemeine Patienteninformationen}

Zur übersichtlichen Darstellung wurden zunächst alle Patienten in nummerierter Reihenfolge aufgelistet. Geschwistern wurde dieselbe Familiennummer zugeteilt (Tabelle 8). Des Weiteren wurde angegeben, ob Patientendaten über ESNEK, Kooperationspartner oder anhand von publizierter Literatur gewonnen wurden. Zur Identifikation wurden Geschlecht und Alter sowohl zum Studienzeitpunkt als auch zum Zeitpunkt der letzten Untersuchung aufgeführt. Als Studienzeitpunkt wurde das Datum gewählt, ab welchem die klinischen Daten der Patienten zur Verfügung gestellt und erstmals ausgewertet wurden. Zusätzlich ermittelten wir die ethnische Herkunft der Eltern.

\subsubsection{Somatische Entwicklung}

Der Verlauf des somatischen Wachstums der Patienten wurde anhand aller erhältlichen Daten zu Geburten und aktueller Auxologie (Gewicht, Länge, Kopfumfang) dargestellt (Tabelle 9). Sowohl zu den Messwerten bei Geburt als auch zu denen zum Zeitpunkt der letzten Untersuchungen wurde der BMI (body mass index) bestimmt. Für Köperlänge, Körpergewicht, BMI und Kopfumfang wurde zusätzlich der Standard Deviation Score (SDS) berechnet. Dieser ermöglicht eine Einordnung des Messwerts in Bezug auf die Mittelwerte der altersentsprechenden Bevölkerungspopulation. Ein physiologischer SDS 
liegt zwischen -2 und 2, dementsprechend gelten Werte außerhalb dieses Bereichs als auffällig. Die Referenzwerte bezüglich dieser Berechnung wurden der aktuellen KiGGS Studie entnommen (Neuhauser et al. 2013). Bezüglich der Geburtsmaße wird der SDS in Abhängigkeit von den Schwangerschaftswochen zum Zeitpunkt der Entbindung bestimmt. Diesbezüglich publizierten Voigt et al. differenzierte Werte, die Grundlage der vorliegenden Berechnung waren (Voigt et al. 2006). Zusätzlich wurde ermittelt, inwieweit Auffälligkeiten beziehungsweise Komplikationen während der Schwangerschaft vorlagen und in welcher Schwangerschaftswoche die Geburt stattfand. Des Weiteren wurde der APGAR-Wert der Neugeborenen erfragt, um das klinische Erscheinungsbild bei und kurz nach der Geburt einzuschätzen.

\subsubsection{Motorische Fähigkeiten und Entwicklung}

Zur Charakterisierung der Motorik wurde ermittelt, ob und wenn ja, ab welchem Lebensalter die Patienten zu Fähigkeiten wie Laufen, Sitzen und einem funktionalen Gebrauch der Hände in der Lage waren und welches die beste motorische Leistung der Kinder war. Erfasst wurde weiterhin, ob Rückschritte und somit Anzeichen einer Regression bezüglich bereits entwickelter motorischer Fertigkeiten beobachtet wurden (Tabelle 10).

\subsubsection{Sprachliche Fähigkeiten und Entwicklung}

Diese Subkategorie stellt dar, inwieweit sprachliche Fähigkeiten im Sinne von expressiver Sprache sowie Lautieren vorhanden waren. Wenn die Kinder in der Lage waren zu sprechen, wurden das Alter beim Erlernen der Sprache und die aktuelle Anzahl an gesprochenen Wörtern ermittelt. Ähnlich wie bei den motorischen Fähigkeiten wurde ebenfalls erfragt, ob die Kinder bereits erworbene Fähigkeiten im Laufe ihrer Entwicklung verlernt hatten (Tabelle 10).

\subsubsection{Soziales Verhalten}

Zur Erfassung des Verhaltensmusters der FOXG1-Kinder wurden Anzeichen sozialer Interaktion, die Fähigkeit zum Augenkontakt und pathologische Schlafmuster dargestellt. Zusätzlich wurde aufgeführt, ob Schreiepisoden und/oder Lachanfälle auftraten. Auch autismusnahe Verhaltensbesonderheiten wurden registriert (Tabelle 11). 


\subsubsection{Gastrointestinale und sonstige Symptome}

Hinsichtlich der gastrointestinalen Symptome wurde zunächst festgehalten, ob sich das Füttern der Kinder schwierig gestaltete. Weiterhin wurden gastro-ösophagealer Reflux, Aspirationen und Obstipation erfasst (Tabelle 11).

Anomalien der Wirbelsäule in Form einer Kyphose oder Skoliose wurden erfragt.

\subsubsection{Neurologische Symptome}

Eine wichtige Subkategorie bezüglich neurologischer Eigenschaften umfasst das Vorliegen von Epilepsien. Diese wurden in Bezug auf Erstmanifestation und Epilepsietyp dargestellt (Tabelle 12).

$\mathrm{Zu}$ den weiteren erfassten neurologischen Symptomen zählten muskuläre Hypotonie, Spastik, motorische Stereotypien, insbesondere von Händen und Zunge, und Dyskinesien. Zudem wurden neuroophthalmologische Symptome wie Strabismus und Nystagmus erfragt. Des Weiteren wurde aufgelistet, ob Hypersalivation oder ein Bruximus vorlagen und ob das Atemmuster pathologische Veränderungen zeigte (Tabelle 12).

\subsubsection{Neuroradiologische Daten}

Sofern cMRT-Daten erhältlich waren, wurden diese für die bereits veröffentlichten Patienten aus den jeweiligen Publikationen und für die neuen Patienten aus den MRTBefunden hinsichtlich Fehlbildungen des Corpus callosum, Myelinisierung, Fehlbildungen der grauen Substanz und Ventrikelweite erfasst (Tabelle 13). Sofern uns die neuroradiologischen Daten von kranialen MR-Tomographien der Patienten auf CD zur Verfügung gestellt werden konnten $(n=22)$, wurden diese MRTs nach einem standardisierten Protokoll ausgewertet. Diese Auswertung erfolgte im Rahmen der Kooperation mit der Neuropädiatrie der Schön-Kliniken Vogtareuth durch die dortigen Kollegen mit besonderer kinder-neuroradiologischer Expertise (Frau Dr. Pringsheim, Dr. Retzl).

\subsubsection{Fasziale Dysmorphien}

Die Analyse der zwölf klinischen Photographien von Patienten ergab keine signifikanten fazialen Dysmorphien (Abbildung 3).

\subsubsection{Genetische Analyse}

Einschlusskriterium in die vorliegende Studie war der bereits erfolgte molekulargenetische Nachweis einer heterozygoten pathogenen oder wahrscheinlich pathogenen FOXG1- 
Variante. Bei den 53 bereits publizierten Patienten waren die Details der Genvariante in der jeweiligen Publikation aufgeführt worden. Bei allen neu rekrutierten Patienten waren diese humangenetischen Untersuchungen im Rahmen der Krankenversorgung von den betreuenden Kinderneurologen bzw. Humangenetikern veranlasst und in 11 verschiedenen humangenetischen Laboren (10 in Deutschland, 1 in den USA) durchgeführt worden (Tabelle 2).

Bei 62 Patienten erfolgte die molekulargenetische Untersuchung mittels Sanger Sequenzierung, bei 19 mittels Next Generation Sequencing Methoden (9 im Rahmen eines Panels, 10 im Rahmen einer Gesamtexom-Sequenzierung, Tabelle 2).

Für die statistische Genotyp-Phänotyp-Analyse wurden die Genvariante nach Lokalisation und Typ in fünf Gruppen eingeteilt (Tabelle 3). Einige der vorliegenden Genveränderungen konnten keiner der Gruppen zugeordnet werden. Die dazugehörigen Patientenanzahlen waren zu gering, um als eigenständige Kohorte mit in die Analyse aufgenommen $\mathrm{zu}$ werden. Insgesamt ergab sich somit ein Patientenkollektiv von $n=76$ Patienten als Grundlage für die Genotyp-Phänotyp-Analyse (3.3).

Tabelle 2: Externe genetische Labore

\begin{tabular}{|l|}
\hline Genetische Labore \\
\hline CeGaT (Center for Genomics and Transcriptomics), Tübingen \\
\hline Praxis für Humangenetik Freiburg \\
\hline Zentrum für Humangenetik Regensburg \\
\hline Institut für Humangenetik Freiburg \\
\hline Institut für Humangenetik Lübeck \\
\hline MVZ (Medizinisches Versorgungszentrum) Lübeck \\
\hline Genetikum Stuttgart \\
\hline Genetikum Leipzig \\
\hline Humangenetische Praxis Dr. Meiner/ Dr. Moghadam, Halle \\
\hline Praxis für Humangenetik und Kinderheilkunde Dr. Huhle, Leipzig \\
\hline Ambry Genetics Aliso Viejo, Kalifornien, USA \\
\hline
\end{tabular}


Tabelle 3: Gruppeneinteilung nach Genvariante

\begin{tabular}{|ll|}
\hline \multicolumn{2}{|l|}{ Gruppeneinteilung nach Genvariante } \\
\hline 1 & Nonsense- und Frameshift-Variante der 5'-Domäne \\
\hline 2 & Missense-Variante des konservierten Bereichs der Forkhead-Domäne \\
\hline 3 & Nonsense- und Frameshift-Variante außerhalb des konservierten Bereichs der Forkhead-Domäne \\
\hline 4 & Missense-Variante außerhalb des konservierten Bereichs der Forkhead-Domäne \\
\hline 5 & Nonsense- und Frameshift-Variante der 3'-Domäne \\
\hline
\end{tabular}

\subsubsection{Schweregrad-Punkteskala des FOXG1-Syndroms}

Um die klinisch-neuroradiologischen Phänotypen, die mit unterschiedlichen pathogenen oder wahrscheinlich pathogenen FOXG1-Varianten assoziiert sind, auf einfache Weise zu quantifizieren, wurde eine Schweregrad-Punkteskala (FOXG1 Clinical Severity Score) für das FOXG1-Syndrom entwickelt (Tabelle 4). Diese Skala orientierte sich an einem früheren Score, der von Mencarelli et al. 2010 in ihrer Publikation über vier neue FOXG1Varianten vorgestellt wurde (Mencarelli et al. 2010). Dieser Score von Mencarelli et al. ist aus unserer Sicht nicht optimal, da er die unterschiedlichen klinischen Domänen nicht sinnvoll gewichtet. So wurden von Mencarelli et al. z. B. maximal 8 Punkte für Sprachentwicklungsstörung, aber nur 2 Punkte für Epilepsie vergeben (bei insgesamt 44 möglichen Punkten).

Unsere Skala umfasst insgesamt 20 Merkmale in fünf Kategorien: somatisches Wachstum, motorische und sprachliche Entwicklung, Verhaltensbesonderheiten, neurologische und gastrointestinale Symptome sowie cMRT Veränderungen. Für jedes der 20 ausgewählten Krankheitsmerkmale wurde je nach Ausprägung ein Punktwert von null (keine klinischen oder neuroradiologischen Symptome) bis zwei (maximale Ausprägung der klinischen oder neuroradiologischen Symptome) Punkten vergeben, sodass höhere Punktwerte einem schwereren Phänotyp entsprechen. Es ergab sich somit eine Spannbreite von Null bis maximal 40 Punkten. Da insbesondere für die 53 bereits veröffentlichten Patienten Informationslücken vorlagen und eine Vergleichbarkeit dadurch schwierig wäre, berücksichtigten wir für die weitere Analyse nur solche Patienten, bei denen für mindestens ein Merkmal in jeder der fünf Kategorien Daten vorlagen (3.4). Dadurch ergab sich ein Kollektiv von 55 Patienten (Tabelle 14). Da jedes der 20 Merkmale mit demselben Gewicht 
gewertet wurde, beeinflussten Kategorien mit mehreren Einzelmerkmalen den Score stärker (z.B. neurologische Eigenschaften).

Für die Genotyp-Phänotyp-Analyse wurde die Mittelwerte der Schweregrade-Skalenwerte der einzelnen genetischen Gruppen miteinander verglichen (3.4.2). Zusätzlich konnten durch Mittelwertberechnungen der Schweregrad der neu rekrutierten Patienten mit dem Schweregrad der Patienten, zu denen bereits publiziert wurde, gegenübergestellt werden (3.4.1). 
Tabelle 4: Schweregradeinteilung

\begin{tabular}{|c|c|c|c|}
\hline & 0 Punkte & 1 Punkt & 2 Punkte \\
\hline \multicolumn{4}{|l|}{ Somatische Entwicklung } \\
\hline Aktuelle Körperlänge & -2 bis 2 SDS & & $<-2$ SDS \\
\hline Aktueller BMI & -2 bis 2 SDS & & $<-2$ SDS \\
\hline Kopfumfang bei Geburt & -2 bis 2 SDS & & $<-2$ SDS \\
\hline Aktueller Kopfumfang & -2 bis 2 SDS & & $<-2$ SDS \\
\hline \multicolumn{4}{|c|}{ Motorische und sprachliche Entwicklung } \\
\hline Sitzen (bei > 1 Jahr) & Ohne Unterstützung & Mit Unterstützung & Nicht möglich \\
\hline Laufen (bei >2 Jahren) & Ohne Unterstützung & Mit Unterstützung & Nicht möglich \\
\hline $\begin{array}{l}\text { Funktioneller Gebrauch der } \\
\text { Hände }\end{array}$ & $\mathrm{Ja}$ & & Nein \\
\hline $\begin{array}{l}\text { Expressive Sprache (bei } \\
>\text { 1Jahr) }\end{array}$ & $\mathrm{Ja}$ & & Nein \\
\hline \multicolumn{4}{|l|}{ Soziales Verhalten } \\
\hline Soziale Interaktion & $\mathrm{Ja}$ & & Nein \\
\hline Augenkontakt & $\mathrm{Ja}$ & Wenig & Nein \\
\hline Abnormes Schlafmuster & Nein & & Ja \\
\hline \multicolumn{4}{|c|}{ Neurologische und andere Symptome } \\
\hline Epilepsie & Nein & & $\mathrm{Ja}$ \\
\hline Spastik & Nein & & $\mathrm{Ja}$ \\
\hline Stereotypische Bewegungen & Nein & & $\mathrm{Ja}$ \\
\hline Dyskinesie & Nein & & $\mathrm{Ja}$ \\
\hline $\begin{array}{l}\text { Schwierigkeiten bei } \\
\text { Nahrungsaufnahme }\end{array}$ & Nein & & $\mathrm{Ja}$ \\
\hline Kyphose / Skoliose & Nein & & $\mathrm{Ja}$ \\
\hline \multicolumn{4}{|l|}{ cMRT Veränderungen } \\
\hline $\begin{array}{l}\text { Corpus callosum } \\
\text { Hypoplasie/Agenesie }\end{array}$ & Nein & & $\mathrm{Ja}$ \\
\hline $\begin{array}{l}\text { Anomalien der weißen } \\
\text { Substanz }\end{array}$ & Nein & & $\mathrm{Ja}$ \\
\hline Kortikale Dysplasie & Nein & & $\mathrm{Ja}$ \\
\hline Punktwert minimal $0, \mathrm{~m}$ & nal 40 & & \\
\hline
\end{tabular}

BMI: body mass index, SDS: Standard Deviation Score 


\subsection{Statistische Analyse}

Die statistische Analyse der Genotyp-Phänotyp-Assoziation erfolgte durch Frau PrivatDozentin Dr. Dörthe Malzahn, Institut für Genetische Epidemiologie, Universitätsmedizin Göttingen. Genutzt wurde die Software von R (Version 3.2.2., http://www.cran.rproject.org). Alle p-Werte wurden in zweiseitigen Tests ermittelt.

Die Phänotypanalyse beinhaltete die Berechnung von Frequenzen der einzelnen phänotypischen Merkmalen des FOXG1-Syndroms (Tabelle 5). Dies erfolgte sowohl in der Kohorte der neu rekrutierten Patienten $(n=30)$ als auch bei den Patienten zu denen bereits publiziert wurde ( $n=53)$. Anschließend wurden die Frequenzen für alle FOXG1-Patienten $(n=83)$ ermittelt. Die Daten wurden mit Hilfe des Fisher's exakter Test (in den einzelnen Kategorien) sowie des Kruskal-Wallis Rangsummentest (Altersvariablen) ausgewertet. Das Signifikanzniveau wurde auf $\mathrm{p} \leq 0,05 / 35=0,0014$ festgelegt.

Bei der Genotyp-Phänotyp-Analyse wurden die Häufigkeiten der ausgewählten 29 klinischen Merkmale in jeder genetischen Gruppe ermittelt (3.3). Es sollte diesbezüglich festgestellt werden, ob signifikante Unterschiede bezüglich der Ausprägung einzelner Krankheitsmerkmale zwischen den genetischen Gruppen vorlagen. Bei der Auswertung kamen folgende Signifikanzniveaus zur Anwendung: $\alpha=0,0301$ für die beiden Assoziationstests der Schweregradeinteilung (Zwei-Gruppen und Fünf-Gruppenvergleich), $\alpha=0,00918$ (fünf multivariate Zwei-Gruppenvergleiche und Abschlusstestprinzip für die univariaten Tests der zu den multivariaten Tests beitragenden Phänotypen) und $\alpha=0,00186$ (29 univariate Fünf-Gruppenvergleiche, Tabelle 6). Die für multiples Testen korrigierten Signifikanzniveaus $(\alpha=0,0301, \quad \alpha=0,00918, \quad \alpha=0,00186) \quad$ wurden anhand von Permutationstests ermittelt. Permutionstests berechneten die Verteilung der Teststatistik der jeweiligen Testfamilie unter der Nullhypothese, dass keine Genotyp-PhänotypAssoziation vorlag. Dafür wurden 50.000 Kopien des originalen Datensatzes mit zufällig permutierter Zuweisung der individuellen genetischen Gruppen erzeugt und der jeweiligen Testfamilie entsprechend auf Genotyp-Phänotyp-Assoziation getestet. Die Korrelation der 29 Phänotypen blieb dabei erhalten. Als univariate Assoziationstests dienten der Fisher's exakter Test (für alle primären Phänotypen) und der Kruskal-Wallis Rangsummentest (für die Schweregradeinteilung).

Die Schweregradeinteilung war eine Form der Datenreduktion. Datenreduktion kann man vermeiden, indem Ausprägungen mehrerer Merkmale in multivariaten Tests gemeinsam getestet werden. Die multivariaten Tests wurden für die fünf Kategorien somatisches Wachstum, motorische und sprachliche Entwicklung, soziale Verhaltensweisen, 
neurologische Eigenschaften sowie cMRT Veränderungen durchgeführt. Dafür wurde die multivariate Rangsummenmethode LNPT (Malzahn et al. 2010) verwendet. LNPT testete, ob ein konsistenter Gesamteffekt der genetischen Gruppen auf die Merkmalsausprägungen innerhalb einer der fünf Kategorien vorlag. Dabei wurden die Ausprägungen aller Merkmale einer Kategorie zusammen analysiert. Die LNPT Teststatistik ähnelte einer heteroskedastischen, einfaktoriellen ANOVA für Wiederholungsmessungen. Der Einflussfaktor war in diesem Fall die genetische Gruppe. Die untersuchten Zielgrößen waren das Auftreten von Krankheitseigenschaften bzw. Abweichungen von der Norm. Diese Zielgrößen gingen als multivariate Rangsummendaten in die Berechnung der Teststatistik ein. LNPT erlaubte und berücksichtigte beliebige multivariate Korrelationen und umfasste alle Patienten zu denen Phänotypdaten vorlagen. Patienten mit unvollständigen Informationen wurden ebenfalls analysiert, ohne Annahmen über fehlende Werte zu machen. LNPT benötigte mindestens zehn Patientendaten für jedes Merkmal pro auszuwertender Kategorie. Deshalb wurde die Gruppe mit den meisten Patienten (Gruppe 1) im Zwei-Gruppenvergleich mit den gepoolten anderen vier genetischen Gruppen getestet. 


\section{Ergebnisse}

\subsection{Analyse des klinischen und neuroradiologischen Phänotyps}

Die Analyse des klinischen Phänotyps erfolgte zunächst separat für die Kohorte der neuen Patienten $(n=30)$ und für die der bereits publizierten Patienten $(n=53)$ sowie anschließend für die Gesamtkohorte ( $n=83$ ). Die Gesamtkohorte umfasst 35 männliche und 48 weibliche Patienten, das Alter lag im Durchschnitt bei 105 Monaten mit einer Spannbreite von 14 bis 384 Monaten (Tabelle 5).

$\mathrm{Zu}$ einigen Merkmalen ergaben sich signifikante Unterschiede zwischen den neu rekrutierten Patienten und den bereits publizierten Patienten. Es fiel auf, dass die Gruppe der neuen Patienten signifikant jünger $(p=0,0006)$ und seltener von Spastik $(p=0,0007)$ betroffen war (Tabelle 5). Grenzwertige Signifikanzen zeigten sich im Vergleich des funktionellen Gebrauchs der Hände $(p=0,0076)$, zu welchem die Kohorte der neu rekrutierten Patienten häufiger in der Lage war (Tabelle 5).

Bei der überwiegenden Anzahl der Krankheitsmerkmale wurden keine signifikanten Unterschiede zwischen der neuen und der bekannten Patientenkohorte festgestellt. Das klinische Bild, welches sich daraus für FOXG1-Patienten ergibt, wird im Folgenden dargestellt.

\subsubsection{Somatische Entwicklung}

Gewicht, Größe, BMI und Kopfumfang galten als von der Altersnorm abweichend, wenn der ermittelte Standard Deviation Score (SDS) außerhalb des Bereiches zwischen -2 bis +2 $\operatorname{lag}(2.3 .1 .2)$.

Bei Betrachtung der Körpermaße zum Geburtszeitpunkt fielen 15\% der FOXG1-Patienten mit einer zu geringen Körperlänge und 7\% wegen Untergewicht auf. Der Kopfumfang lag in 24\% der Fälle bereits bei Geburt unterhalb des Normbereichs (Tabelle 5).

Bei Auswertung der aktuellen Körpermaße zeigte sich bei 48\% der Kinder ein Kleinwuchs. Dystroph, also mit zu geringen BMI-Werten, präsentierten sich 34\% der Patienten, bei 84\% wurde eine Mikrozephalie gemessen (Tabelle 5). 


\subsubsection{Motorik}

Zur Beurteilung motorischer Funktionen wurde zunächst analysiert, ob und zu welchem Zeitpunkt die Kinder in der Lage waren zu sitzen und zu laufen (2.3.1.3). Gesunde Kinder sollten im Alter von etwa acht Monaten das Sitzen und bis zum 18. Lebensmonat das freie Laufen erlernen (Koletzko 2013).

Insgesamt konnten 61\% der Kinder sitzen, davon 45\% eigenständig, 16\% benötigen Hilfestellung. Das Alter, in dem das Sitzen erlernt wurde, betrug im Mittel 28 Monate mit einer Spannbreite von fünf bis 18 Monaten (Tabelle 5). Freies Laufen wurde von 15\% der FOXG1-Patienten erreicht, 11\% liefen mit Unterstützung. Dies erlernten sie in einem Alter von durchschnittlich 53 Monaten (Spannbreite 24 bis 132 Monate, Tabelle 10). Ein zielgerichteter Einsatz der Hände wurde in 40\% der Fälle beobachtet. Bei 18\% der Kinder wurde berichtet, dass sie bereits erworbene motorische Fähigkeiten wieder verlernen.

\subsubsection{Sprache}

Expressive Sprache wurde von 21\% der Patienten erlernt, die Sprachentwicklung war erheblich verzögert (ab einem mittleren Alter von 46 Monaten, Tabelle 5) und begrenzte sich auf meist nur wenige Worte.

\subsubsection{Soziales Verhalten}

Hervorzuheben ist, dass in der Beurteilung der Eltern und/oder der betreuenden Ärzte die meisten Kinder (88\%) zur sozialen Interaktion fähig schienen. Von den FOXG1-Patienten waren $40 \%$ in der Lage, adäquaten Augenkontakt aufzubauen und bei zusätzlichen $52 \%$ beobachtete man dies in abgeschwächter Form verglichen mit gesunden Kindern (Tabelle 5). Das Schlafverhalten war bei einem Großteil der Patienten (71\%) durch sehr kurze, aber häufige Schlafperioden gekennzeichnet. Bei $66 \%$ der Kinder fielen häufige unerklärliche Schreiepisoden auf, und 46\% der Kinder entwickelten Lachattacken, die allem Anschein nach unpassend und anfallsartig auftraten (Tabelle 5).

\subsubsection{Gastrointestinale und sonstige Symptome}

Der Großteil der FOXG1-Patienten (88\%) zeigte Schwierigkeiten bezüglich der Nahrungsaufnahme (Tabelle 11).

Bei 65\% bestand ein gastro-ösophagealer Reflux. Ein Großteil der Kinder (75\%) litt außerdem unter Obstipation, die in vielen Fällen eine medikamentöse Behandlung erforderte (Tabelle 5). Bei 40\% aller FOXG1-Patienten bestand eine Kyphose und/oder Skoliose (Tabelle 5). 


\subsubsection{Neurologische Symptome}

Von Epilepsien waren insgesamt 68\% aller Patienten mit einem breiten Spektrum an Anfallstypen betroffen (Tabelle 5, Tabelle 12). Berichtet wurde von infantilen Spasmen, einfach und komplex fokalen sowie tonisch-klonischen, tonischen, atonischen und myoklonischen generalisierten zerebralen Anfälle. Das mittlere Alter der Erstmanifestation lag bei 25 Monaten (Spannbreite 3 bis 128 Monate).

Ein Lennox-Gastaut-Syndrom (LGS) wurde bei drei Patienten (Patient \#15, \#16, \#36) diagnostiziert.

Anfängliche muskuläre Hypotonie bestand bei 95\% der Patienten, 60\% der Kinder entwickelten im Verlauf eine Spastik. Viele Patienten zeigten pathologische stereotype Bewegungsmuster (90\%) oder Dyskinesien (90\%, Tabelle 5). Bei 84\% der Kinder bestand ein Strabismus. Bei 74\% wurde ein Bruxismus, also ein unbewusstes Zähneknirschen, diagnostiziert, und viele Patienten (64\%) neigten zu einer übermäßigen Speichelbildung (Hypersalivation). Atemprobleme, die oftmals infolge eines Atemweginfekts auftraten, zeigten 28\% der Patienten (Tabelle 5).

\subsubsection{Befunde der kranialen MR-Tomographien}

Anomalien des Corpus callosum in Form einer Hypoplasie oder einer partiellen, selten sogar kompletten Agenesie zeigten 67\% der FOXG1-Patienten (Tabelle 5). Bei über der Hälfte der Kinder (56\%) fiel eine verzögerte Myelinisierung auf. Die Struktur des Kortex war bei 72\% der Patienten pathologisch verändert (Tabelle 5). 


\subsubsection{Faziale Dysmorphien}

Bezüglich der Gesichtsmorphologie von FOXG1-Patienten wurden keine konsistenten Merkmale gefunden, die als charakteristisch für dieses Krankheitsbild beschrieben werden könnten. Abbildung 3 zeigt eine Auswahl klinischer Photographien von neu rekrutierten Patienten mit FOXG1-Variante.

\section{1) Patient \#4}

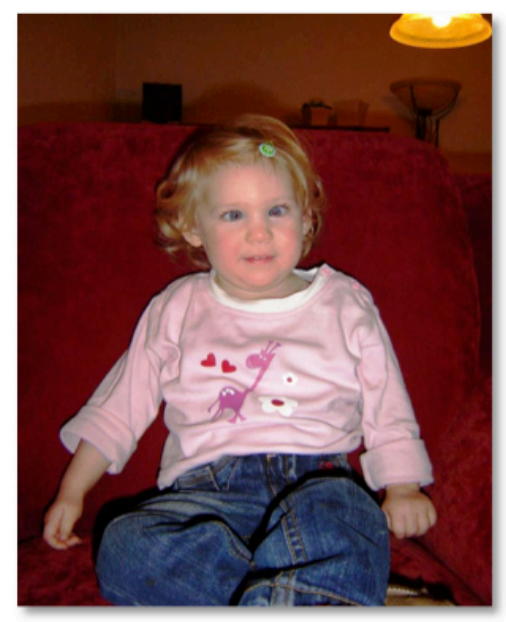

\section{4) Patient \#13}

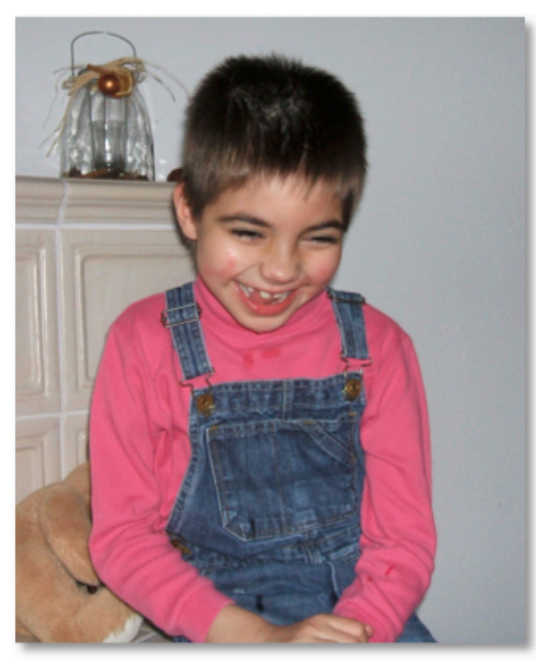

2) Patient \#7

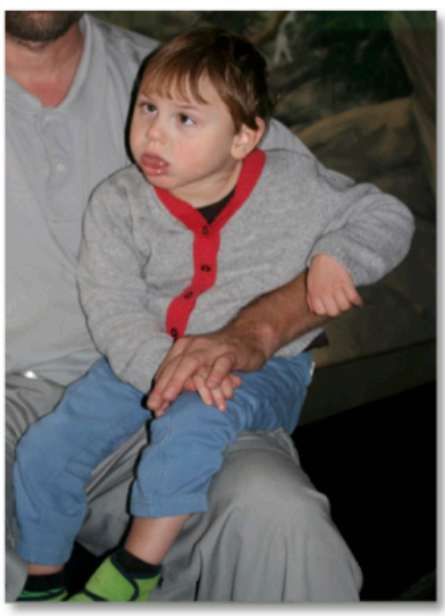

\section{5) Patient \#24}

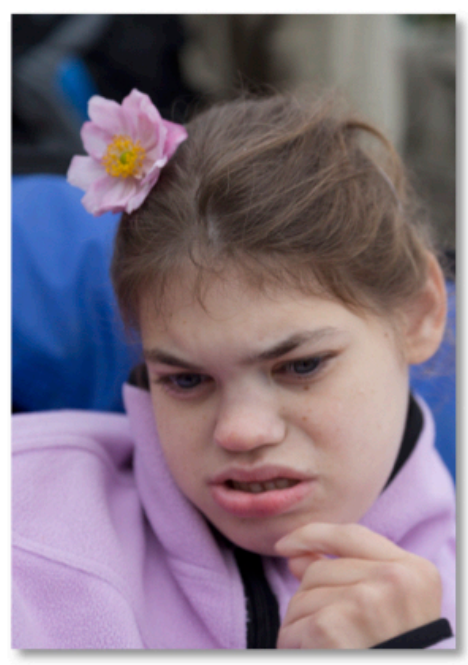

\section{3) Patient \#7}

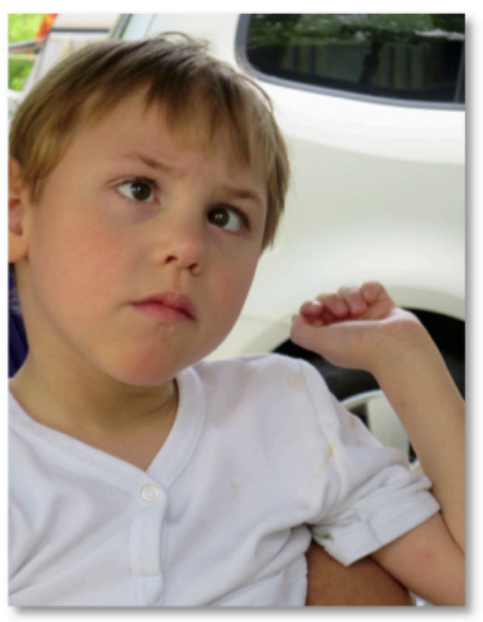

6) Patient \#29

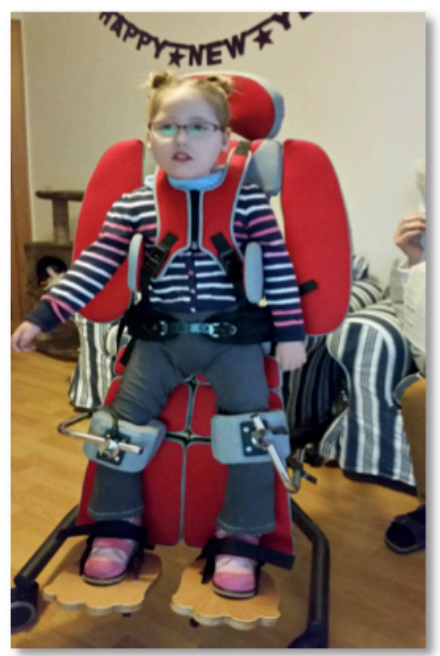

Abbildung 3: Gesichtszüge von Patienten mit FOXG1-Varianten ohne sichere konsistente Dysmorphien 
Tabelle 5: Phänotypauswertung

\begin{tabular}{|c|c|c|c|c|c|c|c|c|}
\hline & & \multicolumn{2}{|c|}{$\begin{array}{l}\text { Neue } \\
\text { Patienten }\end{array}$} & \multicolumn{2}{|l|}{$\begin{array}{l}\text { Publizierte } \\
\text { Patienten }\end{array}$} & \multicolumn{2}{|c|}{ Alle Patienten } & $\begin{array}{l}\text { Neue vs. } \\
\text { publizierte } \\
\text { Patienten }\end{array}$ \\
\hline \multicolumn{2}{|l|}{ Phänotyp } & Wert & $\mathrm{n}$ & Wert & $\mathrm{n}$ & Wert & $\mathrm{n}$ & P-Wert ${ }^{\mathrm{a}}$ \\
\hline \multirow{2}{*}{$\begin{array}{l}\text { Alter bei letzter } \\
\text { Untersuchung } \\
\text { (Monate) }\end{array}$} & $\bar{x} / \tilde{x}$ & $66 / 47$ & \multirow[t]{2}{*}{30} & $128 / 97$ & \multirow[t]{2}{*}{51} & $105 / 78$ & \multirow[t]{2}{*}{81} & \multirow[t]{2}{*}{0,0006} \\
\hline & SDS & 51 & & 94 & & 86 & & \\
\hline \multicolumn{9}{|c|}{ Somatische Entwicklung (Abweichung von Normwerten) } \\
\hline Geburtslänge & $<-2$ SDS & $11 \%$ & 28 & $16 \%$ & 19 & $15 \%$ & 47 & 0,6739 \\
\hline Geburtsgewicht & $<-2 \mathrm{SDS}$ & $10 \%$ & 30 & $4 \%$ & 27 & $7 \%$ & 57 & 0,6135 \\
\hline $\begin{array}{l}\text { Kopfumfang bei } \\
\text { Geburt }\end{array}$ & $<-2 \mathrm{SDS}$ & $26 \%$ & 27 & $23 \%$ & 22 & $24 \%$ & 49 & 1,0000 \\
\hline $\begin{array}{l}\text { Körperlänge bei } \\
\text { letzter Untersuchung }\end{array}$ & $<-2 \mathrm{SDS}$ & $43 \%$ & 30 & $57 \%$ & 14 & $48 \%$ & 44 & 0,5206 \\
\hline $\begin{array}{l}\text { BMI bei letzter } \\
\text { Untersuchung }\end{array}$ & $<-2 \mathrm{SDS}$ & $33 \%$ & 30 & $36 \%$ & 14 & $34 \%$ & 44 & 1,0000 \\
\hline $\begin{array}{l}\text { Kopfumfang bei } \\
\text { letzter Untersuchung }\end{array}$ & $<-2 \mathrm{SDS}$ & $80 \%$ & 30 & $88 \%$ & 32 & $84 \%$ & 62 & 0,5021 \\
\hline \multicolumn{9}{|c|}{ Motorische und sprachliche Entwicklung } \\
\hline \multirow[t]{2}{*}{ Sitzen ${ }^{b}$} & Unterstützt & $14 \%$ & \multirow[t]{2}{*}{28} & $17 \%$ & \multirow[t]{2}{*}{23} & $16 \%$ & \multirow[t]{2}{*}{51} & \multirow[t]{2}{*}{0,8670} \\
\hline & $\mathrm{Ja}$ & $43 \%$ & & $48 \%$ & & $45 \%$ & & \\
\hline \multirow{2}{*}{$\begin{array}{l}\text { Alter Sitzen } \\
\text { (Monate) }\end{array}$} & $\bar{x} / \tilde{x}$ & $25 / 24$ & \multirow[t]{2}{*}{15} & $33 / 17$ & \multirow[t]{2}{*}{10} & $28 / 18$ & \multirow[t]{2}{*}{25} & \multirow[t]{2}{*}{0,5963} \\
\hline & SDS & 15 & & 37 & & 26 & & \\
\hline \multirow[t]{2}{*}{ Laufen ${ }^{b}$} & Unterstützt & $17 \%$ & \multirow[t]{2}{*}{30} & $8 \%$ & \multirow[t]{2}{*}{49} & $11 \%$ & \multirow[t]{2}{*}{79} & \multirow[t]{2}{*}{0,4130} \\
\hline & $\mathrm{Ja}$ & $17 \%$ & & $14 \%$ & & $15 \%$ & & \\
\hline \multirow{2}{*}{$\begin{array}{l}\text { Alter Laufen } \\
\text { (Monate) }\end{array}$} & $\bar{x} / \tilde{x}$ & $54 / 47$ & \multirow[t]{2}{*}{9} & $53 / 42$ & \multirow[t]{2}{*}{9} & $53 / 45$ & \multirow[t]{2}{*}{18} & \multirow[t]{2}{*}{0,8585} \\
\hline & SDS & 33 & & 30 & & 30 & & \\
\hline $\begin{array}{l}\text { Funktionaler } \\
\text { Gebrauch der Hände }\end{array}$ & $\mathrm{Ja}$ & $60 \%$ & 30 & $27 \%$ & 45 & $40 \%$ & 75 & $\underline{0,0076}$ \\
\hline $\begin{array}{l}\text { Verlust motorischer } \\
\text { Fähigkeiten }\end{array}$ & $\mathrm{Ja}$ & $18 \%$ & 28 & $20 \%$ & 10 & $18 \%$ & 38 & 1,0000 \\
\hline Expressive Sprache & $\mathrm{Ja}$ & $30 \%$ & 30 & $15 \%$ & 48 & $21 \%$ & 78 & 0,1490 \\
\hline \multirow{2}{*}{$\begin{array}{l}\text { Alter bei ersten } \\
\text { Worten (Monate) }\end{array}$} & $\bar{x} / \tilde{x}$ & $39 / 30$ & 8 & 108 / 108 & 1 & $46 / 33$ & 9 & - \\
\hline & SDS & 21 & & - & & 31 & & \\
\hline
\end{tabular}

BMI: body mass index, n: Stichprobenumfang, SDS: Standard Derivation Score, $\tilde{x}$ : Median, $\bar{x}$ : Mittelwert

aNeue und bereits publizierte Daten wurden mit dem Fisher's exact test (Kategorien) oder Kruskal-WallisRangsummentest (Altersvariablen, außer Alter bei Sprache) ausgewertet.

bSitzen, Laufen, Soziale Interaktion, Augenkontakt wurden in drei Kategorien bewertet; alle anderen Variablen in zwei Kategorien.

Signifikanzen sind fettgedruckt (Bonferroni: $\mathrm{p} \leq 0,05 / 35=0,0014)$, grenzwertige Signifikanzen unterstrichen Die Analyse beruhte auf den Grundlagen den Daten der gesammelten Patienteninformationen (2.3.1) 
Fortsetzung Tabelle 5: Phänotypauswertung

\begin{tabular}{|c|c|c|c|c|c|c|c|c|c|}
\hline \multirow{2}{*}{ Phänotyp } & & \multicolumn{2}{|c|}{$\begin{array}{l}\text { Neue } \\
\text { Patienten }\end{array}$} & \multicolumn{2}{|c|}{$\begin{array}{l}\text { Publizierte } \\
\text { Patienten }\end{array}$} & \multicolumn{2}{|c|}{ Alle Patienten } & \multirow{2}{*}{$\begin{array}{l}\begin{array}{l}\text { Neue } \\
\text { Publizierte } \\
\text { Patienten }\end{array} \\
\text { P-Wert }\end{array}$} & \\
\hline & & Wert & $\mathbf{n}$ & Wert & $\mathrm{n}$ & Wert & $\mathbf{n}$ & & \\
\hline \multicolumn{10}{|l|}{ Soziales Verhalten } \\
\hline \multirow[t]{2}{*}{ Soziale Interaktion ${ }^{\mathrm{b}}$} & Wenig & $14 \%$ & 28 & $32 \%$ & 37 & $25 \%$ & 65 & 0,0860 & \\
\hline & $\mathrm{Ja}$ & $79 \%$ & & $51 \%$ & & $63 \%$ & & & \\
\hline \multirow[t]{2}{*}{ Augenkontakt $\mathrm{t}^{\mathrm{b}}$} & Wenig & $35 \%$ & 26 & $73 \%$ & 22 & $52 \%$ & 48 & 0,0146 & \\
\hline & $\mathrm{Ja}$ & $50 \%$ & & $27 \%$ & & $40 \%$ & & & \\
\hline $\begin{array}{l}\text { Abnormes } \\
\text { Schlafmuster }\end{array}$ & $\mathrm{Ja}$ & $76 \%$ & 29 & $65 \%$ & 26 & $71 \%$ & 55 & 0,5532 & \\
\hline Schreiepisoden & $\mathrm{Ja}$ & $58 \%$ & 24 & $74 \%$ & 23 & $66 \%$ & 47 & 0,3587 & \\
\hline $\begin{array}{l}\text { Paroxysmale } \\
\text { Lachanfälle }\end{array}$ & $\mathrm{Ja}$ & $46 \%$ & 28 & $44 \%$ & 18 & $46 \%$ & 46 & 1,0000 & \\
\hline \multicolumn{10}{|c|}{ Neurologische Eigenschaften } \\
\hline Epilepsie & $\mathrm{Ja}$ & $57 \%$ & 30 & $75 \%$ & 52 & $68 \%$ & 82 & 0,1384 & \\
\hline Hypotonie & $\mathrm{Ja}$ & $100 \%$ & 29 & $89 \%$ & 27 & $95 \%$ & 56 & 0,1055 & \\
\hline Spastik & $\mathrm{Ja}$ & $39 \%$ & 28 & $89 \%$ & 19 & $60 \%$ & 47 & 0,0007 & \\
\hline $\begin{array}{l}\text { Stereotypische } \\
\text { Bewegungen }\end{array}$ & $\mathrm{Ja}$ & $87 \%$ & 30 & $94 \%$ & 31 & $90 \%$ & 61 & 0,4248 & \\
\hline Dyskinesie & $\mathrm{Ja}$ & $79 \%$ & 28 & $97 \%$ & 34 & $89 \%$ & 62 & 0,0394 & \\
\hline Strabismus & $\mathrm{Ja}$ & $79 \%$ & 29 & $91 \%$ & 22 & $84 \%$ & 51 & 0,4399 & \\
\hline Bruxismus & $\mathrm{Ja}$ & $70 \%$ & 23 & $80 \%$ & 20 & $74 \%$ & 43 & 0,5012 & \\
\hline Hypersalivation & $\mathrm{Ja}$ & $58 \%$ & 24 & $75 \%$ & 12 & $64 \%$ & 36 & 0,4678 & \\
\hline $\begin{array}{l}\text { Abnorme } \\
\text { Atemmuster }\end{array}$ & $\mathrm{Ja}$ & $29 \%$ & 24 & $26 \%$ & 19 & $28 \%$ & 43 & 1,0000 & \\
\hline \multicolumn{10}{|c|}{ Gastrointestinale Eigenschaften / Sonstige Merkmale } \\
\hline $\begin{array}{l}\text { Schwierigkeiten beim } \\
\text { Füttern }\end{array}$ & $\mathrm{Ja}$ & $80 \%$ & 30 & $100 \%$ & 18 & $88 \%$ & 48 & 0,0708 & \\
\hline $\begin{array}{l}\text { Gastro-ösophagealer } \\
\text { Reflux }\end{array}$ & $\mathrm{Ja}$ & $52 \%$ & 27 & $84 \%$ & 19 & $65 \%$ & 46 & 0,0305 & \\
\hline Obstipation & $\mathrm{Ja}$ & $69 \%$ & 29 & $84 \%$ & 19 & $75 \%$ & 48 & 0,3157 & \\
\hline Kyphose/Skoliose & $\mathrm{Ja}$ & $28 \%$ & 25 & $55 \%$ & 20 & $40 \%$ & 45 & 0,1247 & \\
\hline \multicolumn{10}{|c|}{ cMRT Veränderungen } \\
\hline $\begin{array}{l}\text { Aplasie/Hypoplasie } \\
\text { Corpus callosum }\end{array}$ & $\mathrm{Ja}$ & $56 \%$ & 27 & $77 \%$ & 30 & $67 \%$ & 57 & 0,1030 & \\
\hline $\begin{array}{l}\text { Verzögerte } \\
\text { Myelinisierung }\end{array}$ & $\mathrm{Ja}$ & $50 \%$ & 28 & $69 \%$ & 13 & $56 \%$ & 41 & 0,3210 & \\
\hline Kortikale Dysplasie & $\mathrm{Ja}$ & $68 \%$ & 28 & $77 \%$ & 22 & $72 \%$ & 50 & 0,5374 & \\
\hline
\end{tabular}

BMI: body mass index, n: Stichprobenumfang, SDS: Standard Derivation Score, $\tilde{x}$ : Median, $\bar{x}$ : Mittelwert

aNeue und bereits publizierte Daten wurden mit dem Fisher's exact test (Kategorien) oder Kruskal-Wallis-

Rangsummentest (Altersvariablen, außer Alter bei Sprache) ausgewertet. 
bSitzen, Laufen, Soziale Interaktion, Augenkontakt wurden in drei Kategorien bewertet; alle anderen Variablen in zwei Kategorien.

Signifikanzen sind fettgedruckt (Bonferroni: $\mathrm{p} \leq 0,05 / 35=0,0014$ ), grenzwertige Signifikanzen unterstrichen Die Analyse beruhte auf den Grundlagen den Daten der gesammelten Patienteninformationen (2.3.1)

\subsection{Analyse des Genotyps}

Die molekulargenetischen Untersuchungen waren bereits im Vorfeld dieser Studie im Rahmen der Patientenversorgung in verschiedenen genetischen Labors mittels Sanger Sequenzierung oder Next Generation Sequencing durchgeführt worden (2.3.2, Tabelle 8).

Bei den 30 neu rekrutierten FOXG1-Patienten wurden 19 heterozygote pathogene oder wahrscheinlich pathogene Varianten nachgewiesen, die bisher nicht in den Datenbanken „dbSNP“, „1000 Genoms“ und „ExAC Browser“ gelistet waren (Stand Januar 2016). In der Gesamtkohorte ergibt sich ein Spektrum von 54 unterschiedlichen heterozygoten Varianten des FOXG1-Gens. Dazu zählen 20 Frameshift- (37\%), 17 Missense- (31\%), 15 Nonsense- (28\%) und zwei Inframe-Varianten (4\%) (Tabelle 8, Abbildung 4). Auf Proteinebene sind unterschiedliche Domänen betroffen: 19 Varianten in der N-terminalen Domäne (35\%), zehn Varianten innerhalb des konservierten Bereichs der ForkheadDomäne (18\%), 17 Varianten in nicht konservierten Bereichen der Forkhead-Domäne (31\%) und acht Varianten in der C-terminalen Domäne (15\%) des FOXG1-Proteins (Tabelle 8).

Das Basenpaar 460 war in 16 Fällen und somit am häufigsten von Genveränderungen betroffen. Bei einem dieser Patienten (\#7) wurde die Variante c.460delG (p.E154Rfs*38) und bei 15 Patienten aus 13 Familien die Variante c.460dupG (p.E154*Gfs*301) nachgewiesen (Tabelle 8). Bei sieben nicht miteinander verwandten Patienten war das Basenpaar 256 verändert und zwar in Form von c.256delC (p.Q86Rf*s106), c.256dupC (p.Q86fs*34) oder c.256C>T (p.Q86*) (Tabelle 8). Alle anderen Genveränderungen stellten Einzelfälle dar oder kamen innerhalb einer Familie doppelt vor.

Bei 65 Patienten aus 63 Familien konnte sichergestellt werden, dass es sich um de novo Varianten handelt. Bei einer Familie mit drei vom FOXG1-Syndrom betroffenen Kindern wurde ein maternales Mosaik nachgewiesen. Weiterhin ging man bei sieben Kindern aus vier Familien von parentalen Mosaiken aus. In acht Fällen lagen keine Daten bezüglich der Segregation der Genveränderung vor (Tabelle 8). 
Patienten \#11 und \#12 sind ein monozygotes Zwillingspaar mit einer FOXG1 de novo Variante (Tabelle 5). Bei einem Geschwisterpaar (Familie \#20) lagen klinische Informationen nur zu einem der Geschwister vor.

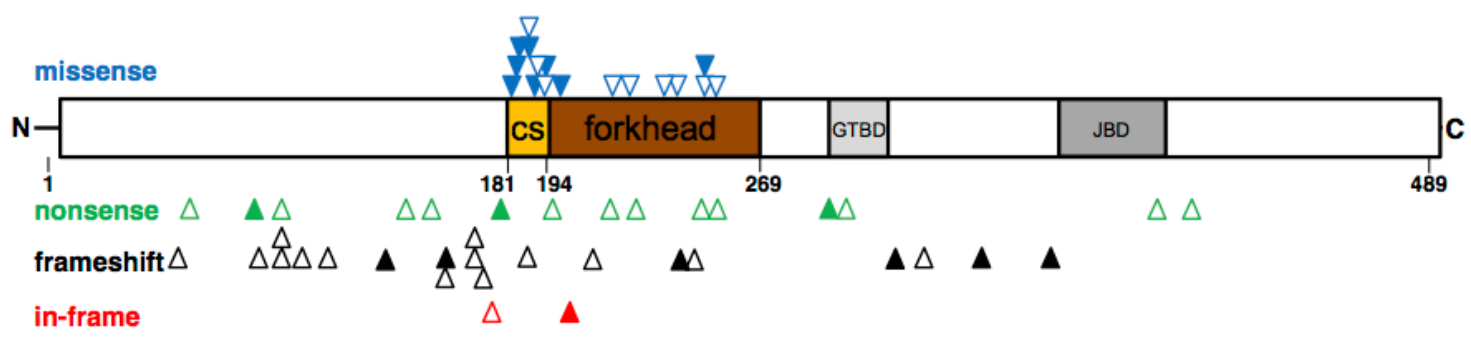

Abbildung 4: Lokalisation der Genveränderungen im FOXG1-Gen (Mitter et al. 2017)

C: C-terminaler Bereich, CS: konservierter Bereich, GTBD: Groucho-Bindungsdomäne (Aminosäureposition 307-406), JBD: JARID1B-Bindungsdomäne (Aminosäureposition 383-406)

Frameshift-Variante: schwarz, Inframe-Variante: rot, Missense-Variante: blau, N: N-terminaler Bereich, NonsenseVariante: grün

Neue FOXG1-Varianten: Ausgefüllte Dreiecke, bereits bekannte FOXG1-Varianten: Umrandete Dreiecke

\subsection{Genotyp-Phänotyp-Assoziationen}

Zur Untersuchung von Genotyp-Phänotyp-Assoziationen wurden die Patienten nach Art und Lokalisation der jeweiligen FOXG1-Variante in fünf genetische Gruppen eingeteilt (2.3.2). Diese Zuordnung umfasste 76 Patienten, davon 27 aus der Kohorte der neu rekrutierten und 49 aus der Kohorte der bereits publizierten Patienten. Wegen der geringen Anzahl an Patienten mit Inframe-Varianten (Patient \#20, \#49, \#50) sowie mit FrameshiftVarianten innerhalb des konservierten Bereichs der Forkhead-Domäne (Patient \#65) wurden diese nicht mit in die Genotyp-Phänotyp-Analyse aufgenommen (Tabelle 8). Ebenfalls wurden drei Patienten mit Missense-Varianten der Aminosäure an Position 187 (N187K, Patient \#15, \#16 und N187D, Patient \#35) wegen ihrer außerordentlichen phänotypischen Besonderheiten nicht in diese Gruppenzuordnung aufgenommen (Tabelle 8).

Insgesamt wurden 29 klinische Merkmale in die Kategorien somatische Entwicklung, Motorik und Sprache, soziales Verhalten, neurologische Symptome und neuroradiologische Veränderungen eingeteilt und ausgewertet. Im Folgenden werden die wichtigsten Unterschiede des klinischen Phänotyps, die sich zwischen den fünf genetischen Gruppen ergaben, beschrieben. Die Häufigkeiten einzelner klinischer Merkmale in den jeweiligen 
Gruppen können Tabelle 6 entnommen werden. Im multivariaten Zweigruppenvergleich wurden die Daten der genetischen Gruppe 1 mit denen der übrigen Gruppen 2 bis 5 verglichen. Die motorische und sprachliche Entwicklung der Patienten mit Nonsense- und Frameshift-Varianten der 5'-Domäne (Gruppe 1) war signifikant schlechter als in den übrigen vier genetischen Gruppen $(\mathrm{p}=0,0007)$ (Tabelle 6). Bezüglich neurologischer und neuroradiologischer Symptome ergaben sich grenzwertig signifikante Unterschiede: auch hier waren die Patienten der Gruppe 1 schwerer betroffen als die Patienten der Gruppen 2 bis 5 (neurologische Symptome $p=0,0098$, neuroradiologische Veränderungen $p=0,0128$, Tabelle 6).

Die univariaten Fünfgruppenvergleiche zeigten signifikante Unterschiede für freies Sitzen $(p=0,00009)$, freies Laufen $(p=0,0001)$ und funktionalen Gebrauch der Hände $(p=0,0004$, Tabelle 6). Alle diese Fähigkeiten waren bei den Patienten der Gruppe 2 häufiger vorhanden als in der Gruppe 1. Grenzwertige signifikante Unterschiede bei univariaten Vergleichen der fünf Gruppen ergaben sich bezüglich der Merkmale Schwierigkeiten beim Füttern ( $\mathrm{p}=0,0078)$, Corpus callosum Anomalien ( $\mathrm{p}=0,0083)$, verzögerte Myelinisierung $(p=0,0034)$ und Mikrozephalie zum Zeitpunkt der letzten Untersuchung $(p=0,0074$, Tabelle 6).

Die Rate der Mikrozephalien zum Zeitpunkt der letzten Untersuchung war in Gruppe 2 niedriger als in Gruppe $1(\mathrm{p}=0,0047)$ und auch niedriger als in den Gruppen 1, 3, 4 und 5 zusammengenommen ( $p=0,0031$, Tabelle 6$)$. 
Tabelle 6: Genotyp-Phänotyp-Analyse

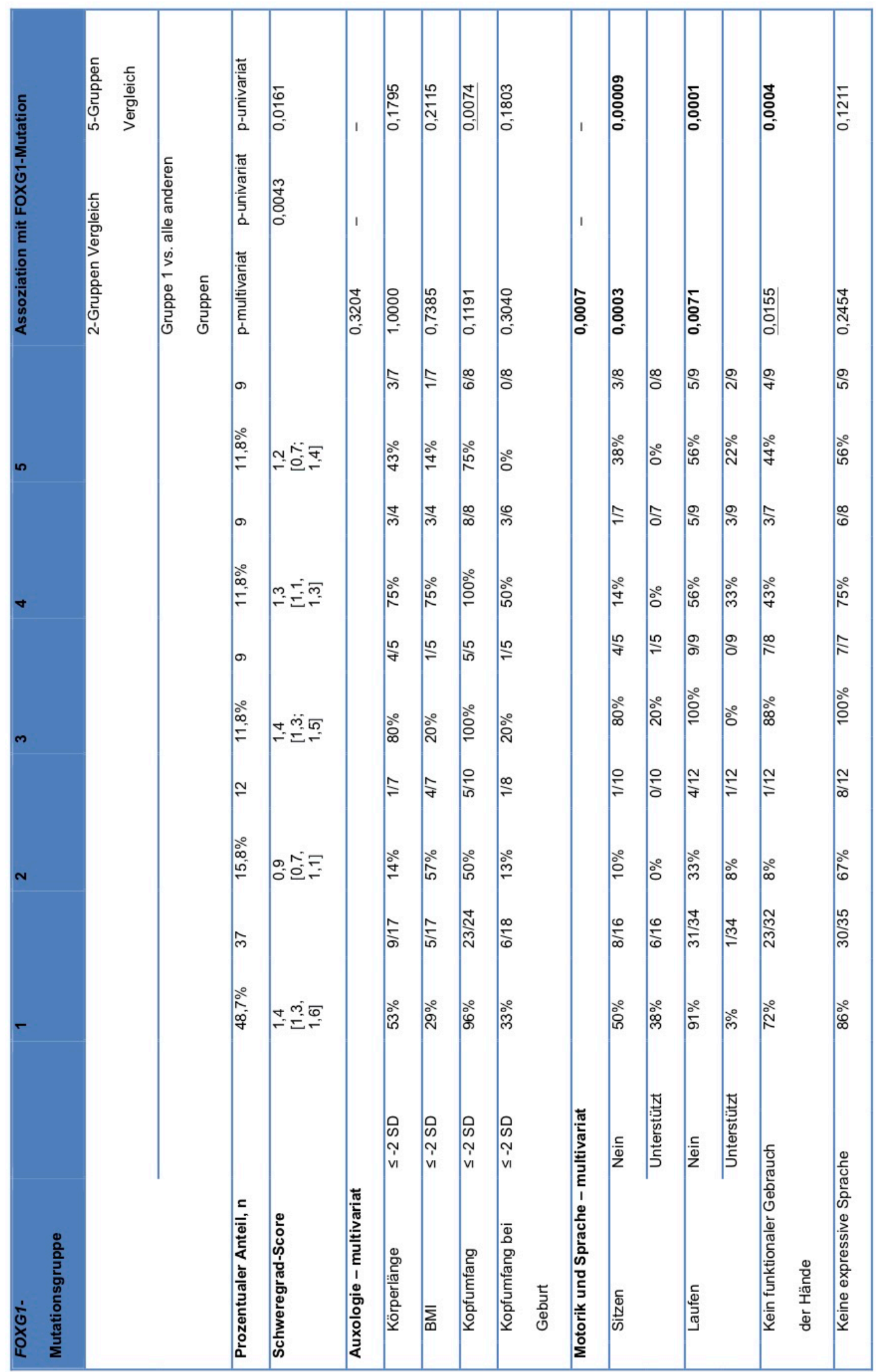

BMI: body mass index, IQ: Interquartilsabstand, KU: Kopfumfang, p-multivariat: p-Wert eines gemeinsamen Tests von verschiedenen Messwerten, p-univariat: p-Wert eines Tests eines einzelnen Messwertes, SDS: Standardabweichung 
Fortsetzung Tabelle 6: Genotyp-Phänotyp-Analyse

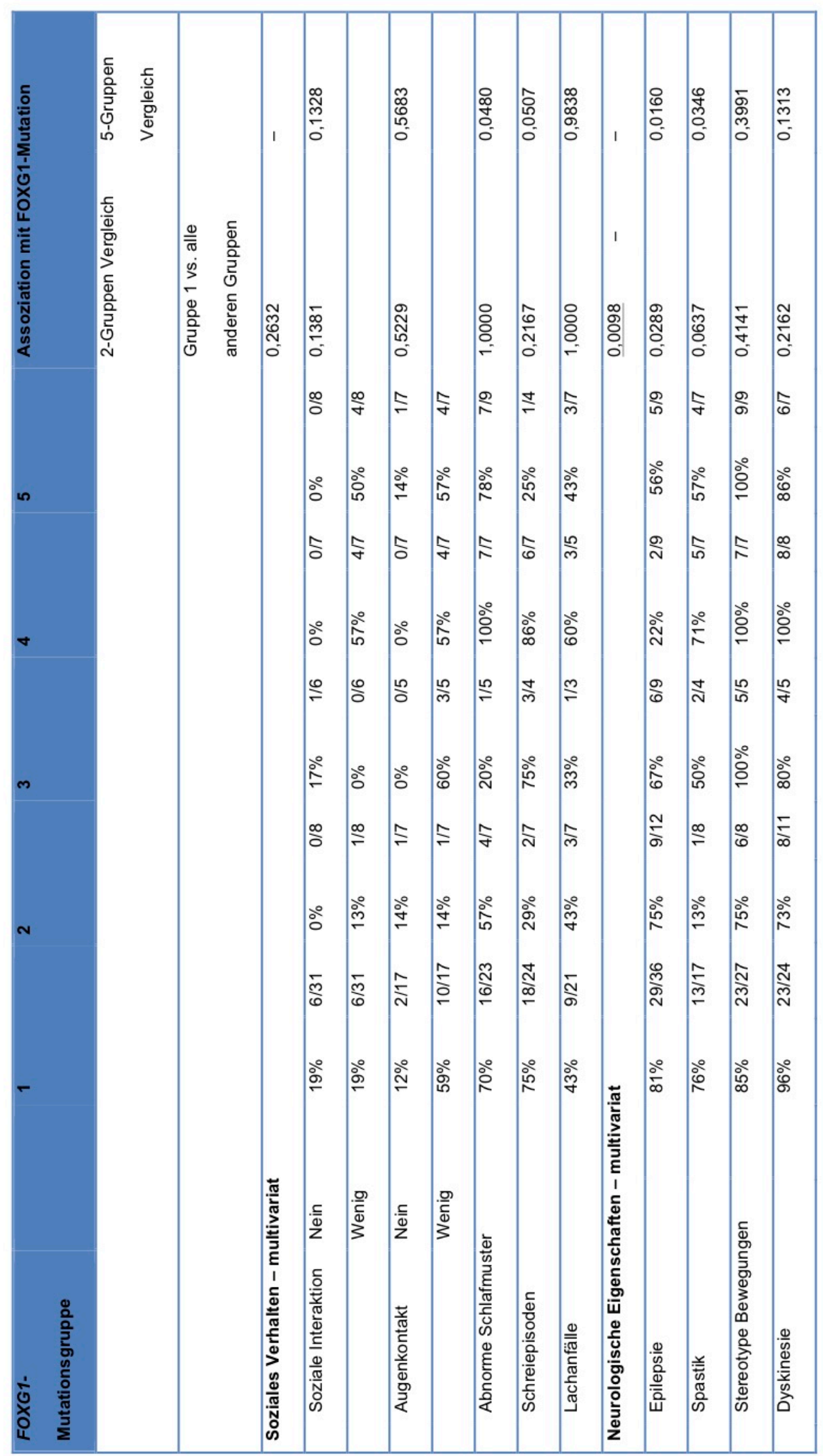

BMI: body mass index, IQ: Interquartilsabstand, KU: Kopfumfang, p-multivariat: p-Wert eines gemeinsamen Tests von verschiedenen Messwerten, p-univariat: p-Wert eines Tests eines einzelnen Messwertes, SDS: Standardabweichung 
Fortsetzung Tabelle 6: Genotyp-Phänotyp-Analyse

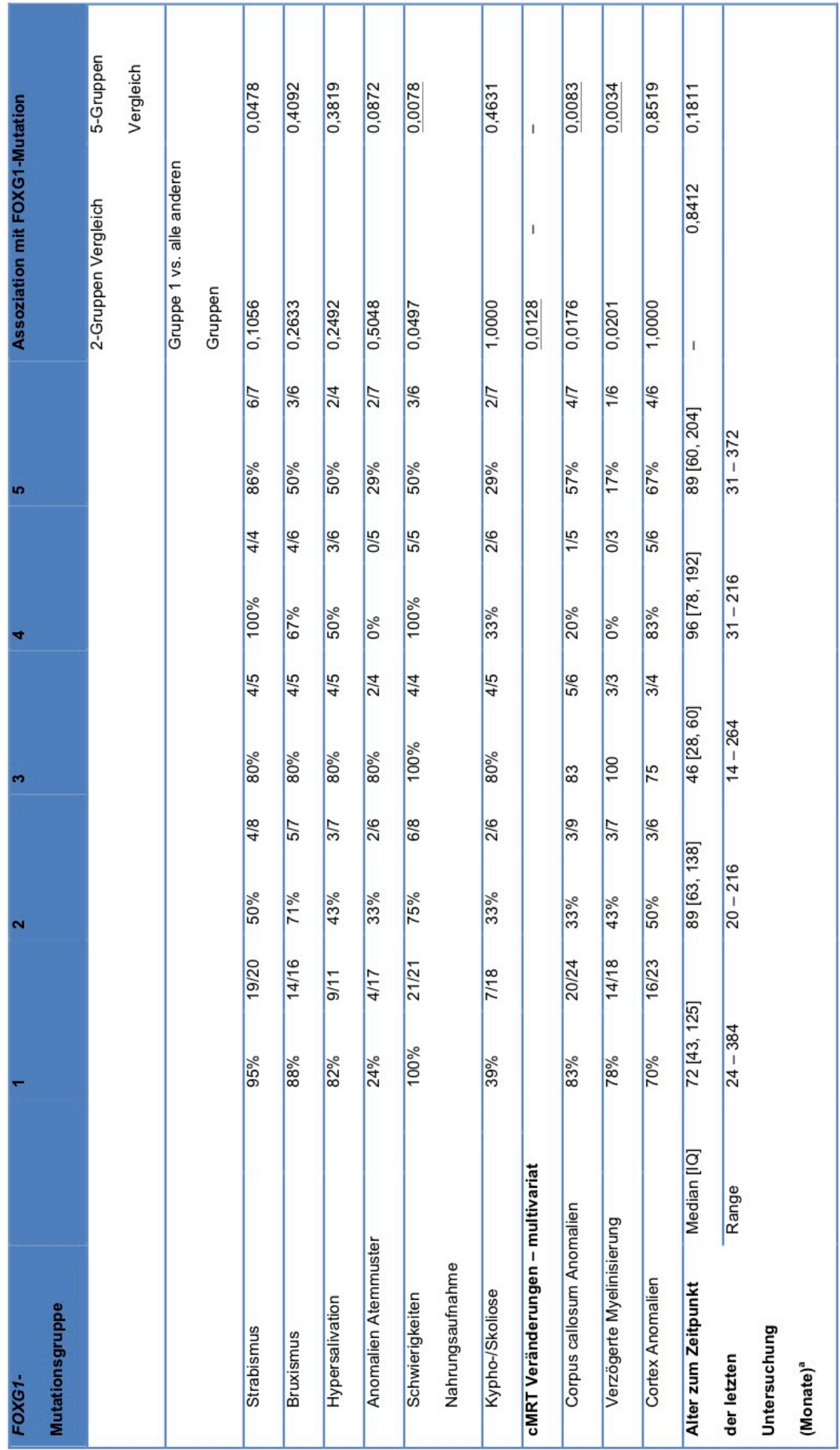

BMI: body mass index, IQ: Interquartilsabstand, KU: Kopfumfang, p-multivariat: p-Wert eines gemeinsamen Tests von verschiedenen Messwerten, p-univariat: p-Wert eines Tests eines einzelnen Messwertes, SDS: Standardabweichung 
Dargestellt werden beobachtete prozentuale Häufigkeiten von klinischen und neurologischen Merkmalen sowie Verhaltensanomalien innerhalb der FOXG1-Gruppen mit einer totalen Anzahl von $\mathrm{n}=76$ Patienten mit FOXG1Syndrom. Signifikante p-Werte für die Genotyp-Phänotyp-Assoziationen sind fettgedruckt, grenzwertig signifikante pWerte sind unterstrichen. Als für multiples Testen angepasste Signifikanzniveaus kommen zur Anwendung: $\alpha=0,0287$ (Schweregradeinteilung für die 20 beschriebenen klinischen und neurologischen Merkmale sowie Verhaltensanomalien, Kruskal-Wallis-Rangsummentest), $\quad \alpha=0,00909 \quad$ (Zwei-Gruppenvergleiche: multivariate Rangsummentests der Phänotypkategorien (p-multivariat) und geschlossene Testprinzipien in Fisher's exaktem Test), $\alpha=0,00188$ (FünfGruppenvergleiche: Fisher's exakter Test). Zwei- und Fünf-Gruppenvergleiche (p-multivariat, p-univariat) beinhalten alle 20 dargestellten klinischen und neurologischen Merkmale sowie Verhaltensauffälligkeiten und als zusätzliche Krankheitseigenschaften: Verlust von motorischen Funktionen, unerklärliche Schreiepisoden, Lachattacken, Strabismus, Bruxismus, Hypersalivation, abnorme Atemmuster, gastro-ösophagealer Reflux, Obstipation. Krankheitsmerkmale, die sehr selten oder bei nahezu bei allen Patienten beobachtet wurden (Nystagmus, hypoplastische Hippocampi, Pachygyrie, muskulärer Hypotonus, Aspiration, autistische Verhaltensmuster) wurden nicht mit in die Genotyp-Phänotyp-Analyse aufgenommen.

aDas Alter zum Zeitpunkt der letzten Untersuchung weist keinen signifikanten Unterschied zwischen den einzelnen FOXG1-Gruppen auf (Kruskal-Wallis-Rangsummentest).

1) Freies Sitzen

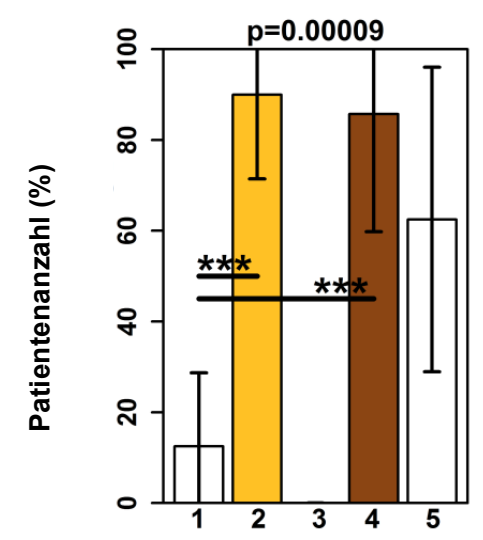

2) Freies Laufen

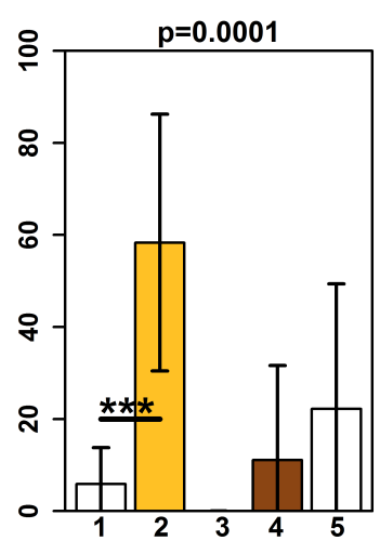

3) Funktioneller Gebrauch der Hände

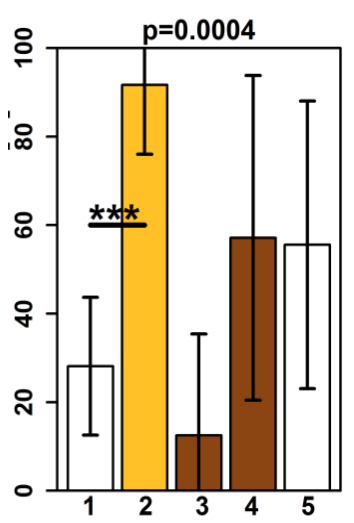

Mutationsgruppe

Abbildung 5: Genotyp-Phänotyp-Analyse: signifikante Unterschiede zwischen den genetischen Gruppen (Mitter et al. 2017)

Die Graphen bilden die prozentualen Anteile der Patienten, die motorische Fähigkeiten erlangten, in 95\%Konfidenzintervallen (Fehlerbalken) ab. Die Sterne kennzeichnen nominale Signifikanzunterschiede $(p \leq 0,0017)$ verglichen mit der FOXG1-Gruppe. 
1) Keine Epilepsie

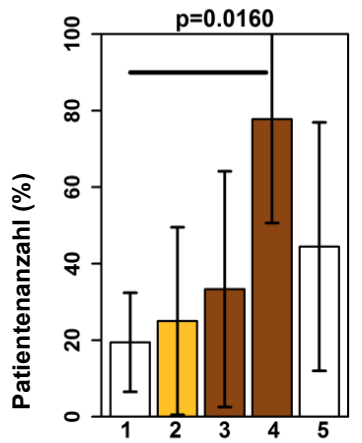

2) Keine Probleme beim Füttern

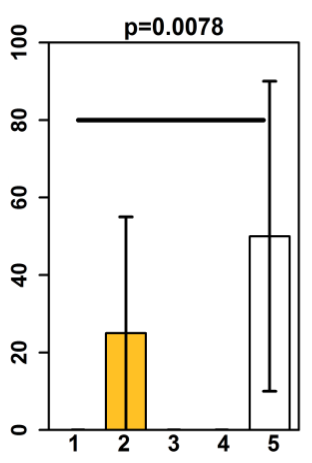

3) Normales Corpus Callosum

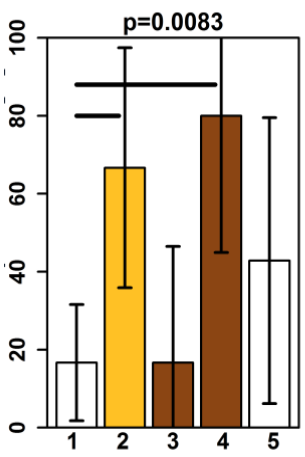

4) Altersentsprechende Myelinisierung

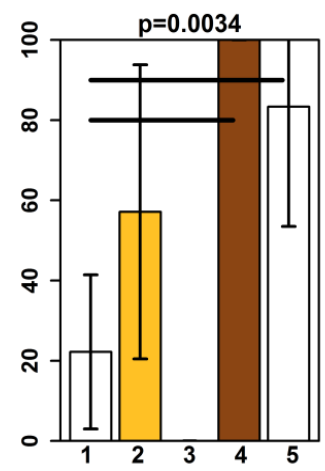

Mutationsgruppen

Abbildung 6: Genotyp-Phänotyp-Analyse: grenzwertige Signifikanzen (Mitter et al. 2017)

Die Graphen bilden die prozentualen Anteile der Patienten, die nicht von den oben genannten neurologischen oder neuroradiologischen Anomalien 1) bis 4) betroffen waren in 95\%-Konfidenzintervallen (Fehlerbalken) ab (p-univariat $\leq$ 0,0160 beim Vergleich aller fünf genetischen Gruppen). Die horizontalen Balken zeigen Differenzen im Vergleich mit Gruppe 1 (keine Epilepsie p=0,0019, keine Probleme beim Füttern $\mathrm{p}=0,0068$, normales Corpus callosum $\mathrm{p} \leq 0,0128$, altersentsprechende Myelinisierung $\mathrm{p} \leq 0,0263$; keine signifikanten Unterschiede nach multivariatem Testen)

\subsection{Schweregradeinteilung mit dem FOXG1 Clinical Severity Score}

Aus dem FOXG1 Clinical Severity Score wurde für jeden Patienten mit ausreichender Datenlage ein Mittelwert berechnet, der zwischen 0 (keine klinischen oder neuroradiologischen Symptome) und 2 (maximale Ausprägung der klinischen oder neuroradiologischen Symptome) liegen konnte (Tabelle 14).

\subsubsection{Vergleich der Schweregradeinteilung zwischen den Gruppen der neu rekrutierten und bereits publizierten Patienten}

Auf der Basis des FOXG1 Clinical Severity Score wurde der klinisch-neuroradiologische Schweregrad dann getrennt für die Gruppe der neu rekrutierten ( $n=27)$ sowie für die Gruppe der bereits publizierten Patienten $(n=28)$ bestimmt. Die neu rekrutierten Patienten erreichten dabei einen Median von 1,2, bei den bereits publizierten Patienten ergab sich ein Median von 1,4 (Tabelle 7). Somit ist die Gruppe der neu rekrutierten Patienten klinischneuroradiologisch weniger schwer betroffen als die Gruppe der bereits publizierten Patienten, dieser Unterschied war statistisch signifikant ( $\mathrm{p}=0,0004$, Tabelle 7). 
Tabelle 7: Schweregrad-Score: Vergleich neu rekrutierte vs. publizierte Patienten

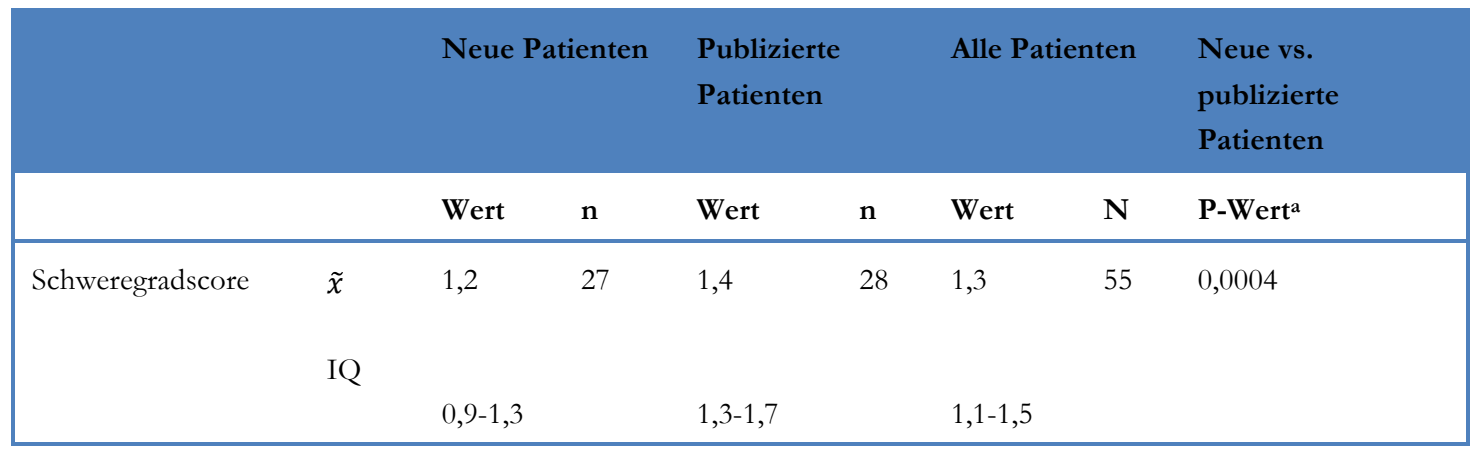

IQ: Interquartilsabstand, n: Stichprobenumfang, $\tilde{x}$ : Median

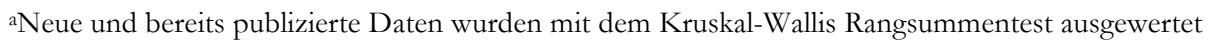

\subsubsection{Vergleich des Schweregrades zwischen den genetischen Gruppen}

In der Gruppe der Patienten mit Nonsense- oder Frameshift-Variante der 5'-Domäne (Gruppe 1) ergab sich anhand von 22 Patientendaten für den FOXG1 Clinical Severity Score ein Median von 1,4. Dieser Schweregrad war signifikant höher als in den übrigen genetischen Gruppen 2 bis 5 ( $p=0,0043$, Tabelle 6). Patienten mit Missense-Variante des konservierten Bereichs der Forkhead-Domäne (Gruppe 2) wiesen mit einem Median von 0,9 den mildesten Schweregrad auf, der signifikant niedriger war als in der Gruppe 1 $(\mathrm{p}=0,0020$, Abbildung 7). Der Schweregrad der Kohorte mit Nonsense- oder FrameshiftVariante außerhalb des konservierten Bereichs der Forkhead-Domäne (Gruppe 3) wurde auf Grundlage von fünf Patienten berechnet. Diese Gruppe erreichte einen Median von 1,4 und verglichen mit dem Schweregrad der Gruppe 1 zeigten sich keine signifikanten Unterschiede $(p=0,6620)$. Demnach sind die Patienten der Gruppen 1 und 3 am schwersten vom FOXG1-Syndrom betroffen (Abbildung 7). In Gruppe 4 (sechs Patienten) ergab sich ein Median von 1,3, also ein geringfügig milderer Phänotyp als in Gruppe 1 $(p=0,1452)$. Ebenfalls einen milderen Schweregrad im Vergleich mit Gruppe 1 zeigten die acht Patienten der Gruppe 5 ( $\mathrm{p}=0,0437)$, der Median des Severity Scores lag hier bei 1,2. 


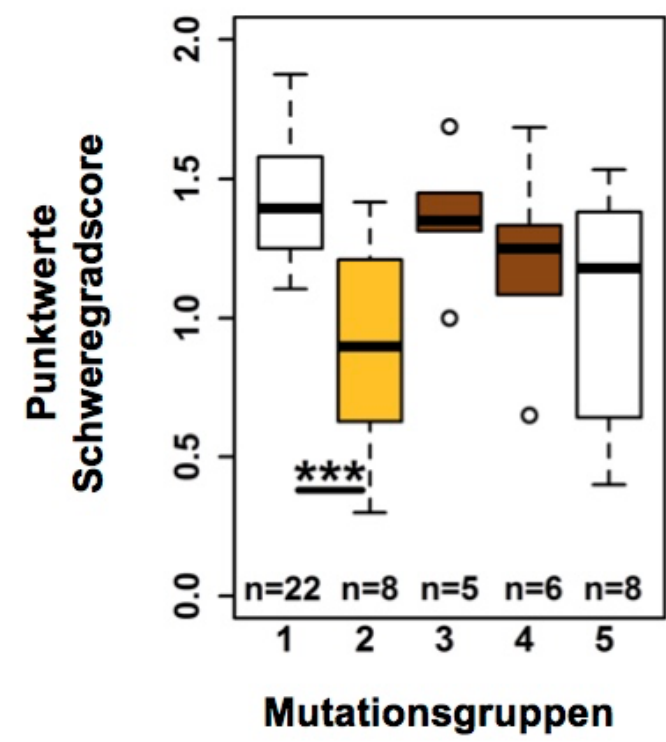

Abbildung 7: Ergebnisse Schweregradanalyse (Mitter et al. 2017)

Abgebildet sind Boxplots des Schweregrades für die genetischen Gruppen 1 bis 5. Signifikant geringerer Schweregrad der Gruppe 2 im Vergleich mit Gruppe 1 (Sterne: $\mathrm{p}=0,0020$ ) 


\section{Diskussion}

In der hier vorliegenden Studie wurden klinische, neuroradiologische und genetische Befunde von 30 neu rekrutierten und 53 bereits publizierten Patienten mit Varianten im FOXG1-Gen ausgewertet. Die Ergebnisse zeigen, dass die Variabilität des klinischen Phänotyps bei Patienten mit FOXG1-Syndrom größer ist als bisher bekannt.

\subsection{Somatische Entwicklung}

Die Entwicklung einer sekundären, also postnatalen Mikrozephalie galt als charakteristisch für Patienten mit FOXG1-Syndrom, und es wurde nur vereinzelt von Fällen mit primärer, also bereits bei Geburt bestehender Mikrozephalie, berichtet (Kortüm et al. 2011). In der hier vorgelegten Studie hingegen weisen 24\% der Kinder bereits bei Geburt eine Mikrozephalie auf. Somit ist es, anders als zuvor angenommen, keine Ausnahme, dass der Kopfumfang von FOXG1-Syndrom Patienten bereits bei Geburt vermindert ist. Da in der Kohorte der bereits publizierten Patienten der Kopfumfang bei Geburt in 59\% der Fälle nicht angegeben wurde, kann bei der Mehrzahl der früher publizierten FOXG1-Patienten nicht beurteilt werden, ob die Mikrozephalie bereits bei Geburt bestand.

Die in dieser Studie ermittelten Daten zu Gewichts- und Längenentwicklung stimmen im Wesentlichen mit den bereits bekannten Daten überein, etwa 50\% der Patienten sind kleinwüchsig, etwa ein Drittel ist dystroph (Kortüm et al. 2011).

\subsection{Motorische und sprachliche Entwicklung}

Charakteristisch für das FOXG1-Syndrom ist eine ausgeprägte, früh beginnende Störung der motorischen, sprachlichen und kognitiven Entwicklung (Mencarelli et al. 2010; Kortüm et al. 2011; Allou et al. 2012). Auch in dieser Studie sind nur wenige betroffene Kinder in der Lage, eigenständig zu laufen und auch andere motorische Fähigkeiten, wie das Sitzen oder ein zielgerichteter Einsatz der Hände, wurden größtenteils nicht erlernt. Die Sprachfähigkeit der Kinder beschränkt sich in der Regel auf ein Lautieren (3.1.2).

Terrone et al. postulierten, dass ein wichtiger Unterschied zur Abgrenzung des FOXG1Syndroms vom Rett-Syndrom eine fehlende Regressionsphase, also das Verlernen bereits erworbener motorischer und sprachlicher Fähigkeiten, ist (Terrone et al. 2014). Dies zeigt 
sich auch in der vorliegenden Analyse, nur bei $18 \%$ der Patienten ist ein Verlust bereits erworbener motorischer Fähigkeiten zu verzeichnen.

\subsection{Soziales Verhalten}

In dieser Studie wird das soziale Verhalten der Kinder im Vergleich zu vorherigen Publikationen von Eltern und betreuenden Ärzten eher günstig beurteilt. Nahezu alle Patienten zeigen Anzeichen sozialer Interaktion und beim Umgang mit vertrauten Personen agieren die Kinder größtenteils offen und suchen soziale Bindungen (3.1.4). Größere Gruppen oder Fremde verursachen aber, ähnlich wie in bisherigen Publikationen beschrieben, Unsicherheiten und einen sozialen Rückzug (Kortüm et al. 2011). Zusätzlich beeinträchtigt wird das soziale Verhalten durch die Unfähigkeit adäquaten Augenkontakt aufzubauen sowie durch Schreiepisoden, unpassende Lachattacken und abnorme Schlafmuster.

\subsection{Gastrointestinale und sonstige Symptome}

Gastrointestinale Symptome sind sehr häufig zu verzeichnen, nur wenige Kinder ließen sich komplikationslos füttern (Tabelle 5). $\mathrm{Zu}$ den häufigsten Problemen gehören Obstipation und ein gastro-ösophagealer Reflux (3.1.5). Die in diesem Kontext beschriebenen Krankheitsmerkmale decken sich mit den Ergebnissen vorausgehender Publikationen (Kortüm et al. 2011; Allou et al. 2012).

Am Bewegungsapparat sind insbesondere Krümmungsanomalien der Wirbelsäule wie Kyphosen und Skoliosen festzustellen, was ebenfalls mit früher publizierten Daten übereinstimmt (Mencarelli et al. 2010).

\subsection{Neurologische Symptome}

Ein wichtiges Krankheitsmerkmal von FOXG1-Patienten sind unterschiedliche Epilepsieformen, die in dieser Studie etwa zwei Drittel der Patienten betreffen (3.1.6). Zu den schwerstwiegenden Epilepsieformen gehören infantile Spasmen und das LennoxGastaut-Syndrom.

In einer vorherigen Studie wurden infantile Spasmen bei sechs von elf Patienten mit Duplikationen des FOXG1-Gens nachgewiesen. Allerdings beobachtete man diese frühkindliche Epilepsieform bei keinem Patient mit FOXG1-Variante (19 Fälle) oder Deletion (vier Fälle) (Seltzer et al. 2014). Deshalb wurde angenommen, dass infantile 
Spasmen typischerweise bei Patienten mit Duplikationen innerhalb des FOXG1-Gens auftreten. In der hier vorliegenden Studie, in welcher ausschließlich Patienten mit intragenischen Varianten analysiert wurden, sind zwei neu rekrutierte und drei bereits publizierte Kinder von infantilen Spasmen betroffen (Van Der Aa et al. 2011; De Bruyn et al. 2014). Infantile Spasmen treten somit nicht ausschließlich bei Duplikationen des FOXG1-Gens auf.

Kennzeichnend für das Krankheitsbild sind als weitere neurologische Symptome muskuläre Hypotonie, stereotype Bewegungen und Dyskinesien (3.1.6). Dieses überwiegend hyperkinetisch-dyskinetische Bewegungsmuster grenzt FOXG1-Patienten von Patienten mit Rett-Syndrom ab, bei denen ein solches Muster kaum beobachtet wird (Cellini et al. 2016).

Viele FOXG1-Patienten entwickelten neuroophthalmologische Symptome, insbesondere in Form eines Strabismus.

\subsection{Neuroradiologische Symptome}

Die für das FOXG1-Syndrom bekannten charakteristischen neuroradiologischen Veränderungen sind auch bei den Patienten dieser Studie zu verzeichnen (3.1.7). Bei etwa zweidrittel der Patienten liegen Anomalien des Corpus callosum vor. Die Kortexstruktur ist bei einem Großteil pathologisch verändert und bei circa der Hälfte der Patienten ist eine verzögerte Myelinisierung nachweisbar (Tabelle 5). Diese Charakteristika können als wichtigstes Kriterium zur Abgrenzung vom Rett-Syndrom genutzt werden, da RettPatienten diese Veränderungen in der Regel nicht aufweisen (Bahi-Buisson et al. 2010b). Insbesondere die partielle Aplasie der vorderen Balkenabschnitte ist so charakteristisch für das FOXG1-Syndrom, dass derartige cMRT Befunde als diagnostisch wegweisend gelten dürfen.

\subsection{Genotyp-Phänotyp-Analyse}

Genauere Genotyp-Phänotyp-Analysen wurden für fünf Patientengruppen, die unterschiedliche Varianten des FOXG1-Gens aufweisen, durchgeführt. Die schwersten Krankheitsausprägungen zeigen Patienten mit Nonsense- oder Frameshift-Variante der Nterminalen Domäne (Gruppe 1) und der Forkhead-Domäne (Gruppe 3). In diesen beiden genetischen Gruppen hat kaum ein Kind eigenständiges Sitzen oder Laufen erlernt, die Hände können größtenteils nicht zielgerichtet eingesetzt werden. Die Patienten dieser 
beiden Gruppen 1 und 3 weisen auch die höchsten Punktwerte des FOXG1-SchweregradScores auf. Im Gegensatz dazu sind die Ausprägungen des FOXG1-Syndroms bei Patienten mit Missense-Variante der Forkhead-Domäne (Gruppe 2, 4) und bei Patienten mit Nonsense- und Frameshift-Variante der 3'-Domäne (Gruppe 5) deutlich milder.

Diese Resultate der Genotyp-Phänotyp-Analysen sind vor dem Hintergrund der Struktur und der Funktionsdomänen des FOXG1-Proteins plausibel. Trunkierende Varianten, also solche aus denen ein verkürztes Genprodukt resultiert, gehen, wenn sie N-terminal (Gruppe 1) oder in der Forkhead-Domäne (Gruppe 3) liegen, mit den schwerstwiegenden Krankheitsausprägungen einher. Der Grund dafür ist, dass die DNA-Bindungsstelle der Forkhead-Domäne bei diesen Varianten ihre Funktion verliert. Dagegen bleiben sowohl bei trunkierenden Varianten innerhalb der C-terminalen Domäne als auch bei MissenseVarianten der Forkhead-Domäne Restfunktionen des Proteins erhalten. Korepressoren können weiterhin an die Groucho-Bindungsdomäne sowie die JARID1B-Domäne binden, und es kommt zu keinem vollständigen Funktionsverlust. Dies erklärt die mildere Ausprägungsform des FOXG1-Syndroms bei solchen Genveränderungen (Gruppen 2, 4 und 5). In früher publizierten Studien war auch darauf hingewiesen worden, dass Varianten mit geringer ausgeprägten funktionellen Konsequenzen (Missense-Varianten, spät trunkierende Varianten) zu milderen klinischen Phänotypen führen als früh trunkierende Varianten oder Deletionen (Kortüm et al. 2011). Frühere Genotyp-Phänotyp-Analysen waren aber in ihrer Signifikanz dadurch beeinträchtigt, dass meist auch Patienten einbezogen wurden, bei denen chromosomale Mikroaberrationen vorlagen, die nicht nur FOXG1, sondern auch weitere benachbarte Gene betrafen (Kortüm et al. 2011, Seltzer et al. 2014)

\subsection{Unterschiede zwischen neu rekrutierten und bereits publizierten Patienten}

Auf der Basis des für diese Studie entwickelten Schweregrad-Scores (FOXG1 Clinical Severity Score) wurden die klinischen Schweregrade der neu rekrutierten und der bereits publizierten Patienten einander gegenübergestellt (Tabelle 7). In der Gruppe der bereits publizierten Patienten ergibt sich ein signifikant höherer Schweregrad. Die neu rekrutierten Kinder sind trotz des signifikant geringeren Alters häufiger zu einem funktionellen Gebrauch der Hände und zu Augenkontakt in der Lage. Zusätzlich zeigt diese Kohorte bessere Sprachfähigkeiten und mehr soziale Interaktion. Da die Einschlusskriterien für genetische Analysen heutzutage weiter gefasst sind, werden vermehrt auch bei Patienten 
mit milderen Krankheitsverläufen genetische Analysen durchgeführt. Zusätzlich verbessert sich die Qualität und die Präsenz solcher Untersuchungen laufend, weshalb es plausibel erscheint, dass in der neuen Kohorte ein größerer Anteil an milden Ausprägungen des FOXG1-Syndroms vorliegt.

\subsection{Funktion des FOXG1}

Das FOXG1-Gen, welches ein kodierendes Exon umfasst, gehört zur ForkheadGenfamilie. Diese Gene wurden bei unterschiedlichen Wirbeltieren und auch beim Menschen nachgewiesen (Wiese et al. 1995; Bredenkamp et al. 2007). FOXG1 fungiert als Transkriptionsrepressor und wird im fetalen und adulten Gehirn exprimiert. Es nimmt somit eine zentrale Rolle für die Bildung des Telenzephalons und davon ausgehender Strukturen ein. Dazu gehören der zerebrale Kortex, der Hippocampus und bei Mäusen die Basalganglien (Dou et al. 1999). FOXG1 beeinflusst hier die frühen Phasen der kortikalen Entwicklung, indem es Proliferation und Differenzierung von Progenitorzellen des Neokortex reguliert. Zusätzlich hat das Gen als Promotor eine Schlüsselfunktion in neokortikalen Laminierungsvorgängen (Hanashima et al. 2002). Aktuelle Studien belegen außerdem, dass FOXG1 eine wichtige Rolle für die dentale Gyrierung des Hippocampus einnimmt (Yang et al. 2015).

Diese bisher beschriebenen Funktionen liefern keine vollständige Erklärung für die phänotypische Ausprägung von Patienten mit Varianten des FOXG1-Gens. Es ergeben sich aber durchaus Erklärungsansätze für einzelne charakteristische Krankheitseigenschaften, wie beispielsweise die Intelligenzminderung, die bei allen Patienten vorliegt, sowie die frontal betonten Fehlbildungen des Corpus callosum.

\subsection{Ausblick}

Bei den ersten, mittlerweile ca. 10 Jahre zurückliegenden wissenschaftlichen Beschreibungen des FOXG1-Syndroms wurden die phänotypischen Gemeinsamkeiten mit dem Rett-Syndrom in den Vordergrund gestellt. Die daran anschließenden klinischgenetischen Untersuchungen zu FOXG1-Patienten haben zeigen können, dass diese - über den kongenitalen Beginn der Symptomatik hinaus - zahlreiche klinische Merkmale aufweisen, die sie von Rett-Patientinnen unterscheiden. Einige der frühen Beschreibungen von FOXG1-Patienten betrafen Fälle mit chromosomalen Mikroaberrationen, die neben dem FOX1-Gen noch weitere, benachbarte Gene einschlossen. Diese Berichte führten zu einer Unschärfe der phänotypischen Abgrenzung. Mittlerweile ist allgemeiner Konsens, 
dass FOXG1-Patienten keine konsistenten, charakteristischen fazialen Dysmorphien aufweisen, wie auch in der hier vorliegenden Untersuchung gezeigt wurde. Zwar können die neuroradiologischen Veränderungen mit frontal betonten Anomalien des Corpus callosum diagnostisch wegweisend sein. Der klinische Phänotyp mit primärer globaler Entwicklungsstörung, Epilepsie und Bewegungsstörung jedoch ist, wie auch durch die hier vorliegende Arbeit untermauert wird, nicht derart spezifisch, dass allein auf der Grundlage des körperlichen Befundes eine sichere Identifizierung von FOXG1-Patienten möglich wird. Vielmehr ist zu erwarten, dass in Zukunft das FOXG1-Syndrom überwiegend über genetische Screening-Untersuchungen, wie Chromosomenanalyse (balancierte Translokationen), vergleichende genomische Hybridisierung (Array-CGH mit Nachweis von Mikrodeletionen und -duplikationen in der Region 14q12) und vor allem Next Generation Sequencing Verfahren (Multigen-Panels, Gesamt-Exom-Sequenzierung mit Nachweis von intragenischen Varianten) diagnostiziert wird. Die in dieser Studie vorgelegten Daten zu Genotyp-Phänotyp-Assoziationen bei intragenischen FOXG1Varianten erlauben zukünftig eine fundiertere genetische Beratung der Familien mit einem betroffenen Kind. 


\section{$5 \quad$ Zusammenfassung}

Das FOXG1-Syndrom wurde erstmals 2008 als kongenitale Variante des Rett-Syndroms bei zwei Patientinnen mit primärer globaler Retardierung, sekundärer Mikrozephalie sowie Hand- und Atemstereotypien beschrieben (Ariani et al. 2008). Diese und weitere frühe Beschreibungen der FOXG1-assoziierten Entwicklungsstörung betrafen überwiegend Patienten mit chromosomalen Mikroaberrationen in der Region 14q12, die das FOXG1Gen und weitere benachbarte Gene einschlossen, es wurden aber auch Nonsense- oder Missense-Varianten im FOXG1-Gen beschrieben. Mit wachsender Kenntnis des klinischen Phänotyps wurde deutlich, dass FOXG1-assoziierte Krankheitsbilder zahlreiche Merkmale aufweisen, die sie vom Rett-Syndrom eindeutig unterscheiden, sodass der Begriff des FOXG1-Syndroms geprägt wurde.

Die vorliegende Studie zielte darauf ab, das klinische Spektrum bei Patienten mit pathogenen oder wahrscheinlich pathogenen FOXG1-Varianten sowie Genotyp-PhänotypAssoziationen zu untersuchen und zu beschreiben.

Dazu wurden über die „Erhebung Seltener Neurologischer Erkrankungen im Kindesalter (ESNEK)“ sowie über Kooperationen mit der Humangenetik Leipzig, der Neuropädiatrie Vogtareuth und weiteren Kliniken und Ärzten 30 bisher nicht publizierte Patienten mit pathogenen oder wahrscheinlich pathogenen FOXG1-Varianten rekrutiert. Zu diesen Patienten wurden von deren Eltern und von den betreuenden Ärzten alle wesentlichen Informationen erfragt. Zusätzlich wurden im Rahmen einer Pubmed-Recherche alle früheren (bis Dezember 2015) englischsprachigen wissenschaftlichen Publikationen zu Patienten mit pathogenen oder wahrscheinlich pathogenen FOXG1-Variante ermittelt. So waren klinische, neuroradiologische und molekulargenetische Daten $\mathrm{zu} 53$ bereits publizierten Patienten mit FOXG1-Varianten erhebbar. Damit konnte für diese Untersuchung eine Kohorte von insgesamt 83 Patienten mit heterozygoten FOXG1Varianten rekrutiert werden. Auf der Basis eines neu entwickelten klinischen FOXG1Schweregrad-Scores wurde der klinische und neuroradiologische Phänotyp vereinfacht quantitativ erfasst. Zur Untersuchung von Genotyp-Phänotyp-Assoziationen wurden die Patienten nach Art und Lokalisation der jeweiligen FOXG1-Variante in fünf genetische Gruppen eingeteilt.

Die Auswertung der Daten zur klinischen Symptomatik ergab, dass die Variabilität des Phänotyps bei Patienten mit FOXG1-Syndrom größer ist als bisher bekannt. Viel häufiger 
als bisher angenommen, liegt bereits bei Geburt eine Mikrozephalie vor. Das klinische Spektrum reicht von schwerst mehrfachbehinderten Patienten bis zu Kindern, die das freie Laufen und in begrenztem Maße auch expressive Sprache erreichen. Eine hyperkinetischdyskinetische Bewegungsstörung besteht bei vielen Patienten. Die Mehrzahl der Patienten ist von einer Epilepsie mit sehr unterschiedlichen Anfallsformen betroffen

Die Genotyp-Phänotyp-Analyse zeigt, dass Patienten mit Nonsense- oder FrameshiftVarianten der N-terminalen Domäne (Gruppe 1) und der Forkhead-Domäne (Gruppe 3) die schwersten Krankheitsausprägungen aufweisen (4.7). Diese Genveränderungen führen zu einem vollständigen Funktionsverlust der DNA-Bindungsstelle der Forkhead-Domäne. Mildere Ausprägungsformen bestehen bei Kindern mit Missense-Varianten der ForkheadDomäne (Gruppe 2, 4) sowie Patienten mit Nonsense- oder Frameshift-Varianten der 3'Domäne (Gruppe 5). Diese Genveränderungen verursachen keinen vollständigen Funktionsverlust des Proteins (4.7).

Allein anhand der klinischen Symptomatik ist es schwer, das FOXG1-Syndrom von anderen schweren Entwicklungsstörungen mit frühkindlichem Beginn abzugrenzen. Durch den vermehrten Einsatz von Next Generation Sequencing Methoden könnten zukünftig mehr Patienten mit FOXG1-Syndrom detektiert und das klinische Bild besser analysiert werden (4.10). Die hier vorgelegten klinisch-genetischen Daten ermöglichen eine fundiertere Beratung der Eltern betroffener Kinder über die Entwicklungsprognose als dies bisher möglich war. 


\section{$6 \quad$ Anhang}

\subsection{Patientendaten}

Tabelle 8: Patientendaten (allgemeine Daten, FOXG1-Varianten)

\begin{tabular}{|c|c|c|c|c|c|c|c|c|c|c|}
\hline $\begin{array}{l}\mathbf{P} \\
\#\end{array}$ & $\begin{array}{l}\mathrm{F} \\
\#\end{array}$ & Daten & G & $\begin{array}{l}\text { Alter SZ } \\
\text { (M) }\end{array}$ & $\begin{array}{l}\text { Alter } \\
\text { LU (M) }\end{array}$ & $\begin{array}{l}\text { Dia- } \\
\text { gnostik }\end{array}$ & $\begin{array}{l}\text { Variante } \\
\text { cDNA }\end{array}$ & Variante AS & $\begin{array}{l}\text { Segre- } \\
\text { gation }\end{array}$ & $\begin{array}{l}\text { Lokalisation \& } \\
\text { Art d. } \\
\text { Genveränderung }\end{array}$ \\
\hline 1 & 1 & ESNEK & M & 41 & 40 & SS & c.256delC & p.Q86Rfs*106 & De novo & $5^{\prime}$ fsh\&non \\
\hline 2 & 2 & ESNEK & M & 79 & 51 & SS & c. $214 \mathrm{C}>\mathrm{T}$ & p.Q72* & De novo & $5^{\prime}$ fsh\&non \\
\hline 3 & 3 & Kooperation USA & M & 36 & 33 & ES & c. $406 \mathrm{G}>\mathrm{T}$ & p.E136* & De novo & 5' fsh\&non \\
\hline 4 & 4 & ESNEK & W & 103 & 100 & SS & c.460dupG & p.E154Gfs*301 & De novo & 5' fsh\&non \\
\hline 5 & 5 & ESNEK & W & 105 & 105 & SS & c.385delG & p.E129Sfs*63 & De novo & $5^{\prime}$ fsh\&non \\
\hline 6 & 6 & ESNEK & W & 75 & 39 & SS & c.460delG & p.E154Rfs*38 & De novo & 5' fsh\&non \\
\hline 7 & 7 & ESNEK & M & 95 & 72 & $\mathrm{PD}$ & c. $460 \operatorname{dupG}$ & p.E154Gfs $* 301$ & n.a. & $5^{\prime}$ fsh\&non \\
\hline 8 & 8 & ESNEK & W & 51 & 45 & PD & c.460dupG & p.E154Gfs*301 & De novo & 5' fsh\&non \\
\hline 9 & 9 & $\begin{array}{l}\text { Kooperation } \\
\text { Deutschland }\end{array}$ & M & 72 & 61 & $\mathrm{PD}$ & c. $460 \mathrm{dupG}$ & p.E154Gfs*301 & De novo & 5' fsh\&non \\
\hline 10 & 10 & ESNEK & W & 34 & 30 & ES & c. $517 \mathrm{G}>\mathrm{T}$ & p.E173* & De novo & $5^{\prime}$ fsh\&non \\
\hline 11 & 11 & $\begin{array}{l}\text { Kooperation } \\
\text { Deutschland }\end{array}$ & M & 82 & 82 & PD & c. $543 \mathrm{G}>\mathrm{C}$ & p.K181N & Pgm & FHD CS mis \\
\hline 12 & 11 & $\begin{array}{l}\text { Kooperation } \\
\text { Deutschland }\end{array}$ & W & 34 & 34 & PD & c. $543 \mathrm{G}>\mathrm{C}$ & p.K181N & Pgm & FHD CS mis \\
\hline 13 & 13 & ESNEK & W & 91 & 85 & Ss & c. $545 \mathrm{C}>\mathrm{A}$ & p.P182Q & De novo & FHD CS mis \\
\hline 14 & 14 & $\begin{array}{l}\text { Kooperation } \\
\text { Deutschland }\end{array}$ & M & 93 & 93 & PD & c. $.553 \mathrm{~A}>\mathrm{T}$ & p.S185C & De novo & FHD CS mis \\
\hline 15 & 15 & Kooperation USA & M & 192 & 192 & ES & c. $.561 \mathrm{C}>\mathrm{A}$ & p.N187K & De novo & FHD CS mis \\
\hline 16 & 16 & Kooperation USA & W & 60 & 62 & ES & c. $.561 \mathrm{C}>\mathrm{A}$ & p.N187K & De novo & FHD CS mis \\
\hline 17 & 17 & ESNEK & W & 37 & 20 & SS & c. $.565 \mathrm{C}>\mathrm{T}$ & p.L189F & De novo & FHD CS mis \\
\hline 18 & 17 & ESNEK & W & 37 & 33 & SS & c. $.565 \mathrm{C}>\mathrm{T}$ & p.L189F & De novo & FHD CS mis \\
\hline 19 & 19 & ESNEK & W & 103 & 72 & ss & c. $581 \mathrm{~T}>\mathrm{G}$ & p.1194S & De novo & FHD CS mis \\
\hline 20 & 20 & ESNEK & W & 96 & 25 & ss & $\begin{array}{l}\text { c.592_594d } \\
\text { elCCC }\end{array}$ & p.P198del & De novo & FHD inf \\
\hline 21 & 21 & ESNEK & M & 64 & 46 & ES & $\begin{array}{l}\text { c.609_616d } \\
\text { elGCTCA } \\
\text { ACG }\end{array}$ & p.L204Hfs $* 248$ & De novo & FHD fsh\&non \\
\hline 22 & 22 & ESNEK & M & 47 & 28 & $\mathrm{PD}$ & c. $624 \mathrm{C}>\mathrm{G}$ & p.Y208* & De novo & FHD fsh\&non \\
\hline 23 & 23 & ESNEK & M & 39 & 31 & PD & c. $730 \mathrm{C}>\mathrm{T}$ & p.R244C & De novo & FHD mis \\
\hline 24 & 24 & Kooperation USA & W & 15 & 14 & ES & $\begin{array}{l}\text { c.732_741d } \\
\text { el }\end{array}$ & p.H245Tfs*78 & De novo & FHD fsh\&non \\
\hline 25 & 25 & Kooperation USA & M & 96 & 89 & ES & c.974dupT & p.L325Ffs*130 & De novo & 3' fsh\&non \\
\hline 26 & 26 & Kooperation USA & W & 24 & 31 & ES & $\begin{array}{l}\text { c.1082dup } \\
\text { G }\end{array}$ & p.L362Pfs*93 & De novo & $3^{\prime}$ fsh\&non \\
\hline
\end{tabular}

AS: Aminosäure, CS: konservierter Bereich, ES: Exom Sequenzierung, F: Familie, FHD: Forkhead-Domäne, fsh: Frameshift, G: Geschlecht, inf: Inframe, L: Literatur, LU: Letzte Untersuchung, M: Männlich, mis: Missense, MM: Maternales Mosaik, M: Monate, non: Nonsense, P: Patient, PD: Panel Diagnostik, Pgm: parentales gonadales Mosaik, SS: Sanger-Sequenzierung, SZ: Studienzeitpunkt, W: Weiblich 
Fortsetzung Tabelle 8: Patientendaten (allgemeine Daten, FOXG1-Varianten)

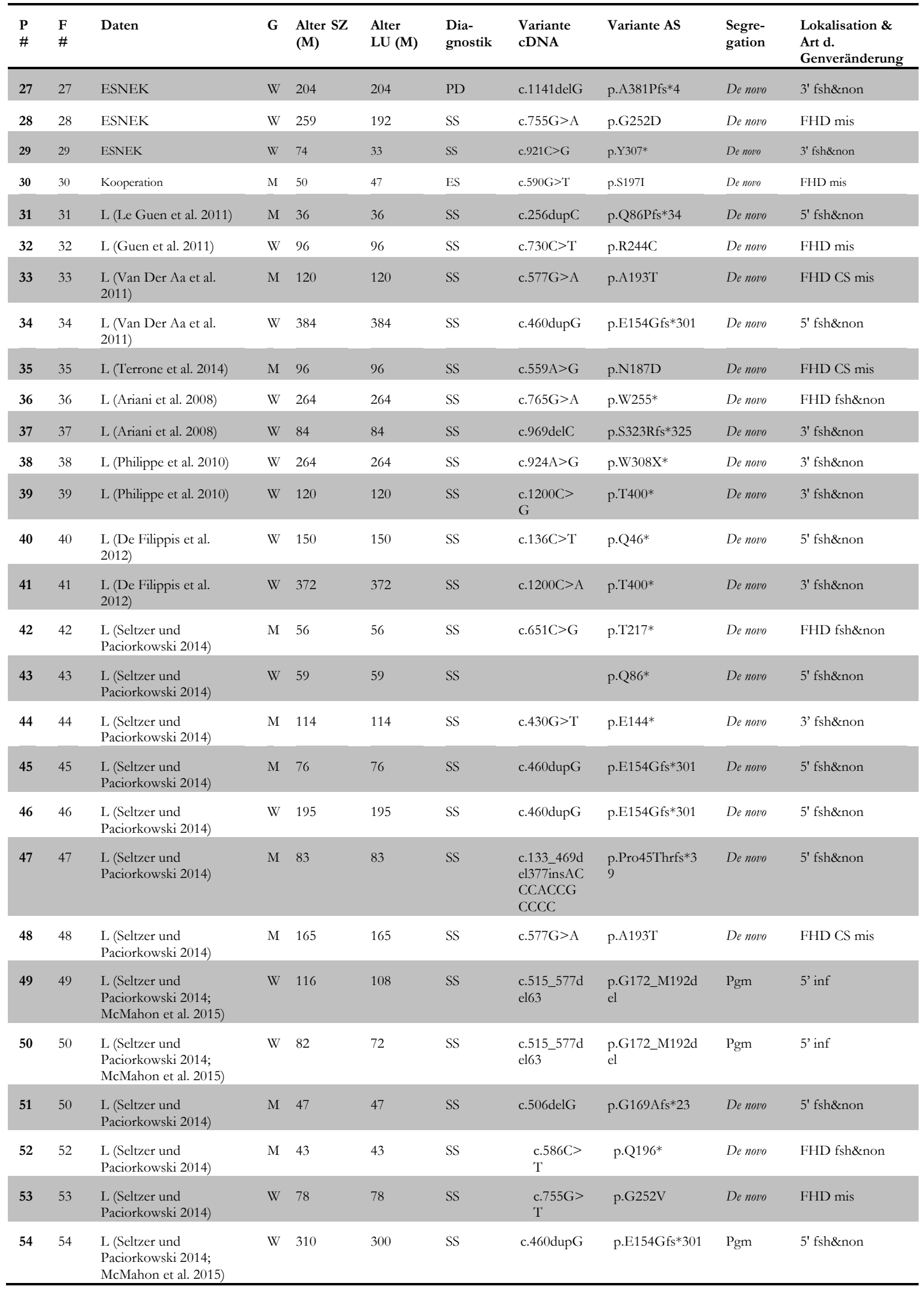

AS: Aminosäure, CS: konservierter Bereich, ES: Exom Sequenzierung, F: Familie, FHD: Forkhead-Domäne, fsh: Frameshift, G: Geschlecht, inf: Inframe, L: Literatur, LU: Letzte Untersuchung, M: Männlich, mis: Missense, MM: Maternales Mosaik, M: Monate, non: Nonsense, P: Patient, PD: Panel Diagnostik, Pgm: parentales gonadales Mosaik, SS: Sanger Sequenzierung, SZ: Studienzeitpunkt, W: Weiblich 
Fortsetzung Tabelle 8: Patientendaten (allgemeine Daten, FOXG1-Varianten)

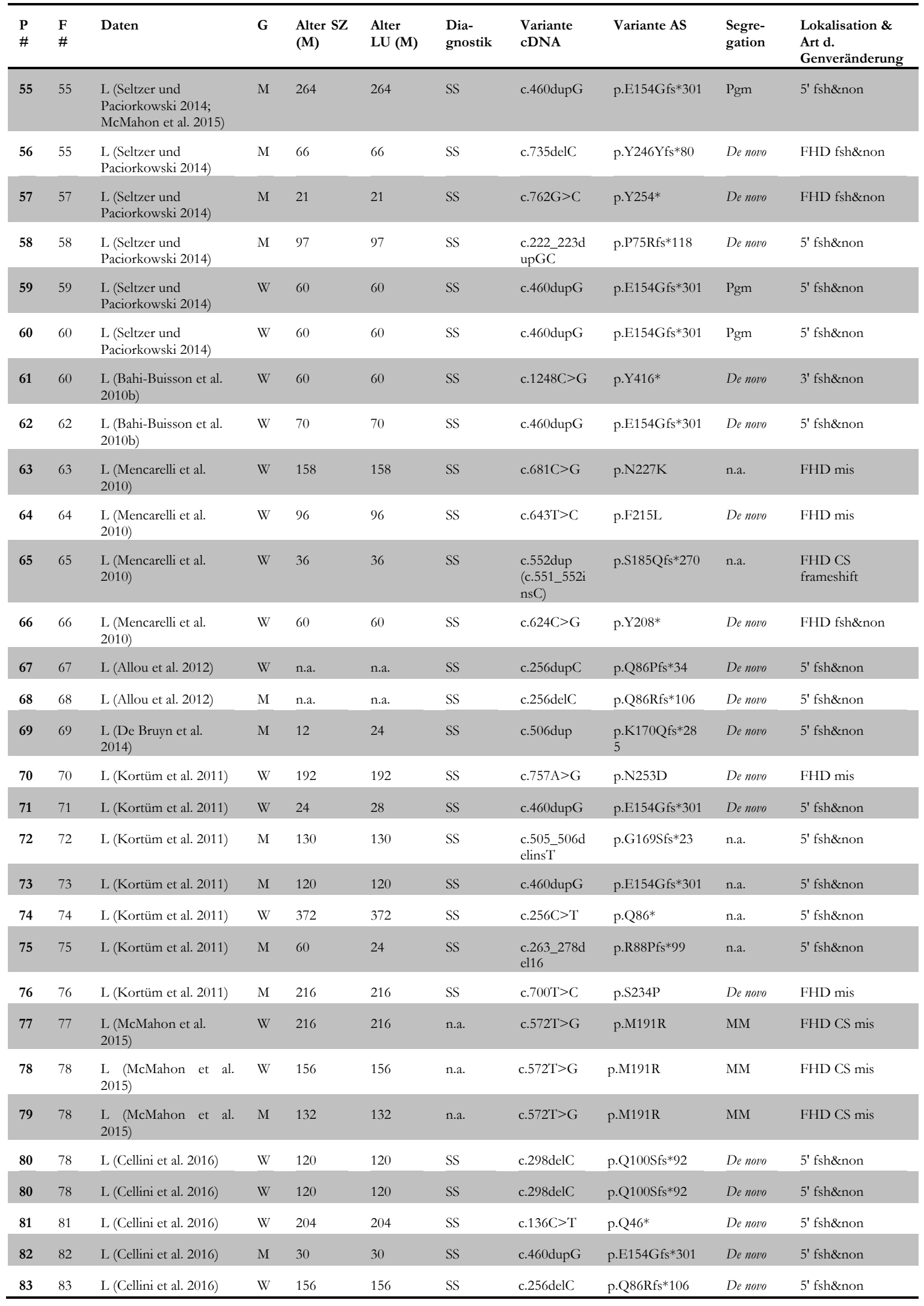

AS: Aminosäure, CS: konservierter Bereich, ES: Exom Sequenzierung, F: Familie, FHD: Forkhead-Domäne, fsh: Frameshift, G: Geschlecht, inf: Inframe, L: Literatur, LU: Letzte Untersuchung, M: Männlich, mis: Missense, MM: Maternales Mosaik, M: Monate, non: Nonsense, P: Patient, PD: Panel Diagnostik, Pgm: parentales gonadales Mosaik, SS: Sanger Sequenzierung, SZ: Studienzeitpunkt, W: Weiblich 
Tabelle 9: Patientendaten (somatische Entwicklung)

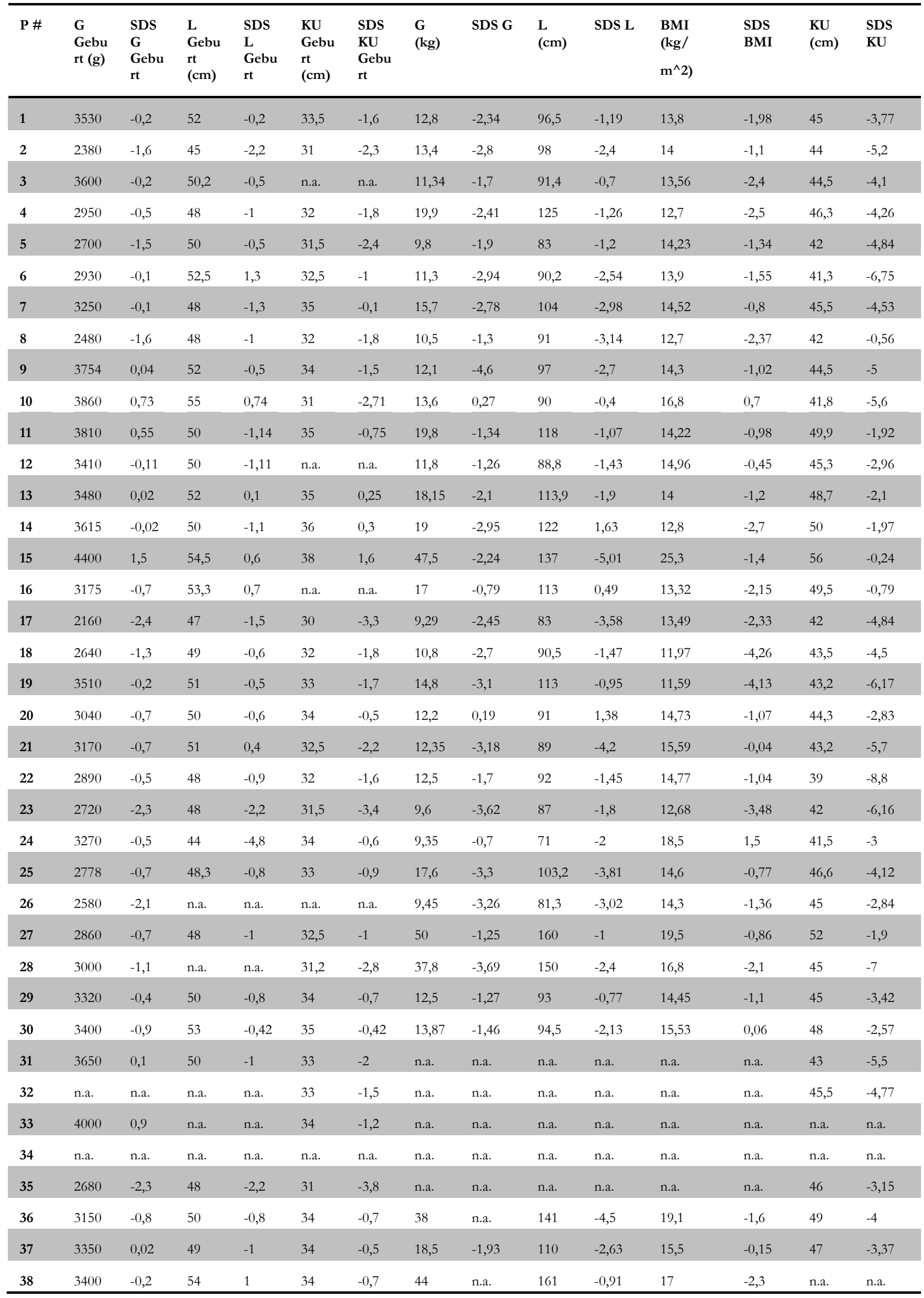

BMI: body mass index, cm: Zentimeter, G: Körpergewicht, g: Gramm, kg: Kilogramm, KU: Kopfumfang, L: Körperlänge, SDS: Standard Deviation Score 
Fortsetzung Tabelle 9: Patientendaten (somatische Entwicklung)

\begin{tabular}{|c|c|c|c|c|c|c|c|c|c|c|c|c|c|}
\hline P \# & $\begin{array}{l}\text { G } \\
\text { Gebu } \\
\text { rt (g) }\end{array}$ & $\begin{array}{l}\text { SDS } \\
\text { G } \\
\text { Gebu } \\
\text { rt }\end{array}$ & $\begin{array}{l}\mathrm{L} \\
\text { Gebu } \\
\mathrm{rt} \\
(\mathrm{cm})\end{array}$ & $\begin{array}{l}\text { SDS } \\
\text { L } \\
\text { Gebu } \\
\text { rt }\end{array}$ & $\begin{array}{l}\text { KU } \\
\text { Gebu } \\
\mathrm{rt} \\
(\mathrm{cm})\end{array}$ & $\begin{array}{l}\text { SDS } \\
\text { KU } \\
\text { Gebu } \\
\text { rt }\end{array}$ & $\begin{array}{l}\text { G } \\
(\mathrm{kg})\end{array}$ & SDS G & $\begin{array}{l}\mathrm{L} \\
(\mathrm{cm})\end{array}$ & $\operatorname{SDS} L$ & $\begin{array}{l}\text { BMI } \\
(\mathrm{kg} / \\
\left.\mathrm{m}^{\wedge} 2\right)\end{array}$ & $\begin{array}{l}\text { SDS } \\
\text { BMI }\end{array}$ & $\begin{array}{l}\mathrm{KU} \\
(\mathrm{cm})\end{array}$ \\
\hline
\end{tabular}

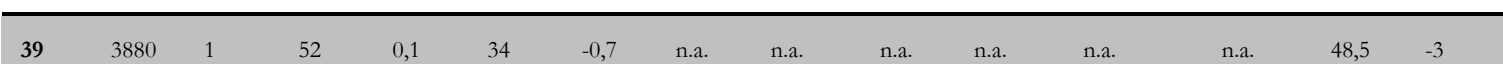

40 n.a. n.a. n.a. n.a. n.a. n.a. n.a. n.a. n.a. n.a. n.a. $\quad$ n.a. 49,8 -2,94

41 n.a. n.a. n.a. n.a. n.a. n.a. n.a. n.a. n.a. n.a. $\quad$ n.a. $\quad$ n.a. $54 \quad-0,41$

42 n.a. n.a. n.a. n.a. n.a. n.a. n.a. n.a. n.a. n.a. n.a. n.a. n.a. n.a.

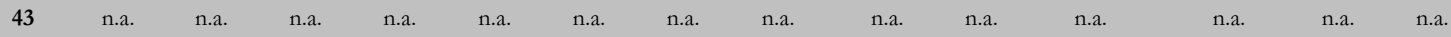

44 n.a. n.a. n.a. n.a. n.a. n.a. n.a. n.a. n.a. n.a. n.a. n.a. n.a.

45 n.a. n.a. n.a. n.a. n.a. n.a. n.a. n.a. n.a. n.a. $\quad$ n.a. $\quad$ n.a. n.a. n.a.

46 n.a. n.a. n.a. n.a. n.a. n.a. n.a. n.a. n.a. n.a. $\quad$ n.a. $\quad$ n.a. n.a. n.a.

47 n.a. n.a. n.a. n.a. n.a. n.a. n.a. n.a. n.a. n.a. $\quad$ n.a. n. n.a.

48 n.a. n.a. n.a. n.a. n.a. n.a. n.a. n.a. n.a. n.a. n.a. n.a. n.a.

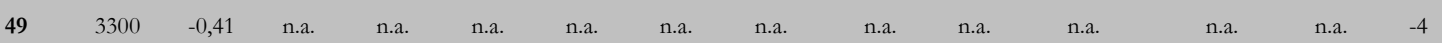

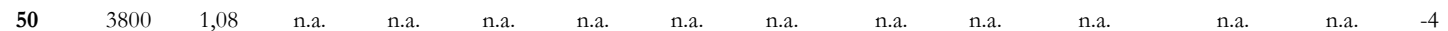

51 n.a. n.a. n.a. n.a. n.a. n.a. n.a. n.a. n.a. n.a. n.a. n.a. n.a. n.

52 n.a. n.a. n.a. n.a. n.a. n.a. n.a. n.a. n.a. n.a. n.a. n.a. n.a. n.a.

53 n.a. n.a. n.a. n.a. n.a. n.a. n.a. n.a. n.a. n.a. $\quad$ n.a. $\quad$ n.a. n.a.

$543400 \quad-0,11 \quad$ n.a. $\quad$ n.a. n.a. n.a. n.a. n.a. n.a. n.a. $\quad$ n.a. $\quad$ n.a. n.a.

$55 \quad 4100 \quad 1,1 \quad$ n.a. $\quad$ n.a. $\quad$ n.a. n.a. $\quad$ n.a. $\quad$ n.a. $\quad$ n.a. n.a. $\quad$ n.a. $\quad$ n.a. n.a. n.a.

56 n.a. n.a. n.a. n.a. n.a. n.a. n.a. n.a. n.a. n.a. $\quad$ n.a. $\quad$ n.a. n.a. n.a.

56 n.a. n.a. n.a. n.a. n.a. n.a. n.a. n.a. n.a. n.a. $\quad$ n.a. $\quad$ n.a. n.a. n.a.

57 n.a. n.a. n.a. n.a. n.a. n.a. n.a. n.a. n.a. n.a. n.a. n.a. n.a.

58 n.a. n.a. n.a. n.a. n.a. n.a. n.a. n.a. n.a. n.a. n.a. n.a. n.a.

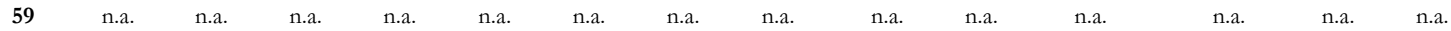

60 n.a. n.a. n.a. n.a. n.a. n.a. $\quad$ n.a. $\quad$ n.a. $\quad$ n.a. n.a. $\quad$ n.a. $\quad$ n.a. n.a. n.a.

$\begin{array}{llllllllllllllll}61 & 3230 & -0,62 & 51 & -0,94 & 34 & -0,58 & 17 & -1 & 106 & -1 & 15,13 & -0,21 & 44 & -4\end{array}$

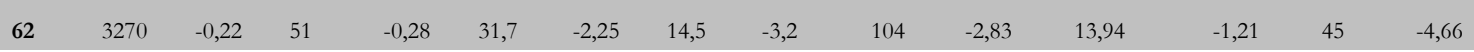

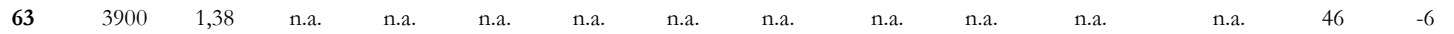

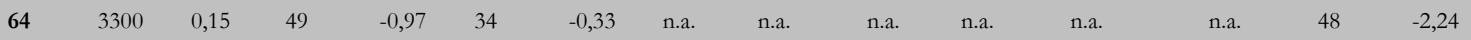

$\begin{array}{lllllllllllllllll}65 & 2800 & -1,91 & 48 & -2,61 & 32,5 & -1,83 & 13,4 & -0,6 & 97 & 0,25 & 14,2 & -1,1 & 43 & -5\end{array}$

$\begin{array}{llllllllllllllll}66 & 3150 & -0,86 & 50 & -1,5 & 33,5 & -1 & 10 & -3,52 & 87 & -2,46 & 13,2 & -2 & 42 & -5\end{array}$

67 n.a. n.a. n.a. n.a. n.a. -1 n.a. n.a. n.a. n.a. $\quad$ n.a. $\quad$ n.a. n.a. -4

68 n.a. n.a. n.a. n.a. n.a. $-1 \quad$ n.a. n.a. n.a. n.a. $\quad$ n.a. $\quad$ n.a. $\quad$ n.a. $-5 \quad$

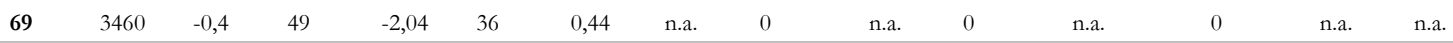

$70 \quad 3570 \quad-0,5 \quad$ n.a. $\quad$ n.a. $\quad$ n.a. $\quad$ n.a. $15,6 \quad-2 \quad$ n.a. $\quad$ n.a. $\quad$ n.a. $\quad$ n.a. $48 \quad-4,4$

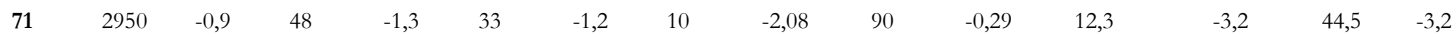

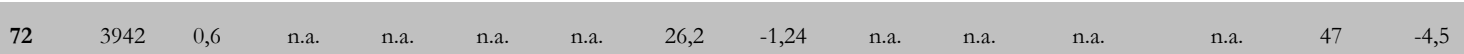

$\begin{array}{llllllllllllllll}73 & \text { n.a. } & \text { n.a. } & \text { n.a. } & \text { n.a. } & \text { n.a. } & \text { n.a. } & 27 & -1 & 126,4 & -2,27 & 16,9 & 0 & 44 & -6,4\end{array}$

$\begin{array}{lllllllllllllllll}\mathbf{7 4} & 4400 & 2,88 & 52 & -0,39 & \text { n.a. } & \text { n.a. } & 37,4 & \text { n.a. } & 145 & -3,82 & 17,8 & -2,1 & 47,5 & -5,3\end{array}$

BMI: body mass index, cm: Zentimeter, G: Körpergewicht, g: Gramm, kg: Kilogramm, KU: Kopfumfang, L: Körperlänge,

SDS: Standard Deviation Score 
Fortsetzung Tabelle 9: Patientendaten (somatische Entwicklung)

\begin{tabular}{|c|c|c|c|c|c|c|c|c|c|c|c|c|c|c|}
\hline P \# & $\begin{array}{l}\text { G } \\
\text { Gebu } \\
\text { rt (g) }\end{array}$ & $\begin{array}{l}\text { SDS } \\
\text { G } \\
\text { Gebu } \\
\text { rt }\end{array}$ & $\begin{array}{l}\text { L } \\
\text { Gebu } \\
\text { rt } \\
(\mathrm{cm})\end{array}$ & $\begin{array}{l}\text { SDS } \\
\text { L } \\
\text { Gebu } \\
\text { rt }\end{array}$ & $\begin{array}{l}\text { KU } \\
\text { Gebu } \\
\text { rt } \\
(\mathrm{cm})\end{array}$ & $\begin{array}{l}\text { SDS } \\
\text { KU } \\
\text { Gebu } \\
\text { rt }\end{array}$ & $\begin{array}{l}\text { G } \\
(\mathrm{kg})\end{array}$ & SDS G & $\begin{array}{l}\mathrm{L} \\
(\mathrm{cm})\end{array}$ & SDS L & $\begin{array}{l}\text { BMI } \\
(\mathrm{kg} / \\
\left.\mathrm{m}^{\wedge} 2\right)\end{array}$ & $\begin{array}{l}\text { SDS } \\
\text { BMI }\end{array}$ & $\begin{array}{l}\mathrm{KU} \\
(\mathrm{cm})\end{array}$ & $\begin{array}{l}\text { SDS } \\
\text { KU }\end{array}$ \\
\hline 75 & 3710 & $-0,05$ & 52 & $-0,7$ & 33 & $-2,9$ & 11,13 & $-1,42$ & 80 & $-2,3$ & 17,4 & 0,9 & 42 & $-5,3$ \\
\hline 76 & 2800 & $-0,57$ & 50 & $-0,17$ & 32 & $-2,6$ & 37 & n.a. & 155 & $-3,5$ & 15,4 & $-3,4$ & 49,2 & $-4,4$ \\
\hline 78 & n.a. & n.a. & n.a. & n.a. & n.a. & n.a. & n.a. & n.a. & n.a. & n.a. & n.a. & n.a. & 56 & 1,4 \\
\hline 79 & n.a. & n.a. & n.a. & n.a. & n.a. & n.a. & n.a. & n.a. & n.a. & n.a. & n.a. & n.a. & 55 & 0,7 \\
\hline 82 & n.a. & n.a. & n.a. & n.a. & n.a. & n.a. & n.a. & n.a. & n.a. & n.a. & n.a. & n.a. & n.a. & -4 \\
\hline 83 & n.a. & n.a. & n.a. & n.a. & n.a. & n.a. & n.a. & n.a. & n.a. & n.a. & n.a. & n.a. & n.a. & $-3,5$ \\
\hline
\end{tabular}

BMI: body mass index, cm: Zentimeter, G: Körpergewicht, g: Gramm, kg: Kilogramm, KU: Kopfumfang, L: Körperlänge, SDS: Standard Deviation Score 
Tabelle 10: Patientendaten (Motorik, Sprache)

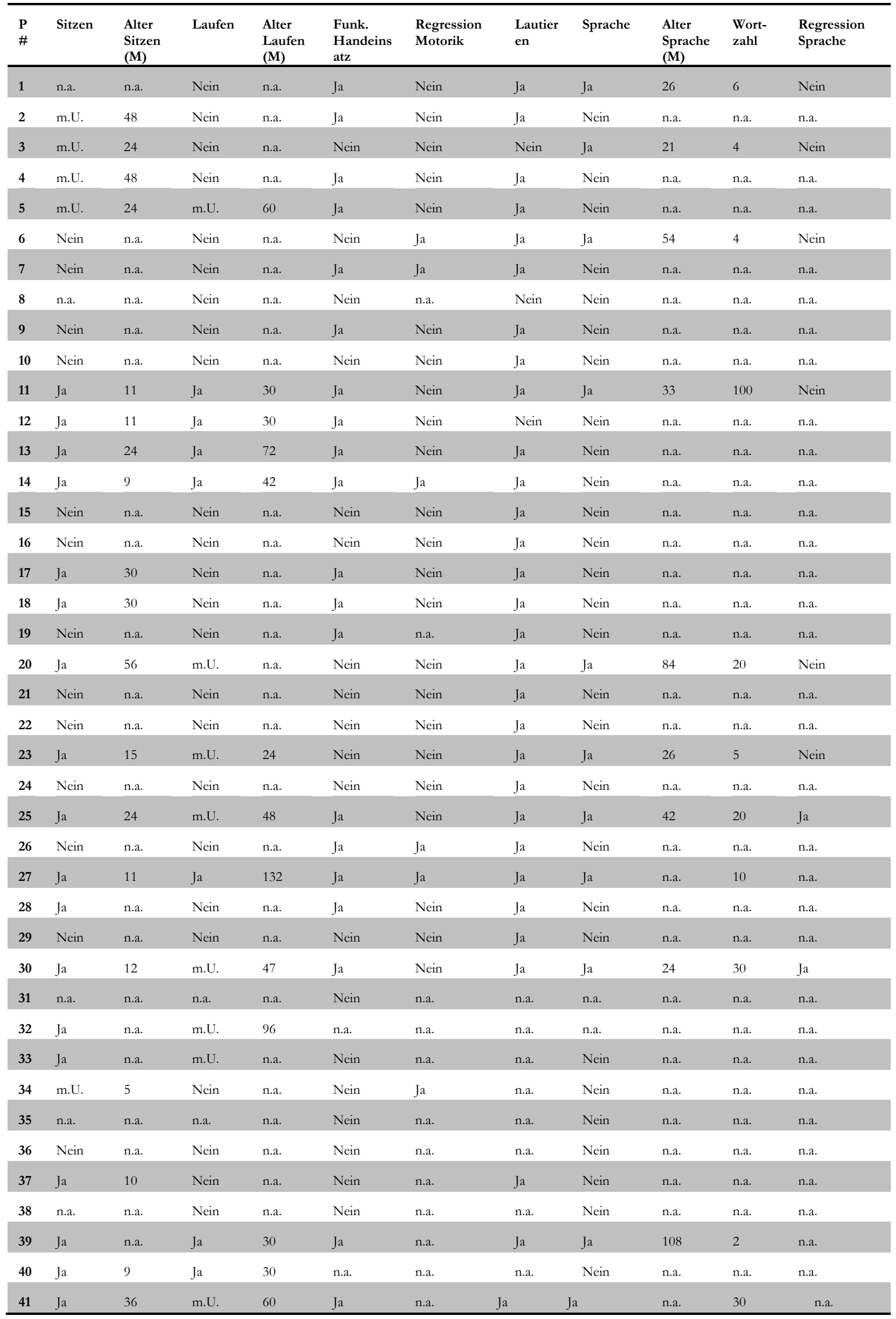

M: Monate, m.U.: mit Unterstützung, P: Patient 
Fortsetzung Tabelle 10: Patientendaten (Motorik, Soziales Verhalten)

\begin{tabular}{|c|c|c|c|c|c|c|c|c|c|c|c|}
\hline $\begin{array}{l}\mathbf{P} \\
\#\end{array}$ & Sitzen & $\begin{array}{l}\text { Alter } \\
\text { Sitzen } \\
(M) \\
\end{array}$ & Laufen & $\begin{array}{l}\begin{array}{l}\text { Alter } \\
\text { Laufen } \\
\text { (M) }\end{array} \\
\end{array}$ & $\begin{array}{l}\text { Funk. } \\
\text { Hand- } \\
\text { einsatz }\end{array}$ & $\begin{array}{l}\text { Re- } \\
\text { gression } \\
\text { Motorik }\end{array}$ & $\begin{array}{l}\text { Lautie } \\
\text { ren }\end{array}$ & Sprache & $\begin{array}{l}\text { Alter } \\
\text { Sprache } \\
(\mathbf{M})\end{array}$ & $\begin{array}{l}\text { Wort- } \\
\text { zahl }\end{array}$ & $\begin{array}{l}\text { Regression } \\
\text { Sprache }\end{array}$ \\
\hline 42 & n.a. & n.a. & Nein & n.a. & Nein & n.a. & n.a. & Nein & n.a. & n.a. & n.a. \\
\hline 43 & n.a. & n.a. & Nein & n.a. & Nein & n.a. & n.a. & Nein & n.a. & n.a. & n.a. \\
\hline 44 & n.a. & n.a. & Nein & n.a. & Nein & n.a. & n.a. & Nein & n.a. & n.a. & n.a. \\
\hline 45 & n.a. & n.a. & Nein & n.a. & Nein & n.a. & n.a. & Nein & n.a. & n.a. & n.a. \\
\hline 46 & n.a. & n.a. & Nein & n.a. & Nein & n.a. & n.a. & Nein & n.a. & n.a. & n.a. \\
\hline 47 & n.a. & n.a. & Nein & n.a. & Nein & n.a. & n.a. & Nein & n.a. & n.a. & n.a. \\
\hline 48 & n.a. & n.a. & Nein & n.a. & $\mathrm{Ja}$ & n.a. & n.a. & Nein & n.a. & n.a. & n.a. \\
\hline 49 & m.U. & 108 & Nein & n.a. & Nein & n.a. & Nein & Nein & n.a. & n.a. & n.a. \\
\hline 50 & n.a. & n.a. & m.U. & 72 & Nein & n.a. & Nein & Nein & n.a. & n.a. & n.a. \\
\hline 51 & n.a. & n.a. & Nein & n.a. & Nein & n.a. & n.a. & Nein & n.a. & n.a. & n.a. \\
\hline 52 & n.a. & n.a. & Nein & n.a. & Nein & n.a. & n.a. & Nein & n.a. & n.a. & n.a. \\
\hline 53 & n.a. & n.a. & Nein & n.a. & Nein & n.a. & n.a. & Nein & n.a. & n.a. & n.a. \\
\hline 54 & n.a. & n.a. & Nein & n.a. & $\mathrm{Ja}$ & n.a. & Nein & Nein & n.a. & n.a. & n.a. \\
\hline 55 & n.a. & n.a. & Nein & n.a. & $\mathrm{Ja}$ & n.a. & Nein & Nein & n.a. & n.a. & n.a. \\
\hline 56 & n.a. & n.a. & Nein & n.a. & Nein & n.a. & n.a. & n.a. & n.a. & n.a. & n.a. \\
\hline 57 & n.a. & n.a. & Nein & n.a. & n.a. & n.a. & n.a. & n.a. & n.a. & n.a. & n.a. \\
\hline 58 & n.a. & n.a. & Nein & n.a. & Nein & n.a. & n.a. & n.a. & n.a. & n.a. & n.a. \\
\hline 59 & n.a. & n.a. & Nein & n.a. & Nein & n.a. & $\mathrm{Ja}$ & $\mathrm{Ja}$ & n.a. & n.a. & n.a. \\
\hline 60 & n.a. & n.a. & Nein & n.a. & Nein & n.a. & $\mathrm{Ja}$ & $\mathrm{Ja}$ & n.a. & n.a. & n.a. \\
\hline 61 & Nein & n.a. & Nein & n.a. & Nein & Nein & $\mathrm{Ja}$ & Nein & n.a. & n.a. & n.a. \\
\hline 62 & m.U. & n.a. & Nein & n.a. & Nein & n.a. & n.a. & Nein & n.a. & n.a. & n.a. \\
\hline 63 & n.a. & n.a. & Nein & n.a. & n.a. & n.a. & Nein & Nein & n.a. & n.a. & n.a. \\
\hline 64 & $\mathrm{Ja}$ & 15 & Nein & n.a. & Nein & Nein & $\mathrm{Ja}$ & Nein & n.a. & n.a. & n.a. \\
\hline 65 & Nein & n.a. & Nein & n.a. & Nein & n.a. & Nein & Nein & n.a. & n.a. & n.a. \\
\hline 66 & m.U. & n.a. & Nein & n.a. & $\mathrm{Ja}$ & n.a. & $\mathrm{Ja}$ & Nein & n.a. & n.a. & n.a. \\
\hline 67 & n.a. & n.a. & n.a. & n.a. & Nein & n.a. & n.a. & Nein & n.a. & n.a. & n.a. \\
\hline 68 & n.a. & n.a. & n.a. & n.a. & Nein & n.a. & n.a. & Nein & n.a. & n.a. & n.a. \\
\hline 69 & Nein & n.a. & Nein & n.a. & Nein & n.a. & n.a. & Nein & n.a. & n.a. & n.a. \\
\hline 70 & Ja & 95 & $\mathrm{Ja}$ & 96 & $\mathrm{Ja}$ & Nein & n.a. & Nein & n.a. & n.a. & n.a. \\
\hline 71 & Nein & n.a. & Nein & n.a. & Nein & Nein & n.a. & Nein & n.a. & n.a. & n.a. \\
\hline 72 & $\mathrm{Ja}$ & 18 & Nein & n.a. & Nein & Nein & n.a. & Nein & n.a. & n.a. & n.a. \\
\hline 73 & n.a. & n.a. & Nein & n.a. & Nein & Nein & n.a. & Nein & n.a. & n.a. & n.a. \\
\hline 74 & Nein & n.a. & Nein & n.a. & Nein & $\mathrm{Ja}$ & n.a. & Nein & n.a. & n.a. & n.a. \\
\hline 75 & Nein & n.a. & Nein & n.a. & $\mathrm{Ja}$ & Nein & n.a. & Nein & n.a. & n.a. & n.a. \\
\hline 76 & Nein & n.a. & Nein & n.a. & $\mathrm{Ja}$ & Nein & n.a. & Nein & n.a. & n.a. & n.a. \\
\hline 77 & $\mathrm{Ja}$ & 18 & $\mathrm{Ja}$ & 24 & $\mathrm{Ja}$ & n.a. & $\mathrm{Ja}$ & $\mathrm{Ja}$ & n.a. & 10 & n.a. \\
\hline 78 & $\mathrm{Ja}$ & 12 & $\mathrm{Ja}$ & 24 & $\mathrm{Ja}$ & n.a. & $\mathrm{Ja}$ & $\mathrm{Ja}$ & n.a. & 10 & n.a. \\
\hline 79 & n.a. & n.a. & $\mathrm{Ja}$ & 42 & $\mathrm{Ja}$ & n.a. & $\mathrm{Ja}$ & $\mathrm{Ja}$ & n.a. & 20 & n.a. \\
\hline 80 & n.a. & n.a. & Nein & n.a. & n.a. & n.a. & n.a. & Nein & n.a. & n.a. & n.a. \\
\hline 81 & n.a. & n.a. & $\mathrm{Ja}$ & n.a. & n.a. & n.a. & n.a. & Nein & n.a. & n.a. & n.a. \\
\hline 82 & n.a. & n.a. & Nein & n.a. & n.a. & n.a. & n.a. & Nein & n.a. & n.a. & n.a. \\
\hline 83 & n.a. & n.a. & Nein & n.a. & n.a. & n.a. & n.a. & Nein & n.a. & n.a. & n.a. \\
\hline
\end{tabular}


Tabelle 11: Patientendaten (soziales Verhalten, gastrointestinale und skelettale Symptome)

\begin{tabular}{|c|c|c|c|c|c|c|c|c|c|c|c|}
\hline P \# & Soz. IA. & $\begin{array}{l}\text { Augen- } \\
\text { kontakt }\end{array}$ & Abn. SV. & $\begin{array}{l}\begin{array}{l}\text { Schrei- } \\
\text { episoden }\end{array} \\
\end{array}$ & $\begin{array}{l}\text { Lach- } \\
\text { anfälle }\end{array}$ & Aut. V. & $\begin{array}{l}\text { Fütter- } \\
\text { probleme }\end{array}$ & GÖR & $\begin{array}{l}\text { Aspi- } \\
\text { ration }\end{array}$ & $\begin{array}{l}\text { Obstip } \\
\text { ation }\end{array}$ & $\begin{array}{l}\text { Kyphose/ } \\
\text { Skoliose }\end{array}$ \\
\hline 1 & $\mathrm{Ja}$ & Wenig & $\mathrm{Ja}$ & $\mathrm{Ja}$ & Nein & Nein & $\mathrm{Ja}$ & Nein & n.a. & Ja & Ja \\
\hline 2 & $\mathrm{Ja}$ & Wenig & Nein & $\mathrm{Ja}$ & $\mathrm{Ja}$ & Nein & $\mathrm{Ja}$ & Nein & Nein & Nein & Nein \\
\hline 3 & Nein & Nein & $\mathrm{Ja}$ & $\mathrm{Ja}$ & Ja & Nein & $\mathrm{Ja}$ & $\mathrm{Ja}$ & Nein & $\mathrm{Ja}$ & Nein \\
\hline 4 & $\mathrm{Ja}$ & Ja & $\mathrm{Ja}$ & Nein & Nein & Nein & $\mathrm{Ja}$ & $\mathrm{Ja}$ & Nein & $\mathrm{Ja}$ & $\mathrm{Ja}$ \\
\hline 5 & $\mathrm{Ja}$ & Wenig & $\mathrm{Ja}$ & $\mathrm{Ja}$ & Nein & Nein & $\mathrm{Ja}$ & $\mathrm{Ja}$ & Ja & Ja & Nein \\
\hline 6 & $\mathrm{Ja}$ & Nein & $\mathrm{Ja}$ & $\mathrm{Ja}$ & $\mathrm{Ja}$ & $\mathrm{Ja}$ & $\mathrm{Ja}$ & Nein & n.a. & $\mathrm{Ja}$ & n.a. \\
\hline 7 & n.a. & n.a. & n.a. & $\mathrm{Ja}$ & Nein & n.a. & $\mathrm{Ja}$ & $\mathrm{Ja}$ & n.a. & Ja & Nein \\
\hline 8 & $\mathrm{Ja}$ & Wenig & $\mathrm{Ja}$ & $\mathrm{Ja}$ & Nein & $\mathrm{Ja}$ & $\mathrm{Ja}$ & n.a. & n.a. & $\mathrm{Ja}$ & Nein \\
\hline 9 & $\mathrm{Ja}$ & Ja & $\mathrm{Ja}$ & Nein & Ja & Nein & $\mathrm{Ja}$ & Ja & Nein & Ja & Ja \\
\hline 10 & n.a. & $\mathrm{Ja}$ & $\mathrm{Ja}$ & n.a. & n.a. & n.a. & $\mathrm{Ja}$ & $\mathrm{Ja}$ & n.a. & n.a. & Nein \\
\hline 11 & $\mathrm{Ja}$ & Ja & Nein & Nein & Nein & Nein & $\mathrm{Ja}$ & Nein & Nein & Nein & Nein \\
\hline 12 & $\mathrm{Ja}$ & Ja & $\mathrm{Ja}$ & Nein & Nein & Nein & Nein & Nein & Nein & Nein & Nein \\
\hline 13 & $\mathrm{Ja}$ & Ja & $\mathrm{Ja}$ & $\mathrm{Ja}$ & Ja & $\mathrm{Ja}$ & Nein & Nein & $\mathrm{Ja}$ & Ja & Ja \\
\hline 14 & $\mathrm{Ja}$ & Nein & $\mathrm{Ja}$ & Nein & $\mathrm{Ja}$ & $\mathrm{Ja}$ & $\mathrm{Ja}$ & Nein & Nein & Nein & Nein \\
\hline 15 & Nein & Wenig & $\mathrm{Ja}$ & n.a. & $\mathrm{Ja}$ & Nein & $\mathrm{Ja}$ & Nein & $\mathrm{Ja}$ & $\mathrm{Ja}$ & Nein \\
\hline 16 & $\mathrm{Ja}$ & $\mathrm{Ja}$ & $\mathrm{Ja}$ & n.a. & Nein & Nein & $\mathrm{Ja}$ & $\mathrm{Ja}$ & $\mathrm{Ja}$ & $\mathrm{Ja}$ & n.a. \\
\hline 17 & $\mathrm{Ja}$ & n.a. & Nein & Nein & Nein & Nein & $\mathrm{Ja}$ & Nein & n.a. & Nein & Nein \\
\hline 18 & $\mathrm{Ja}$ & n.a. & Nein & Nein & Nein & Nein & $\mathrm{Ja}$ & Nein & n.a. & Nein & Ja \\
\hline 19 & $\mathrm{Ja}$ & Ja & $\mathrm{Ja}$ & n.a. & n.a. & n.a. & $\mathrm{Ja}$ & n.a. & n.a. & $\mathrm{Ja}$ & n.a. \\
\hline 20 & $\mathrm{Ja}$ & Wenig & $\mathrm{Ja}$ & $\mathrm{Ja}$ & $\mathrm{Ja}$ & $\mathrm{Ja}$ & Nein & n.a. & n.a. & $\mathrm{Ja}$ & Nein \\
\hline 21 & $\mathrm{Ja}$ & Wenig & Nein & Nein & Nein & Nein & $\mathrm{Ja}$ & Nein & n.a. & $\mathrm{Ja}$ & Ja \\
\hline 22 & $\mathrm{Ja}$ & Wenig & Nein & $\mathrm{Ja}$ & $\mathrm{Ja}$ & $\mathrm{Ja}$ & $\mathrm{Ja}$ & $\mathrm{Ja}$ & n.a. & $\mathrm{Ja}$ & $\mathrm{Ja}$ \\
\hline 23 & $\mathrm{Ja}$ & Ja & $\mathrm{Ja}$ & $\mathrm{Ja}$ & $\mathrm{Ja}$ & $\mathrm{Ja}$ & $\mathrm{Ja}$ & $\mathrm{Ja}$ & $\mathrm{Ja}$ & Nein & Nein \\
\hline 24 & $\mathrm{Ja}$ & $\mathrm{Ja}$ & Nein & $\mathrm{Ja}$ & Nein & Nein & $\mathrm{Ja}$ & $\mathrm{Ja}$ & $\mathrm{Ja}$ & Nein & Nein \\
\hline 25 & $\mathrm{Ja}$ & Ja & $\mathrm{Ja}$ & n.a. & Nein & $\mathrm{Ja}$ & Nein & $\mathrm{Ja}$ & $\mathrm{Ja}$ & $\mathrm{Ja}$ & n.a. \\
\hline 26 & $\mathrm{Ja}$ & n.a. & $\mathrm{Ja}$ & n.a. & $\mathrm{Ja}$ & Nein & Nein & $\mathrm{Ja}$ & n.a. & $\mathrm{Ja}$ & n.a. \\
\hline 27 & $\mathrm{Ja}$ & Ja & $\mathrm{Ja}$ & Nein & Nein & $\mathrm{Ja}$ & Nein & Nein & Nein & $\mathrm{Ja}$ & Nein \\
\hline 28 & $\mathrm{Ja}$ & Wenig & $\mathrm{Ja}$ & $\mathrm{Ja}$ & $\mathrm{Ja}$ & $\mathrm{Ja}$ & $\mathrm{Ja}$ & $\mathrm{Ja}$ & n.a. & $\mathrm{Ja}$ & Nein \\
\hline 29 & $\mathrm{Ja}$ & Nein & $\mathrm{Ja}$ & Nein & Nein & Nein & $\mathrm{Ja}$ & Nein & Ja & Nein & Nein \\
\hline 30 & $\mathrm{Ja}$ & $\mathrm{Ja}$ & $\mathrm{Ja}$ & $\mathrm{Ja}$ & $\mathrm{Ja}$ & Nein & $\mathrm{Ja}$ & $\mathrm{Ja}$ & Nein & $\mathrm{Ja}$ & Ja \\
\hline 31 & n.a. & Ja & $\mathrm{Ja}$ & $\mathrm{Ja}$ & n.a. & n.a. & $\mathrm{Ja}$ & n.a. & n.a. & n.a. & n.a. \\
\hline 32 & n.a. & $\mathrm{Ja}$ & $\mathrm{Ja}$ & $\mathrm{Ja}$ & n.a. & n.a. & n.a. & n.a. & n.a. & n.a. & n.a. \\
\hline 33 & n.a. & $\mathrm{Ja}$ & n.a. & $\mathrm{Ja}$ & $\mathrm{Ja}$ & n.a. & $\mathrm{Ja}$ & n.a. & n.a. & n.a. & n.a. \\
\hline 34 & n.a. & n.a. & n.a. & $\mathrm{Ja}$ & n.a. & $\mathrm{Ja}$ & $\mathrm{Ja}$ & $\mathrm{Ja}$ & n.a. & n.a. & n.a. \\
\hline 35 & n.a. & Ja & n.a. & n.a. & n.a. & n.a. & n.a. & n.a. & n.a. & n.a. & n.a. \\
\hline 36 & n.a. & Wenig & $\mathrm{Ja}$ & $\mathrm{Ja}$ & n.a. & $\mathrm{Ja}$ & n.a. & n.a. & n.a. & $\mathrm{Ja}$ & n.a. \\
\hline 37 & $\mathrm{Ja}$ & Wenig & $\mathrm{Ja}$ & $\mathrm{Ja}$ & n.a. & Nein & n.a. & $\mathrm{Ja}$ & n.a. & $\mathrm{Ja}$ & n.a. \\
\hline 38 & $\mathrm{Ja}$ & n.a. & $\mathrm{Ja}$ & n.a. & $\mathrm{Ja}$ & Nein & $\mathrm{Ja}$ & n.a. & $\mathrm{Ja}$ & $\mathrm{Ja}$ & n.a. \\
\hline 39 & $\mathrm{Ja}$ & Wenig & Nein & n.a. & $\mathrm{Ja}$ & Nein & n.a. & n.a. & n.a. & Nein & n.a. \\
\hline 40 & $\mathrm{Ja}$ & n.a. & $\mathrm{Ja}$ & n.a. & n.a. & Nein & n.a. & n.a. & n.a. & $\mathrm{Ja}$ & n.a. \\
\hline 41 & n.a. & Wenig & $\mathrm{Ja}$ & n.a. & n.a. & $\mathrm{Ja}$ & n.a. & n.a. & n.a. & Nein & n.a. \\
\hline
\end{tabular}

Abn. SV: Abnormes Schlafverhalten, Aut. V.: Autismusnahe Verhaltensbesonderheiten, GÖR: Gastro-ösophagealer Reflux, P: Patient, Soz.IA.: Soziale Interaktion 
Fortsetzung Tabelle 11: Patientendaten (soziales Verhalten, gastrointestinale und skelettale Symptome)

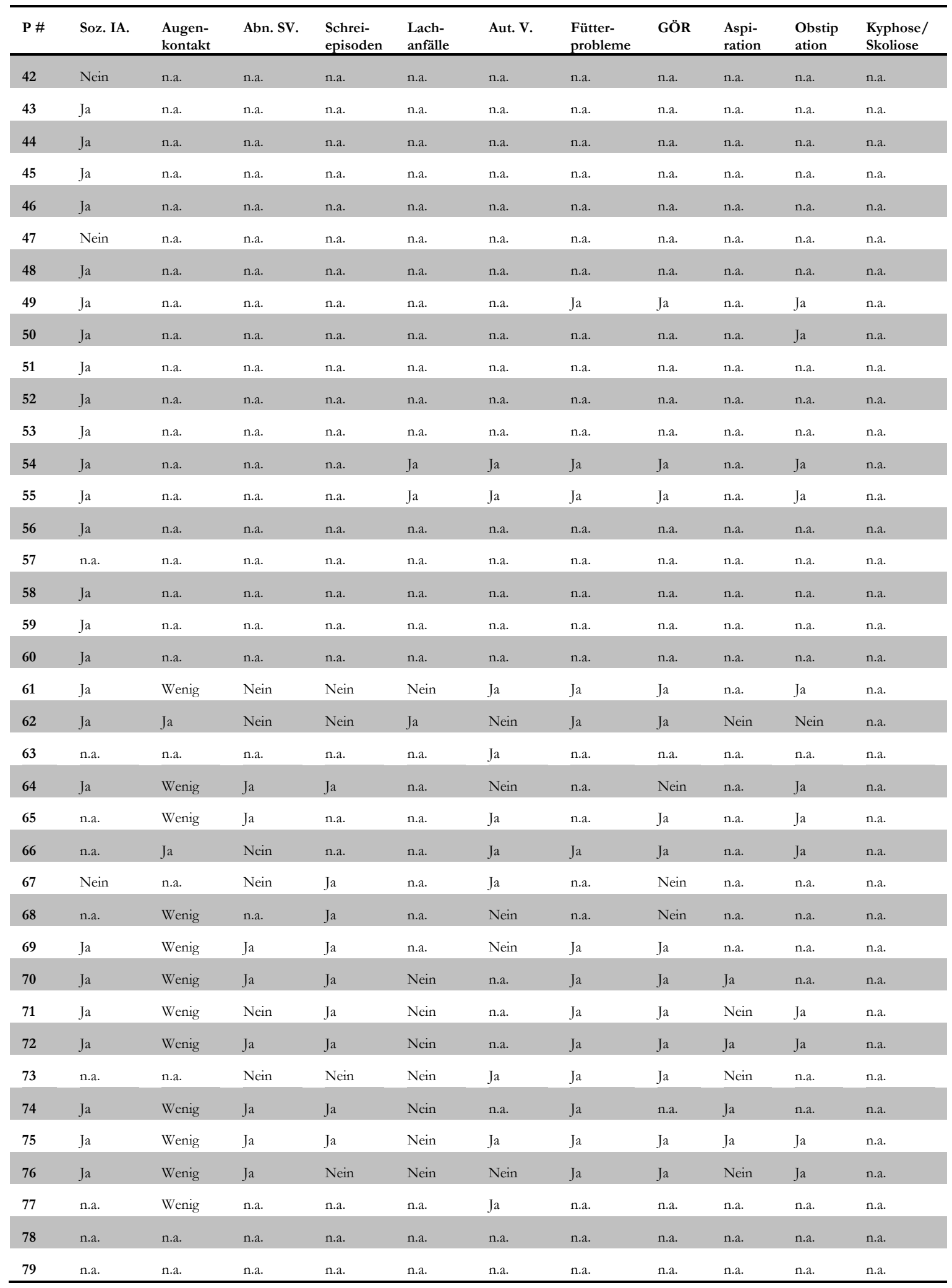

Abn. SV: Abnormes Schlafverhalten, Aut. V.: Autismusnahe Verhaltensbesonderheiten, GÖR: Gastro-ösophagealer Reflux, P: Patient, Soz.IA.: Soziale Interaktion 
Fortsetzung Tabelle 11: Patientendaten (soziales Verhalten, gastrointestinale und skelettale Symptome)

\begin{tabular}{|c|c|c|c|c|c|c|c|c|c|c|c|}
\hline P \# & Soz. IA. & $\begin{array}{l}\text { Augen- } \\
\text { kontakt }\end{array}$ & Abn. SV. & $\begin{array}{l}\begin{array}{l}\text { Schrei- } \\
\text { episoden }\end{array} \\
\end{array}$ & $\begin{array}{l}\text { Lach- } \\
\text { anfälle }\end{array}$ & Aut. V. & $\begin{array}{l}\text { Fütter- } \\
\text { probleme }\end{array}$ & GÖR & $\begin{array}{l}\text { Aspi- } \\
\text { ration }\end{array}$ & $\begin{array}{l}\text { Obstip } \\
\text { ation }\end{array}$ & $\begin{array}{l}\text { Kyphose/ } \\
\text { Skoliose }\end{array}$ \\
\hline 80 & $\mathrm{Ja}$ & n.a. & Nein & Ja & $\mathrm{Ja}$ & n.a. & n.a. & n.a. & n.a. & n.a. & n.a. \\
\hline 81 & Nein & n.a. & $\mathrm{Ja}$ & Nein & Nein & n.a. & n.a. & n.a. & n.a. & n.a. & n.a. \\
\hline 82 & Nein & n.a. & $\mathrm{Ja}$ & Ja & $\mathrm{Ja}$ & n.a. & n.a. & n.a. & n.a. & n.a. & n.a. \\
\hline
\end{tabular}

Abn. SV: Abnormes Schlafverhalten, Aut. V.: Autismusnahe Verhaltensbesonderheiten, GÖR: Gastro-ösophagealer Reflux, P: Patient, Soz.IA.: Soziale Interaktion 
Tabelle 12: Patientendaten (neurologische Symptome)

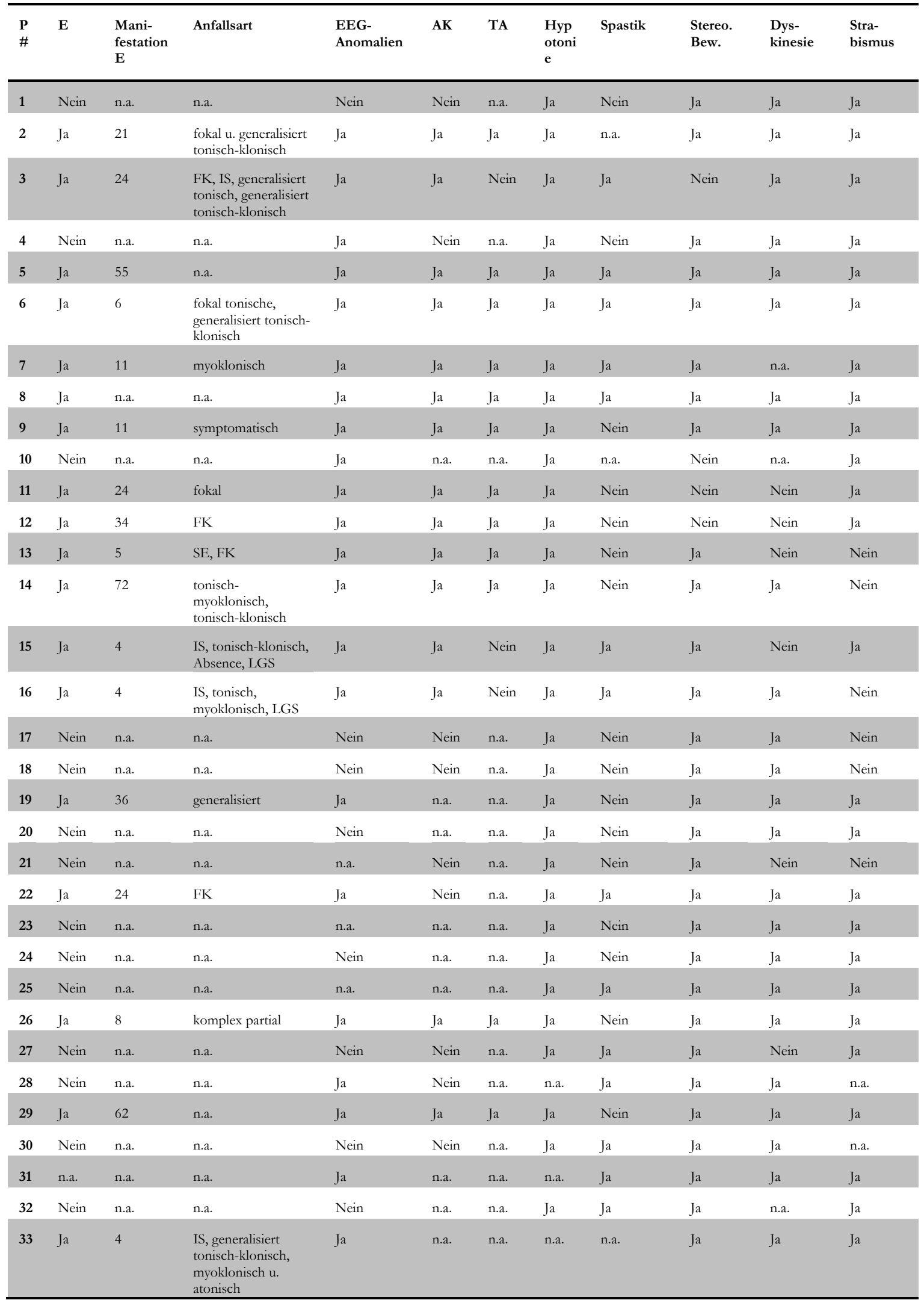

AK: Antikonvulsiva, E: Epilepsie, FK: Fieberkrampf, IS: infantile Spasmen, LGS: Lennox-Gastaut-Syndrom, P: Patient, SE: Status epilepticus, TA: Therapieansprechen 
Fortsetzung Tabelle 12: Patientendaten (neurologische Symptome)

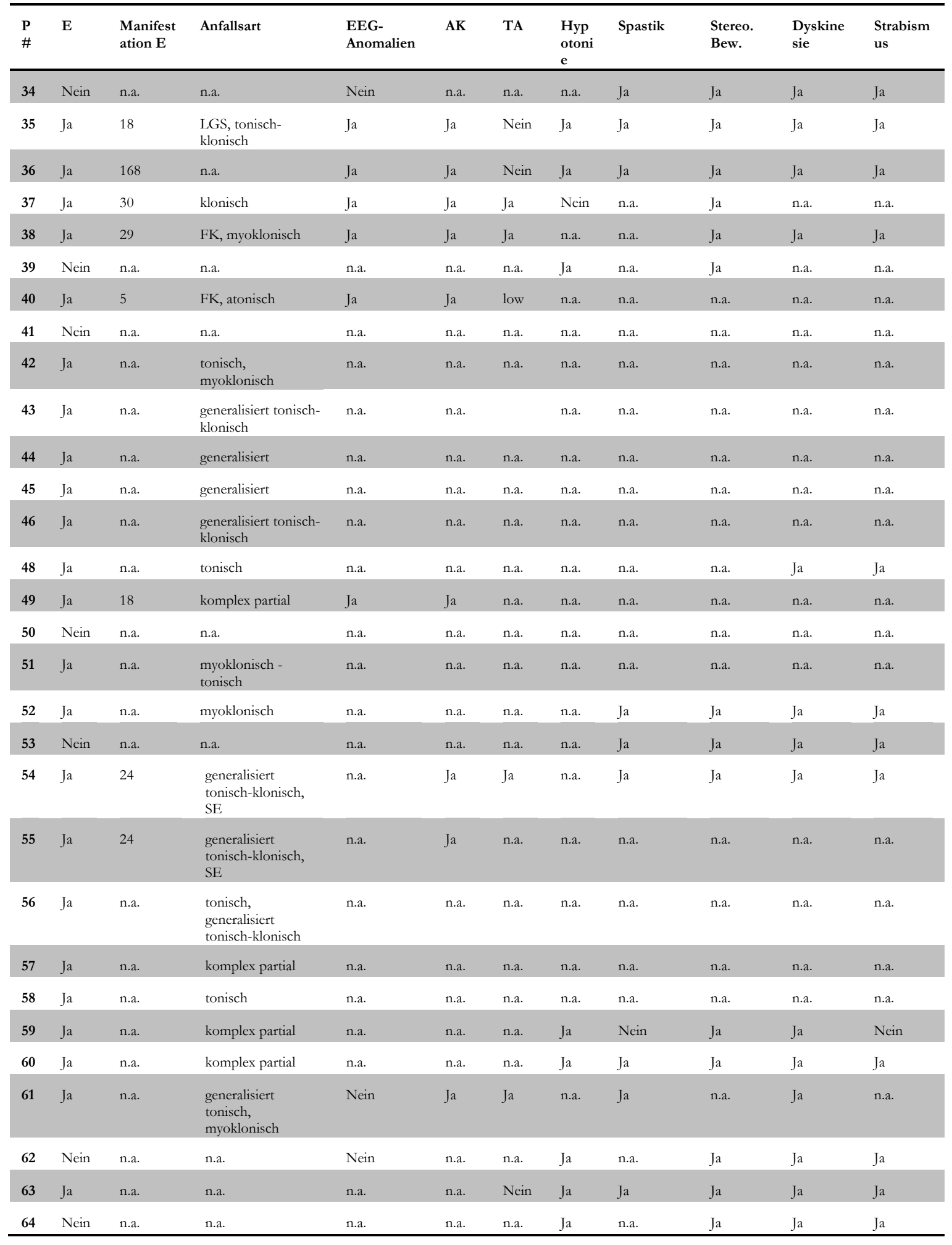

AK: Antikonvulsiva, E: Epilepsie, FK: Fieberkrampf, IS: infantile Spasmen, LGS: Lennox-Gastaut-Syndrom, P: Patient, SE: Status epilepticus, TA: Therapieansprechen 
Fortsetzung Tabelle 12: Patientendaten (neurologische Symptome)

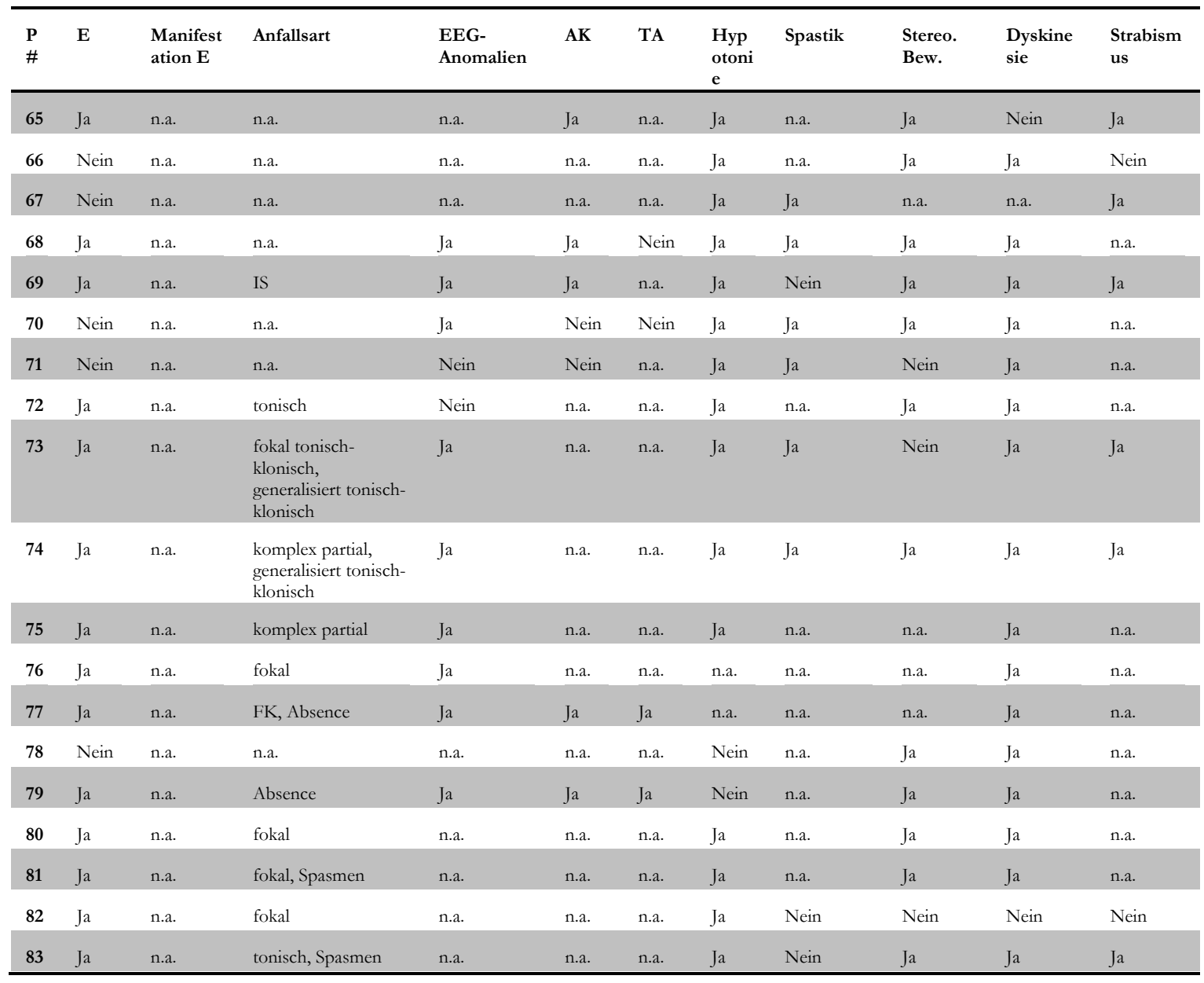

AK: Antikonvulsiva, E: Epilepsie, FK: Fieberkrampf, IS: infantile Spasmen, LGS: Lennox-Gastaut-Syndrom, P: Patient, SE: Status epilepticus, TA: Therapieansprechen 
Tabelle 13: Patientendaten (neurologische Symptome, cMRT Veränderungen)

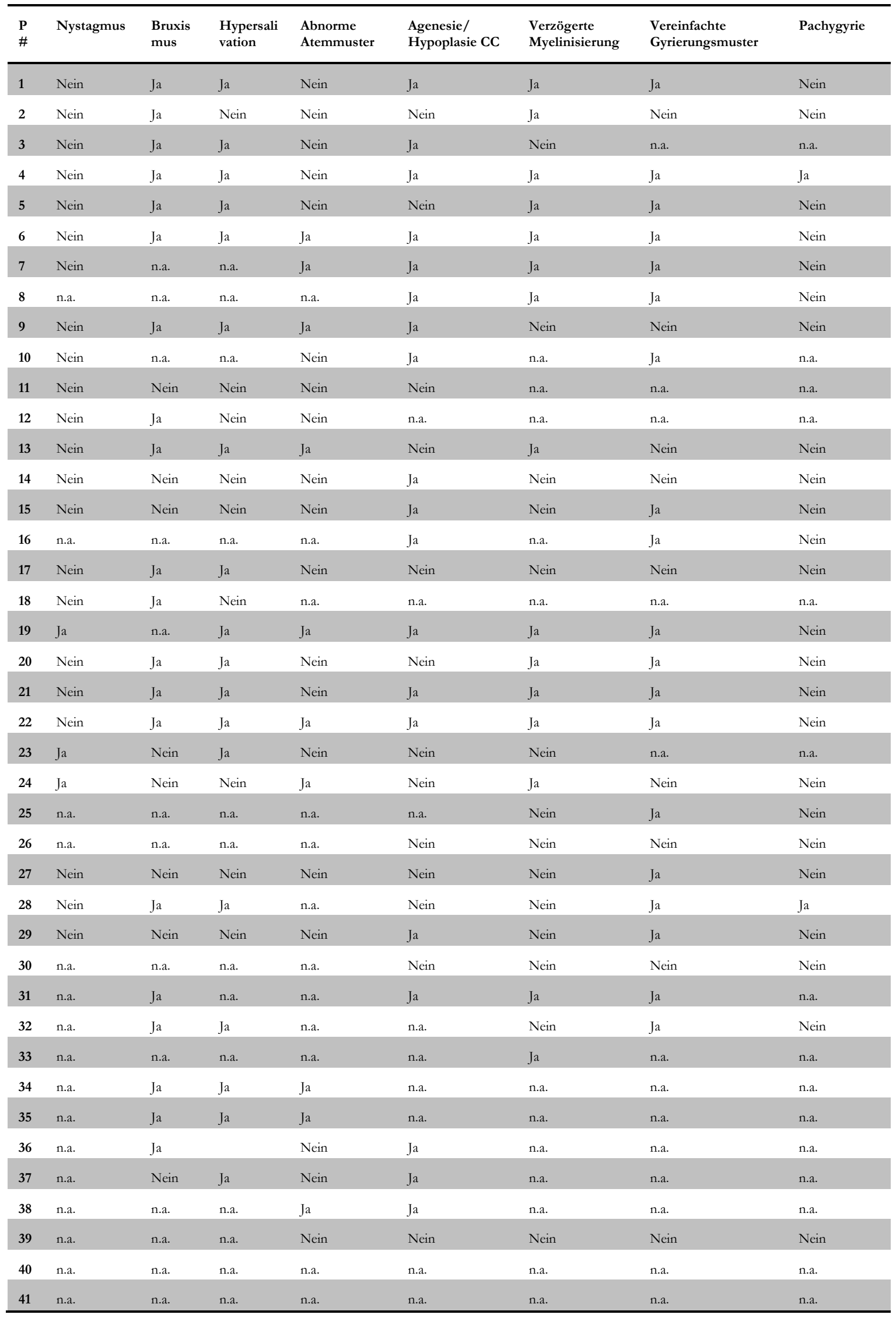

CC: Corpus callosum, P: Patient 
Fortsetzung Tabelle 13: Patientendaten (neurologische Symptome, cMRT Veränderungen)

\begin{tabular}{|c|c|c|c|c|c|c|c|c|}
\hline $\begin{array}{l}\mathbf{P} \\
\#\end{array}$ & Nystagmus & $\begin{array}{l}\text { Bruxis } \\
\text { mus }\end{array}$ & $\begin{array}{l}\text { Hypersal } \\
\text { ivation }\end{array}$ & $\begin{array}{l}\text { Abnorme } \\
\text { Atemmuster }\end{array}$ & $\begin{array}{l}\text { Agenesie/ } \\
\text { Hypoplasie CC }\end{array}$ & $\begin{array}{l}\text { Verzögerte } \\
\text { Myelinisierung }\end{array}$ & $\begin{array}{l}\text { Vereinfachte } \\
\text { Gyrierungsmuster }\end{array}$ & Pachygyrie \\
\hline 42 & n.a. & n.a. & n.a. & n.a. & n.a. & n.a. & n.a. & n.a. \\
\hline 43 & n.a. & n.a. & n.a. & n.a. & n.a. & n.a. & n.a. & n.a. \\
\hline 44 & n.a. & n.a. & n.a. & n.a. & n.a. & n.a. & n.a. & n.a. \\
\hline 45 & n.a. & n.a. & n.a. & n.a. & n.a. & n.a. & n.a. & n.a. \\
\hline 46 & n.a. & n.a. & n.a. & n.a. & n.a. & n.a. & n.a. & n.a. \\
\hline 47 & n.a. & n.a. & n.a. & n.a. & n.a. & n.a. & n.a. & n.a. \\
\hline 48 & n.a. & n.a. & n.a. & n.a. & n.a. & n.a. & n.a. & n.a. \\
\hline 49 & n.a. & n.a. & n.a. & n.a. & $\mathrm{Ja}$ & n.a. & $\mathrm{Ja}$ & n.a. \\
\hline 50 & n.a. & n.a. & n.a. & n.a. & $\mathrm{Ja}$ & n.a. & $\mathrm{Ja}$ & n.a. \\
\hline 51 & n.a. & n.a. & n.a. & n.a. & n.a. & n.a. & n.a. & n.a. \\
\hline 52 & n.a. & n.a. & n.a. & n.a. & Ja & n.a. & $\mathrm{Ja}$ & n.a. \\
\hline 53 & n.a. & n.a. & n.a. & n.a. & n.a. & n.a. & n.a. & n.a. \\
\hline 54 & $\mathrm{Ja}$ & n.a. & n.a. & n.a. & n.a. & n.a. & n.a. & n.a. \\
\hline 55 & n.a. & n.a. & n.a. & n.a. & $\mathrm{Ja}$ & n.a. & $\mathrm{Ja}$ & n.a. \\
\hline 56 & n.a. & n.a. & n.a. & n.a. & n.a. & n.a. & n.a. & n.a. \\
\hline 57 & n.a. & n.a. & n.a. & n.a. & n.a. & n.a. & n.a. & n.a. \\
\hline 58 & n.a. & n.a. & n.a. & n.a. & n.a. & n.a. & n.a. & n.a. \\
\hline 59 & Nein & $\mathrm{Ja}$ & n.a. & $\mathrm{Ja}$ & n.a. & n.a. & n.a. & n.a. \\
\hline 60 & Nein & $\mathrm{Ja}$ & n.a. & n.a. & n.a. & n.a. & n.a. & n.a. \\
\hline 61 & n.a. & $\mathrm{Ja}$ & Nein & n.a. & $\mathrm{Ja}$ & $\mathrm{Ja}$ & $\mathrm{Ja}$ & Nein \\
\hline 62 & n.a. & Nein & Nein & Nein & Nein & Ja & Nein & Nein \\
\hline 63 & n.a. & $\mathrm{Ja}$ & $\mathrm{Ja}$ & Nein & n.a. & n.a. & n.a. & n.a. \\
\hline 64 & n.a. & $\mathrm{Ja}$ & Ja & Ja & Nein & n.a. & $\mathrm{Ja}$ & Nein \\
\hline 65 & n.a. & $\mathrm{Ja}$ & $\mathrm{Ja}$ & Nein & $\mathrm{Ja}$ & $\mathrm{Ja}$ & n.a. & n.a. \\
\hline 66 & n.a. & $\mathrm{Ja}$ & Nein & Nein & $\mathrm{Ja}$ & n.a. & n.a. & n.a. \\
\hline 67 & n.a. & $\mathrm{Ja}$ & n.a. & n.a. & n.a. & n.a. & n.a. & n.a. \\
\hline 68 & n.a. & n.a. & n.a. & Nein & $\mathrm{Ja}$ & Ja & n.a. & n.a. \\
\hline 69 & n.a. & Nein & n.a. & Nein & $\mathrm{Ja}$ & Nein & $\mathrm{Ja}$ & Nein \\
\hline 70 & n.a. & $\mathrm{Ja}$ & n.a. & Nein & $\mathrm{Ja}$ & n.a. & $\mathrm{Ja}$ & Ja \\
\hline 71 & n.a. & Nein & n.a. & Nein & $\mathrm{Ja}$ & n.a. & $\mathrm{Ja}$ & Nein \\
\hline 72 & n.a. & n.a. & n.a. & Nein & $\mathrm{Ja}$ & n.a. & $\mathrm{Ja}$ & $\mathrm{Ja}$ \\
\hline 73 & n.a. & $\mathrm{Ja}$ & $\mathrm{Ja}$ & Nein & $\mathrm{Ja}$ & n.a. & $\mathrm{Ja}$ & Nein \\
\hline 74 & n.a. & $\mathrm{Ja}$ & $\mathrm{Ja}$ & Nein & $\mathrm{Ja}$ & n.a. & $\mathrm{Ja}$ & Nein \\
\hline 75 & n.a. & n.a. & n.a. & n.a. & $\mathrm{Ja}$ & n.a. & $\mathrm{Ja}$ & Nein \\
\hline 76 & n.a. & n.a. & n.a. & n.a. & Nein & n.a. & $\mathrm{Ja}$ & Nein \\
\hline 77 & n.a. & n.a. & n.a. & n.a. & Nein & n.a. & n.a. & n.a. \\
\hline 78 & n.a. & n.a. & n.a. & n.a. & Nein & n.a. & n.a. & n.a. \\
\hline 79 & n.a. & n.a. & n.a. & n.a. & $\mathrm{Ja}$ & n.a. & n.a. & n.a. \\
\hline 80 & n.a. & n.a. & n.a. & n.a. & $\mathrm{Ja}$ & $\mathrm{Ja}$ & $\mathrm{Ja}$ & n.a. \\
\hline 81 & n.a. & n.a. & n.a. & n.a. & Nein & Nein & Nein & n.a. \\
\hline 82 & Nein & n.a. & n.a. & n.a. & $\mathrm{Ja}$ & Ja & Nein & n.a. \\
\hline 83 & Nein & $\mathrm{Ja}$ & Nein & Nein & $\mathrm{Ja}$ & $\mathrm{Ja}$ & Nein & n.a. \\
\hline
\end{tabular}

CC: Corpus callosum, P: Patient 


\subsection{Schweregrad-Score Berechnungen}

Tabelle 14: Schweregradanalyse

\begin{tabular}{|c|c|c|c|c|c|}
\hline P\# & Gesamt & Maximal zu erreichende Punkte & P\# & Gesamt & Maximal zu erreichende Punkte \\
\hline 1 & 21 & 38 & 32 & 13 & 24 \\
\hline 2 & 22 & 38 & 33 & 17 & 24 \\
\hline 3 & 25 & 36 & 36 & 27 & 32 \\
\hline 4 & 25 & 40 & 37 & 24 & 34 \\
\hline 5 & 25 & 40 & 38 & 22 & 30 \\
\hline 6 & 30 & 38 & 39 & 5 & 30 \\
\hline 8 & 29 & 38 & 49 & 19 & 22 \\
\hline 9 & 24 & 40 & 50 & 13 & 18 \\
\hline 10 & 20 & 32 & 61 & 27 & 40 \\
\hline 11 & 4 & 36 & 62 & 23 & 40 \\
\hline 13 & 14 & 40 & 64 & 17 & 30 \\
\hline 14 & 16 & 38 & 65 & 27 & 34 \\
\hline 15 & 27 & 40 & 66 & 21 & 32 \\
\hline 16 & 27 & 34 & 68 & 17 & 22 \\
\hline 17 & 14 & 34 & 69 & 21 & 34 \\
\hline 19 & 26 & 38 & 70 & 19 & 30 \\
\hline 20 & 16 & 40 & 71 & 23 & 36 \\
\hline 21 & 27 & 40 & 72 & 25 & 30 \\
\hline 22 & 29 & 40 & 73 & 22 & 28 \\
\hline 23 & 17 & 38 & 74 & 29 & 32 \\
\hline 24 & 14 & 36 & 75 & 27 & 38 \\
\hline 25 & 17 & 36 & 76 & 31 & 40 \\
\hline 26 & 20 & 34 & 77 & 5 & 11 \\
\hline 27 & 10 & 40 & 80 & 18 & 22 \\
\hline 28 & 27 & 40 & 81 & 14 & 22 \\
\hline 29 & 24 & 40 & 82 & 20 & 22 \\
\hline 30 & 13 & 40 & 83 & 16 & 22 \\
\hline 31 & 18 & 22 & & & \\
\hline
\end{tabular}

P: Patient 


\subsection{Informationsschrift und Einverständnis zur Studienteilnahme}
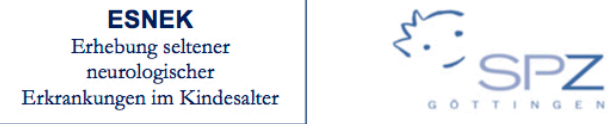

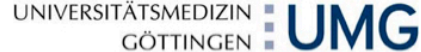

Klinik für Kinder- und Jugendmedizin

Direktorin: Prof. Dr. Jutta Gärtner

ESNEK,Sozialpädiatrisches Zentrum Ärztliche Leitung: Prof. Dr. Knut Brockmann

37099 Göttingen Briefpostadresse Robert-Koch-Str. 40, 37075 Göttingen Hausadresse

Sekretariat

0551 - 39-10358 Telefon

0551 - 39-13245 Telefax

esnek@med.uni-goettingen.de xx.xx.2015

Sehr geehrte Familie, liebe Eltern,

Sie erhalten dieses Schreiben von Ihrer behandelnden Kinderneurologin, xxx.

Bei Ihrem Kind wurde als Ursache der Entwicklungsstörung eine krankheitsverursachende Veränderung (Mutation) in einem speziellen Gen (FOXG1) auf Chromosom 14, also eine seltene neurologische Erkrankung, festgestellt.

Wir, Kinderneurologen in der Universitäts-Kinderklinik Göttingen, wollen ein Forschungsprojekt zu dieser seltenen Erkrankung durchführen und wir laden Sie ein, sich an diesem Projekt zu beteiligen. Ihre Teilnahme ist absolut freiwillig und es entstehen Ihnen keinerlei Nachteile, wenn Sie nicht teilnehmen möchten. Wir wollen herausfinden, welche krankheitsverursachenden Veränderungen (Mutationen) im FOXG1-Gen mit welchen Krankheitssymptomen gekoppelt sind. Möglicherweise sind manche Mutationen in diesem Gen mit milderen Krankheitszeichen und andere mit schwereren neurologischen Symptomen verknüpft. Dafür würden wir von Ihnen Kopien der wichtigsten Befunde und Berichte der behandelnden Ärzte erbitten, aus denen die Entwicklung, die neurologische Symptomatik und die genetischen Befunde Ihres Kindes hervorgehen. Wir wollen Sie auch fragen, ob Sie Ihr Einverständnis geben, dass wir Ihren behandelnden Kinderneurologen ggf. um weitere Informationen bitten dürfen. Dafür müssten Sie diese Ärzte von ihrer Schweigepflicht uns gegenüber entbinden.

Sofern Sie bei diesem Projekt mitmachen wollen und uns Unterlagen über Ihr Kind zusenden, so werden diese Briefe und Berichte sorgfältig an einem verschlossenen Ort hier in der Kinderklinik verwahrt, wie es mit allen Patientenakten geschieht. Die Angaben zu Ihrem Kind würden wir dann in pseudonymisierter (verschlüsselter) Form in eine Tabelle übertragen, d. h. wir ordnen Ihrem Kind eine bestimmte Kombination aus Buchstaben und Zahlen zu (z. B. FOXG1.7), sodass ein Dritter aus diesem Kürzel keine Rückschlüsse auf Ihr Kind ziehen kann. Diese Ta- 
belle ist dann die Grundlage für die weitere wissenschaftliche Auswertung. Nach Abschluss des Projektes werden alle Befundkopien wieder vernichtet. Zu Einzelheiten des Datenschutzes verweisen wir auf die Information auf Seite 3 dieses Schreibens.

Sofern Sie grundsätzlich Interesse haben, an diesem Projekt teilzunehmen, so sprechen Sie bitte mit Ihrer Kinderneurologin, Dr. Rating, darüber.

Sie können sich aber auch direkt mit uns in Verbindung setzen. Dazu tragen Sie bitte hier unten Ihre Kontaktdaten ein und senden uns bitte dieses Schreiben in dem beigefügten Briefumschlag zurück, der bereits adressiert und frankiert ist. Dann würden wir uns bei Ihnen melden und die Einzelheiten unseres Forschungsvorhabens sowie das weitere Vorgehen besprechen. Auch falls Sie an der Studie nicht teilnehmen möchten, wären wir Ihnen dankbar, wenn Sie sich zurückmelden.

Für Rückfragen stehen wir Ihnen gerne zur Verfügung

Telefonisch können Sie uns unter Tel. 0551 / 39-8106 oder über das Sekretariat des Sozialpädiatrischen Zentrums Tel. 0551 / 39-10358 erreichen. Sie können aber auch gerne eine Email schreiben an: esnek@med.uni-goettingen.de.

Mit freundlichen Grüßen

Prof. Dr. Knut Brockmann Kinderarzt und Neurologe
Dr. Simone Schröder Dipl.-Biologin

[ ] Ja, ich habe Interesse, an diesem FOXG1- Forschungsprojekt teilzunehmen.

[ ] Ja, ich bin damit einverstanden, dass Sie aus der Kinderklinik Göttingen mich wegen dieser Studie anrufen.

[ ] Nein, danke, ich möchte an diesem Forschungsvorhaben nicht teilnehmen.

Vorname: Name:

Name u. Geburtsdatum meines betroffenen Kindes:

Adresse: PLZ, Ort: Straße, Nr.:

Telefon: Email:

Ort, Datum: Unterschrift: 


\section{Datenschutz:}

Mir ist bekannt, dass bei diesem Forschungsvorhaben personenbezogene Daten, insbesondere medizinische Befunde über mein/unser Kind erhoben, gespeichert und ausgewertet werden sollen. Die Verwendung der Angaben über die Gesundheit meines/unseres Kindes erfolgt nach gesetzlichen Bestimmungen und setzt vor der Teilnahme an dem Forschungsvorhaben folgende freiwillig abgegebene Einwilligungserklärung voraus, das heißt ohne die nachfolgende Einwilligung kann ich nicht an dem Forschungsvorhaben teilnehmen.

1. Ich erkläre mich damit einverstanden, dass im Rahmen dieses Forschungsvorhabens personenbezogene Daten, insbesondere Angaben über die Gesundheit meines/unseres Kindes, erhoben und in Papierform sowie auf elektronischen Datenträgern bei Prof. Dr. Knut Brockmann, Frau cand. med. Kim Sarah Plümacher, Frau Dr. Simone Schröder und Prof. Dr. Dr. Birgit Zirn Sozialpädiatrisches Zentrum (SPZ), Universitätsmedizin Göttingen, aufgezeichnet werden. Soweit erforderlich, dürfen die erhobenen Daten pseudonymisiert (verschlüsselt) weitergegeben werden an andere Mitarbeiter des SPZ zum Zwecke der wissenschaftlichen Auswertung.

2. Ich bin darüber aufgeklärt worden, dass ich jederzeit die Teilnahme an dem Forschungsvorhaben beenden kann. Beim Widerruf meiner Einwilligung, an dem Forschungsvorhaben teilzunehmen, habe ich das Recht, die Löschung aller meiner bis dahin gespeicherten personenbezogenen Daten zu verlangen.

3. Ich erkläre mich damit einverstanden, dass meine Daten nach Beendigung oder Abbruch des Forschungsvorhabens für höchstens 10 Jahre aufbewahrt werden. Danach werden meine personenbezogenen Daten gelöscht, soweit nicht gesetzliche, satzungsmäßige oder vertragliche Aufbewahrungsfristen entgegenstehen.

Ort, Datum: Unterschrift: 


\subsection{Einverständniserklärung zur Veröffentlichung von Photographien}

Sehr geehrte Eltern,

im Rahmen unserer Studie zur FOXG1-Erkrankung bitten wir Sie um Ihre Einwilligung zur Veröffentlichung von Fotos Ihres Kindes. Die Daten werden durch die Bilder viel anschaulicher, was unsere Arbeit sehr bereichert.

Falls Sie einverstanden sind, schicken Sie uns bitte das nachfolgende Formular ausgefüllt zurück.

Sobald die Studie abgeschlossen ist und es zu einer Veröffentlichung kommt werden Sie zeitnah informiert.

Vielen Dank für Ihr Interesse und Ihre Mithilfe.

Mit freundlichen Grüßen, 


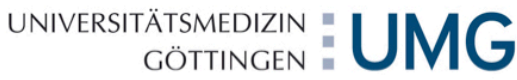

$\{\cdot$

SPZ

Name, Vorname:

Geburtsdatum:

Hiermit erkläre ich mein Einverständnis, dass zum Zwecke der Lehre und Forschung identifizierbare Fotos meines Kindes mit FOXG1-Mutation

[ ] veröffentlicht werden

[ ] im Rahmen einer Vorlesung/einer Fortbildungsveranstaltung gezeigt werden:

Mir ist bekannt dass dieses Einverständnis absolut freiwillig erfolgt und ich dies jederzeit ohne Angabe von Gründen widerrufen kann, ohne dass mir oder meinem Kind daraus Nachteile für die Behandlung entstehen.

Ort, Datum

Unterschrift des Sorgeberechtigten 


\section{$7 \quad$ Literaturverzeichnis}

Allou L, Lambert L, Amsallem D, Bieth E, Edery P, Destrée A, Rivier F, Amor D, Thompson E, Nicholl J, et al. (2012): 14q12 and severe Rett-like phenotypes: new clinical insights and physical mapping of FOXG1-regulatory elements. Eur J Hum Genet 20, 1216-1223

Amir RE, Van den Veyver IB, Wan M, Tran CQ, Francke U, Zoghbi HY (1999): Rett syndrome is caused by mutations in X-linked MECP2, encoding methyl-CpG-binding protein 2. Nat Genet 23, 185-188

Ariani F, Hayek G, Rondinella D, Artuso R, Mencarelli MA, Spanhol-Rosseto A, Pollazzon M, Buoni S, Spiga O, Ricciardi S, et al. (2008): FOXG1 Is Responsible for the Congenital Variant of Rett Syndrome. Am J Hum Genet 83, 89-93

Bahi-Buisson N, Bienvenu T (2011): CDKL5-Related Disorders: From Clinical Description to Molecular Genetics. Mol Syndromol 137-152

Bahi-Buisson N, Girard B, Gautier A, Nectoux J, Fichou Y, Saillour Y, Poirier K, Chelly J, Bienvenu T (2010a): Epileptic encephalopathy in a girl with an interstitial deletion of Xp22 comprising promoter and exon 1 of the CDKL5 gene. Am J Med Genet Part B Neuropsychiatr Genet 153, 202-207

Bahi-Buisson N, Nectoux J, Girard B, Van Esch H, De Ravel T, Boddaert N, Plouin P, Rio M, Fichou Y, Chelly J, Bienvenu T (2010b): Revisiting the phenotype associated with FOXG1 mutations: two novel cases of congenital Rett variant. Neurogenetics $\underline{11}$, 241-249

Bredenkamp N, Seoighe C, Illing N (2007): Comparative evolutionary analysis of the FoxG1 transcription factor from diverse vertebrates identifies conserved recognition sites for microRNA regulation. Dev Genes Evol 217, 227-233

Brunetti-Pierri N, Paciorkowski AR, Ciccone R, Mina E Della, Bonaglia MC, Borgatti R, Schaaf CP, Sutton VR, Xia Z, Jelluma N, et al. (2011): Duplications of FOXG1 in $14 \mathrm{q} 12$ are associated with developmental epilepsy, mental retardation, and severe speech impairment. Eur J Hum Genet 19, 102-107 
De Bruyn C, Vanderhasselt T, Tanyalçin I, Keymolen K, Van Rompaey KL, De Meirleir L, Jansen AC (2014): Thin genu of the corpus callosum points to mutation in FOXG1 in a child with acquired microcephaly, trigonocephaly, and intellectual developmental disorder: A case report and review of literature. Eur J Paediatr Neurol 18, 420-426

Cellini E, Vignoli A, Pisano T, Falchi M, Molinaro A, Accorsi P, Bontacchio A, Pinelli L, Giordano L, Guerrini R (2016): The hyperkinetic movement disorder of FOXG1 related epileptic-dyskinetic encephalopathy. Dev Med Child Neurol 58, 93-97

Chen G, Courey AJ (2000): Groucho/TLE family proteins and transcriptional repression. Gene 249, 1-16

Clarke A (1996): Rett syndrome. J Med Genet 33, 693-9

D’Esposito M, Quaderi N a., Ciccodicola a., Bruni P, Esposito T, D’Urso M, Brown SDM (1996): Isolation, physical mapping, and Northern analysis of the X-linked human gene encoding methyl CpG-binding protein, MECP2. Mamm Genome 7, 533-535

Danesin C, Houart C (2012): A Fox stops the Wnt: implications for forebrain development and diseases. Curr Opin Genet Dev 22, 323-30

Dastidar SG, Landrieu PMZ, D’Mello SR (2011): FoxG1 Promotes the Survival of Postmitotic Neurons. J Neurosci 31, 402-413

De Bona C, Zappella M, Hayek G, Meloni I, Vitelli F, Bruttini M, Cusano R, Loffredo P, Longo I, Renieri a (2000): Preserved speech variant is allelic of classic Rett syndrome. Eur J Hum Genet $\underline{8}, 325-30$

Deidrick KM, Percy AK, Schanen NC, Mamounas L, Maria BL (2004): Rett Syndrome: Pathogenesis, Diagnosis, Strategies, Therapies, and Future Research Directions. $708-717$

Dou C, Lee J, Liu B, Liu F, Massague J, Xuan S, Lai E (2000): BF-1 interferes with transforming growth factor beta signaling by associating with Smad partners. Mol Cell Biol 20, 6201-6211

Dou CL, Li S, Lai E (1999): Dual role of brain factor-1 in regulating growth and patterning of the cerebral hemispheres. Cereb Cortex $\underline{9}, 543-550$

Duggan CD, DeMaria S, Baudhuin A, Stafford D, Ngai J (2008): Foxg1 is required for development of the vertebrate olfactory system. J Neurosci 28, 5229-5239 
Fehr S, Wilson M, Downs J, Williams S, Murgia A, Sartori S, Vecchi M, Ho G, Polli R, Psoni S, et al. (2013): The CDKL5 disorder is an independent clinical entity associated with early-onset encephalopathy. Eur J Hum Genet 21, 266-273

De Filippis R, Pancrazi L, Bjørgo K, Rosseto a., Kleefstra T, Grillo E, Panighini a., Cardarelli F, Meloni I, Ariani F, et al. (2012): Expanding the phenotype associated with FOXG1 mutations and in vivo FoxG1 chromatin-binding dynamics. Clin Genet $\underline{82}, 395-403$

Flindt Mutationsanalyse des FOXG1-Gens bei Patienten mit geistiger Behinderung und verschiedenen Gehirnfehlbildungen. Med. Diss. Hamburg 2011

Fuchs C, Trazzi S, Torricella R, Viggiano R, De Franceschi M, Amendola E, Gross C, Calzà L, Bartesaghi R, Ciani E (2014): Loss of CDKL5 impairs survival and dendritic growth of newborn neurons by altering AKT/GSK-3 $\beta$ signaling. Neurobiol Dis $\underline{70}$, $53-68$

Guen T Le, Fichou Y, Nectoux J, Bahi-Buisson N, Rivier F, Boddaert N, Diebold B, Héron D, Chelly J, Bienvenu T (2011): A missense mutation within the fork-head domain of the forkhead box G1 Gene (FOXG1) affects its nuclear localization. Hum Mutat 32, E2026-E2035

Guerrini R, Parrini E (2012): Epilepsy in Rett syndrome, and CDKL5 - and FOXG1 -generelated encephalopathies. Epilepsia 53, 2067-2078

Hagberg B (2002): Clinical manifestations and stages of Rett syndrome. Ment Retard Dev Disabil Res Rev $\underline{8}, 61-5$

Hagberg B, Aicardi J, Dias K, Ramos O (1983): A progressive syndrome of autism, dementia, ataxia, and loss of purposeful hand use in girls: Rett's syndrome: report of 35 cases. Ann Neurol 14, 471-479

Hanashima C, Shen L, Li SC, Lai E (2002): Brain factor-1 controls the proliferation and differentiation of neocortical progenitor cells through independent mechanisms. J Neurosci 22, 6526-6536

Hanashima C, Li SC, Shen L, Lai E, Fishell G (2004): Foxg1 suppresses early cortical cell fate. Science $\underline{303}, 56-59$.

Hanashima C, Fernandes M, Hebert JM, Fishell G (2007): The role of Foxg1 and dorsal midline signaling in the generation of Cajal-Retzius subtypes. The jouranl of neuroscience 27(41), 11103-1111. 
Hanefeld F (1985): The clinical pattern of the Rett syndrome. Brain Dev $\underline{7}, 320-5$.

Huh S, Hatini V, Marcus RC, Li SC, Lai E (1999): Dorsal-ventral patterning defects in the eye of BF-1-deficient mice associated with a restricted loss of shh expression. Dev Biol 211, 53-63

Jacob FD, Ramaswamy V, Andersen J, Bolduc F V (2009): Atypical Rett syndrome with selective FOXG1 deletion detected by comparative genomic hybridization: case report and review of literature. Eur J Hum Genet 17, 1577-1581

Jeffrey L. Neul, Kaufmann WE, Glaze DG, Christodoulou J, Clarke AJ, Bahi-Buisson N, Leonard H, Bailey MES, Schanen NC, Zappella M, et al. (2010): Rett syndrome: Revised diagnostic criteria and nomenclature. Ann Neurol 68, 944-950

Johnston M, Ammanuel S, O’Driscoll C, Wozniak A, Naidu S, Kadam SD (2014): Twentyfour hour quantitative-EEG and in-vivo glutamate biosensor detects activity and circadian rhythm dependent biomarkers of pathogenesis in Mecp2 null mice. Front Syst Neurosci $\underline{8}, 1-13$

Kalscheuer VM, Tao J, Donnelly A, Hollway G, Schwinger E, Kübart S, Menzel C, Hoeltzenbein M, Tommerup N, Eyre H, et al. (2003): Disruption of the Serine/Threonine Kinase 9 Gene Causes Severe X-Linked Infantile Spasms and Mental Retardation. Am J Hum Genet 72, 1401-1411

Kishi N, Macklis JD (2005): Dissecting MECP2 function in the central nervous system. J Child Neurol 20, 753-759

Kortüm F, Das S, Flindt M, Morris-Rosendahl DJ, Stefanova I, Goldstein A, Horn D, Klopocki E, Kluger G, Martin P, et al. (2011): The core FOXG1 syndrome phenotype consists of postnatal microcephaly, severe mental retardation, absent language, dyskinesia, and corpus callosum hypogenesis. J Med Genet 48, 396-406

Le Guen T, Bahi-Buisson N, Nectoux J, Boddaert N, Fichou Y, Diebold B, Desguerre I, Raqbi F, Daire VC, Chelly J, Bienvenu T (2011): A FOXG1 mutation in a boy with congenital variant of Rett syndrome. Neurogenetics $12,1-8$

Li J, Vogt PK (1993): The retroviral oncogene qin belongs to the transcription factor family that includes the homeotic gene fork head. Proc Natl Acad Sci U S A 90, 4490-4494

Li W, Pozzo-Miller L (2014): BDNF deregulation in Rett syndrome. Neuropharmacology 76, 737-746 
Malzahn D, Schillert A, Müller M, Bickeböller H (2010): The longitudinal nonparametric test as a new tool to explore gene-gene and gene-time effects in cohorts. Genet Epidemiol 34, 469-478

Mari F (2005): CDKL5 belongs to the same molecular pathway of MeCP2 and it is responsible for the early-onset seizure variant of Rett syndrome. Hum Mol Genet 14 , 1935-1946

Matijevic T, Knezevic J, Slavica M, Pavelic J (2009): Rett Syndrome: From the Gene to the Disease. Eur Neurol 61, 3-10

McMahon KQ, Papandreou A, Ma M, Barry BJ, Mirzaa GM, Dobyns WB, Scott RH, Trump N, Kurian M a., Paciorkowski AR (2015): Familial recurrences of FOXG1 related disorder: Evidence for mosaicism. Am J Med Genet 167A, 3096-3102

Mencarelli M a, Spanhol-Rosseto a, Artuso R, Rondinella D, De Filippis R, Bahi-Buisson N, Nectoux J, Rubinsztajn R, Bienvenu T, Moncla a, et al. (2010): Novel FOXG1 mutations associated with the congenital variant of Rett syndrome. J Med Genet $\underline{47}$, $49-53$

Mitter D, Pringsheim M, Kaulisch M, Plümacher KS, Schröder S, Warthemann R, Abou Jamra R, Baethmann M, Bast T, Büttel H-M, et al. (2017): FOXG1 syndrome: genotype-phenotype association in 83 patients with FOXG1 variants. Genet Med 20, 98

Mnatzakanian GN, Lohi H, Munteanu I, Alfred SE, Yamada T, MacLeod PJ, Jones JR, Scherer SW, Schanen NC, Friez MJ, et al. (2004): A previously unidentified MECP2 open reading frame defines a new protein isoform relevant to Rett syndrome. Nat Genet 36, 339-341

Neuhauser H, Schienkiewitz A, Kurth B-M: Referenzperzentile für anthropometrische Maßzahlen und Blutdruck aus der Studie zur Gesundheit von Kindern und Jugendlichen in Deutschland (KiGGS). Band 32; 2013

Neul JL, Kaufmann WE, Glaze DG, Christodoulou J, Clarke AJ, Bahi-Buisson N, Leonard H, Bailey ME, Schanen CN, Zappella M, et al. (2010): Rett syndrome: revised diagnostic criteria and nomenclature. NIH Public Access. 68, 944-950 
Papa FT, Mencarelli MA, Caselli R, Katzaki E, Sampieri K, Meloni I, Ariani F, Longo I, Maggio A, Balestri P, et al. (2008): A 3 Mb deletion in 14q12 causes severe mental retardation, mild facial dysmorphisms and rett-like features. Am J Med Genet Part A 146, 1994-1998

Philippe C, Amsallem D, Francannet C, Lambert L, Saunier a, Verneau F, Jonveaux P (2010): Phenotypic variability in Rett syndrome associated with FOXG1 mutations in females. J Med Genet 47, 59-65

Pini G, Bigoni S, Congiu L, Romanelli a. M, Scusa MF, Di Marco P, Benincasa a., Morescalchi P, Ferlini a., Bianchi F, et al. (2016): Rett syndrome: a wide clinical and autonomic picture. Orphanet J Rare Dis $\underline{11}, 132$

Ranke MB, von Harnack GA, Koletzko B: Wachstum, Entwicklung und Reife. In: Koletzko B (Hrsg.): Kinder- und Jugendmedizin. 14. Auflage; Springer-Verlag, Berlin Heidelberg 2013, 11-15 (zu sehen unter https://www.springer.com/de/book/9783642113789)

Rett A: Ueber ein Cerebrales Syndrom bei Hyperammonämie. Brüder Hollinek, Wien 1966. Schröder S, Brockmann K (2015): Erhebung seltener neurologischer Erkrankungen im Kindesalter (ESNEK). Neuropädiatrie Klinik und Praxis 14, 1-2

Segawa M, Nomura Y (2005): Rett syndrome. Curr Opin Neurol 18, 97-104

Seltzer LE, Paciorkowski AR (2014): Genetic disorders associated with postnatal microcephaly. Am J Med Genet Part C Semin Med Genet 166, 140-155

Seltzer LE, Ma M, Ahmed S, Bertrand M, Dobyns WB, Wheless J, Paciorkowski AR (2014): Epilepsy and outcome in FOXG1-related disorders. Epilepsia 55, 1292-1300

Tao J, Van Esch H, Hagedorn-Greiwe M, Hoffmann K, Moser B, Raynaud M, Sperner J, Fryns J-P, Schwinger E, Gécz J, et al. (2004): Mutations in the X-Linked CyclinDependent Kinase-Like 5 (CDKL5/STK9) Gene Are Associated with Severe Neurodevelopmental Retardation. Am J Hum Genet 75, 1149-1154

Terrone G, Bienvenu T, Germanaud D, Barthez-Carpentier M-A, Diebold B, Delanoe C, Passemard S, Auvin S (2014): A case of Lennox-Gastaut syndrome in a patient with FOXG1-related disorder. Epilepsia 55, e116-e119

Tian C, Gong Y, Yang Y, Shen W, Wang K, Liu J, Xu B, Zhao J, Zhao C (2012): Foxg1 Has an Essential Role in Postnatal Development of the Dentate Gyrus. J Neurosci 32 , 2931-2949 
Trappe R, Laccone F, Cobilanschi J, Meins M, Huppke P, Hanefeld F, Engel W (2001): MECP2 mutations in sporadic cases of Rett syndrome are almost exclusively of paternal origin. Am J Hum Genet 68, 1093-1101

Van Der Aa N, Van Den Bergh M, Ponomarenko N, Verstraete L, Ceulemans B, Storm K (2011): Analysis of FOXG1 is highly recommended in male and female patients with rett syndrome. Mol Syndromol 1, 290-293

Voigt M, Fusch C, Olbertz D, Hartmann K, Rochow N, Renken C, Schneider KTM (2006): Analyse des neugeborenenkollektivs der Bundesrepublik Deutschland: 12. Mitteilung: Vorstellung engmaschiger perzentilwerte (-kurven) für die körpermaße neugeborener. Geburtshilfe Frauenheilkd 66, 956-970

Wiese S, Murphy DB, Schlung A, Burfeind P, Schmundt D, Schnülle V, Mattei MG, Thies $\mathrm{U}$ (1995): The genes for human brain factor 1 and 2, members of the fork head gene family, are clustered on chromosome 14q. BBA - Gene Struct Expr 1262, 105-112

Yang Y, Shen W, Ni Y, Su Y, Yang Z, Zhao C (2015): Impaired Interneuron Development after Foxg1 Disruption. Cereb Cortex bhv297

Yao J, Lai E, Stifani S (2001): The winged-helix protein brain factor 1 interacts with groucho and hes proteins to repress transcription. Mol Cell Biol 21, 1962-72

Young JI, Hong EP, Castle JC, Crespo-Barreto J, Bowman AB, Rose MF, Kang D, Richman R, Johnson JM, Berget S, Zoghbi HY (2005): Regulation of RNA splicing by the methylation-dependent transcriptional repressor methyl-CpG binding protein 2 . Proc Natl Acad Sci U S A $\underline{102,17551-17558}$

Zappella M, Gillberg C, Ehlers S (1998): The preserved speech variant: a subgroup of the Rett complex: a clinical report of 30 cases. J Autism Dev Disord 28, 519-526

\section{Internetquellen:}

http://www.cran.r-project.org, Zugriff am 10. April 2017

http://www.esped.uniduesseldorf.de, Zugriff am 20.Juni 2017

https://gorare.med.uni-goettingen.de/das-esnek-konzept.html, Zugriff am 07.10.2018

http://www.omim.org, Zugriff am 10. April 2016 


\section{Danksagung}

Zunächst bedanke ich mich bei Herrn Professor Dr. Knut Brockmann, der mir die Anregung für diese Dissertationsarbeit im Sozialpädiatrischen Zentrum der Klinik für Kinder- und Jugendmedizin der Universitätsmedizin Göttingen gab. Die stetige Betreuung, wertvolle Ratschläge und die Geduld beim Korrekturlesen haben mir die Arbeit sehr erleichtert. Durch seine sehr angenehme und hilfsbereite Art entstand für mich ein motivierendes und immer nettes Arbeitsklima.

Vielen Dank an Frau Professorin Dr. Diana Mitter für Zusammenarbeit und die Zuordnung der FOXG1-Varianten zu den fünf genetischen Gruppen. Außerdem bedanke ich mich bei Dr. Simone Schröder und Dr. Rita Warthemann für die Betreuung und organisatorische Hilfe bei der Patientenrekrutierung und Auswertung sowie bei Frau Dr. Dörthe Malzahn, Institut für Medizinische Statistik der UMG, für die statistische Auswertung der Daten dieser Studie.

Ein großer Dank gilt den Patienten und deren Familien, die sich an dieser Studie beteiligten. Durch die sehr informativen Gespräche und die große Bereitschaft, Informationen zur Verfügung zu stellen, ist diese Arbeit möglich geworden. 